Illinois State University

ISU ReD: Research and eData

Theses and Dissertations

$7-22-2020$

\title{
The Development Of A New Entry Point Into Enantiomerically Enriched Sulfinyl Derivatives
}

Jessica Shaw

Illinois State University, shawjess08@gmail.com

Follow this and additional works at: https://ir.library.illinoisstate.edu/etd

Part of the Organic Chemistry Commons

\section{Recommended Citation}

Shaw, Jessica, "The Development Of A New Entry Point Into Enantiomerically Enriched Sulfinyl Derivatives" (2020). Theses and Dissertations. 1309.

https://ir.library.illinoisstate.edu/etd/1309

This Thesis is brought to you for free and open access by ISU ReD: Research and eData. It has been accepted for inclusion in Theses and Dissertations by an authorized administrator of ISU ReD: Research and eData. For more information, please contact ISUReD@ilstu.edu. 


\title{
THE DEVELOPMENT OF A NEW ENTRY POINT INTO ENANTIOMERICALLY ENRICHED SULFINYL DERIVATIVES
}

\author{
JESSICA SHAW
}

\section{Pages}

Optical probes may be used as reliable tools for detecting and imagining the inside of cells for medical diagnostics. Among available options, the use of thiol probes is of interest as thiols are present in nearly all cells, and their levels are tightly regulated, thus any variation is associated with disease. A proper thiol bioimaging probe must have a thiol cleavage group/reactive group and a fluorophore. It is found that novel sulfinate aryl ester (phenoxysulfinate esters) probes selectively cleave thiols at physiological $\mathrm{pH}$ and show much promise as effective tools for bioimaging.

In this context, the synthesis of the related sulfinate alkyl esters has been extensively reported in the chemical literature. In contrast, the synthesis and application of sulfinate aryl esters has been much less explored. Recently, Menezes, Oliveira, and coworkers reported the attempted synthesis of sulfinate aryl esters but failed to accomplish this goal due to the reactive nature of these compounds. Our interest in the synthesis of the sulfinate aryl esters is two-fold: (1) the development of a facile methodology for the synthesis of sulfinate aryl esters for bioimaging, and (2) the development of sulfinate aryl esters as activated sulfinate esters that would be able to serve as cost-effective, shelf stable reagents allowing for the direct synthesis of sulfinate alkyl esters.

This presentation will discuss the development of a new synthetic method for sulfinate aryl esters (phenoxysulfinate esters), their relative stabilities, and their application in the 
synthesis of sulfinate alkyl esters as stand-alone reagents. Finally, this work will also evaluate other processes that involve the rapid and efficient synthesis of sulfinate alkyl and aryl esters.

KEYWORDS: Sulfinate alkyl esters; phenoxy sulfinate esters; shelf-stable tools; bioimaging 


\title{
THE DEVELOPMENT OF A NEW ENTRY POINT INTO ENANTIOMERICALLY ENRICHED SULFINYL DERIVATIVES
}

\author{
JESSICA SHAW
}

A Thesis Submitted in Partial Fulfillment of the Requirements for the Degree of

\section{MASTER OF SCIENCE}

Department of Chemistry

ILLINOIS STATE UNIVERSITY 
(C) 2020 JESSICA SHAW 


\title{
THE DEVELOPMENT OF A NEW ENTRY POINT INTO ENANTIOMERICALLY ENRICHED SULFINYL DERIVATIVES
}

\author{
JESSICA SHAW
}

COMMITTEE MEMBERS:

Shawn Hitchcock, Chair

Christopher Mulligan

Richard Nagorski 


\section{ACKNOWLEDGMENTS}

This work would not have been accomplished without the support and guidance of numerous people. I would like to express my gratitude to my dissertation committee of Dr. Richard Nagorski and Dr. Christopher Mulligan for their guidance in classroom and being always being open for discussions. I would also like to thank Samantha Willens, who taught me the fundamental techniques in the laboratory and making me feel comfortable with doing research. In addition, I would like to think my peers McKenzie Biswell, Ashley Stelmack, Kayla Love, Zain Becerra, and Adrienne Sulit as well as my parents for their moral support and guidance through my graduate career. I would also like to thank the Illinois State University Chemistry Department for fostering such a great environment for learning chemistry. Finally, I would like to show my utmost gratitude to Dr. Shawn Hitchcock, my research advisor, for his guidance in research. 


\section{CONTENTS}

Page

ACKNOWLEDGMENTS

$\begin{array}{ll}\text { TABLES } & \text { iii }\end{array}$

FIGURES

SCHEMES

CHAPTER I: INTRODUCTION 1

Amine synthesis: Introduction and applications 1

Chiral amines: synthetic methods $\quad 2$

Sulfinate esters: synthetic and biological applications 4

$\begin{array}{ll}\text { Modern methods for the synthesis of sulfinate esters } & 7\end{array}$

A novel methodology for sulfinate ester synthesis via activated phenoxy sulfinate esters 12

Dynamic kinetic resolution: Can phenoxysulfinate esters achieve kinetic resolution? 14

CHAPTER II: THE DESIGN, SYNTHESIS, AND APPLICATION OF PHENOXY

SULFINATE ESTERS AS PREPARATIVE TOOLS FOR THE SYNTHESIS 16

OF SULFINATE ESTERS AND SULFINAMIDES 16

$\begin{array}{ll}\text { Introduction } & 16\end{array}$

Synthesis of a L-phenylglycine based sulfinamide: The diastereomer dilemma 18

Synthesis of a series of imines for the catalytic asymmetric reduction 23

Application of the imines in the synthesis of racemic amine standards 24

Conclusion of the catalytic asymmetric reduction of imines with sulfinamide catalysts $\quad 28$

CHAPTER III: THE SYNTHESIS, STABILITY, APPLICATION OF 29

PHENOXYSULFINATE ESTERS 29

$\begin{array}{ll}\text { Introduction } & 29\end{array}$ 
A New Synthetic Paradigm for the Synthesis of Sulfinate esters and Sulfinamides:

Synthesis of Phenoxy Sulfinate Esters

Time Trials of Phenoxysulfinate Esters

The time trial study for the degradation of the p-Bromophenylphenoxysulfinate ester

The time trial study for the degradation of the p-tert-butylphenoxysulfinate ester

The time trial study for the degradation of the p-methoxyphenoxysulfinate ester

Two-step alcohol pathway synthesis of alkoxy sulfinate esters

One-pot alcohol pathway synthesis of alkoxy sulfinate esters

Conclusion of the Phenoxy Sulfinate Esters

CHAPTER IV: THE EXPLORATION OF A NEW MOTHOD FOR ALKOXY SULFINATE ESTER SYNTHESIS

Exploration of a new method for alkoxy sulfinate ester synthesis

Conclusion of the CDI method

CHAPTER V: THE CONCLUSION

WORKS CITED

APPENDIX B: SELECTED NMR SPECTRA

APPENDIX C: SELECTED HRMS ESI SPECTRA 


\section{TABLES}

Table

Page

1. Synthetic approach to sulfinate esters via $p$-tolylsulfonylmethyl isocyanide

2. Optimization of the synthesis of racemic amines via catalytic asymmetric reduction

3. Initial Synthesis of phenoxysulfinate esters 35a-d

4. Entire time trial ${ }^{1} \mathrm{H}$ NMR spectra analysis of the standalone PSE derivatives (4a-d) with their associated three samples $(\alpha, \beta, \gamma)$ at each time mark.

5. Time trial ${ }^{1} \mathrm{H}$ NMR spectrum analysis of the bromo-PSE derivative

6. Time trial ${ }^{1} \mathrm{H}$ NMR spectrum analysis of the tert-butyl-PSE derivative

7. Time trial ${ }^{1} \mathrm{H}$ NMR spectrum analysis of the methoxy-PSE

8. Optimization of alkoxy sulfinate ester synthesis via PSE derivative

9. Reaction scheme for proposed CDI method for optimization investigations

10. CDI Method optimization of the reaction time 


\section{FIGURES}

Figure $\quad$ Page

1. Crude ${ }^{1} \mathrm{H}$ NMR diastereomeric mixture of sulfinamide diastereomers $\mathbf{2 8 a} \boldsymbol{\&} \mathbf{2 8 b} \quad 19$

2. $400 \mathrm{MHz}{ }^{1} \mathrm{H}$ NMR spectrum of the third fraction derived from chromatography 20

3. Recrystallized pure $400 \mathrm{MHz}{ }^{1} \mathrm{HNMR}$ of sulfinamide target product 21

4. X-ray crystal structure of the sulfinamide $(S, S)$-diastereomer $\mathbf{2 8 b} 22$

5. Observed decomposition of the standalone PSE derivatives after 48 hours at $25^{\circ} \mathrm{C} \quad 33$

6. Time trial spectra comparison of the bromo-PSE derivative Entry 1 outlined in red and Entry 4 outlined in blue $\quad 39$

7. Time trial spectra comparison of the tert-butyl-PSE derivative Entry 1 outlined in red and Entry 4 outlined in blue

8. Time trial spectra comparison of the methoxy-PSE derivative Entry 1 outlined in red and Entry 4 outlined in blue $\quad 45$

9. ${ }^{1} \mathrm{H}$ NMR of 4-nitrobenzyl 4-methylbenzenesilfinate crude product 49 


\section{SCHEMES}

Scheme

Page

1. Structural comparison of Xyzal to Zyrtec. 2

2. Amine synthesis depicted in literature. 3

3. Sulfur-containing reagents in organic synthesis. 5

4. Synthesis of sulfoxides and sulfinamides from sulfinate esters. 5

5. Chakrapani and coworkers sulfinate ester as a thiol probe. 6

6. Acid catalyzed synthesis of sulfinic acids $\quad 7$

7. Synthetic approach to sulfinate esters via oxidative formation 9

8. Acid catalyzed Basak diazonium cation 10

9. Electrochemical synthesis of sulfinate esters 11

10. Pre-existing phenoxy sulfinate ester syntheses 12

11. Phenoxy sulfinate ester synthesis via EDC method 13

12. Sulfinate ester synthesis via PSE 13

13. Dynamic kinetic resolution 14

14. Sun and coworkers catalytic asymmetric reduction 16

15. Proposed new sulfinamide catalyst 17

16. Synthesis of the L-phenylglycine methyl ester sulfinamide $\quad 18$

17. Imine synthesis using the method of White and coworkers 23

18. Rationale for the synthesis of the racemic amines 24

19. Synthesis of racemic standards for HPLC 25

20. Synthesis of chiral amines via catalytic asymmetric reduction 26

21. Synthesis of racemic amines via catalytic asymmetric reduction, version two 27

22. Synthesis of the L-phenylglycine methyl ester sulfinamide 29 
23. Phenoxysulfinate esters for dynamic kinetic resolution

24. Attempted synthesis of the $p$-nitrophenoxysulfinate ester

25. Quantitative assessment of the relative amounts of PSE derivative and phenol

26. Two-step synthesis via in-situ bromo-PSE intermediate with two structurally diverse alcohols

27. Two-step synthesis via in-situ tert-butyl-PSE intermediate with ten structurally diverse alcohols

28. Two-step synthesis via in-situ Methoxy-PSE intermediate with five structurally diverse alcohols

29. One-step synthesis using stand-alone Methoxy-PSE with five structurally diverse alcohols

30. Literature use of $N, N$-carbonyldiimidazole (CDI) with carboxylic acids

31. Proposed synthesis with N-N'-Carbonyldiimidazole (CDI) and sulfinic acids

32. Sulfinyl imidazoles $\mathbf{4 0}$ for dynamic kinetic resolution 


\section{CHAPTER I: INTRODUCTION}

\section{Amine synthesis: Introduction and applications}

The development of a synthetic method for the asymmetric synthesis of amines has been of interest due to their utility in pharmaceutical drug production. Chiral amines are found in more than $75 \%$ of pharmaceutical drugs and drug candidates and can influence the potency of said drugs. ${ }^{1}$ As there is an ever-increasing demand for chiral amines because of their importance, the development of novel methods for their enantioselective preparation is an ongoing enterprise. Enantioselectivity is of importance in drug production as specific enantiomers can be more potent than the other or they can have dire consequences. When a specific enantiomeric drug gives the desired pharmacological response and effect, it is known as the eutomer; and if the enantiomeric material gives the undesired or inert activity it is known as the distomer. ${ }^{2}$ While many chiral drugs are sold as racemic mixtures, it is desirable to make the stand-alone eutomers in drug production when greater efficacy is sought.

Cetirizine is a chiral drug that is an anti-histamine used to fight symptoms associated with allergies. The racemic mixture of cetirizine is commonly known as Zyrtec. ${ }^{3}$ Pflum and coworkers developed a large-scale synthesis of enantiomerically pure $(S)$-enantiomer, the eutomer, of cetirizine dihydrochloride. ${ }^{3}$ Application of this newly developed synthesis containing only the eutomer of cetirizine, rather than the racemic mixture, lead to a more desirable and profitable drug known as Xyzal (Scheme 1). ${ }^{3}$ 
Scheme 1: Structural comparison of Xyzal to Zyrtec

$$
\text { Xyzal }
$$
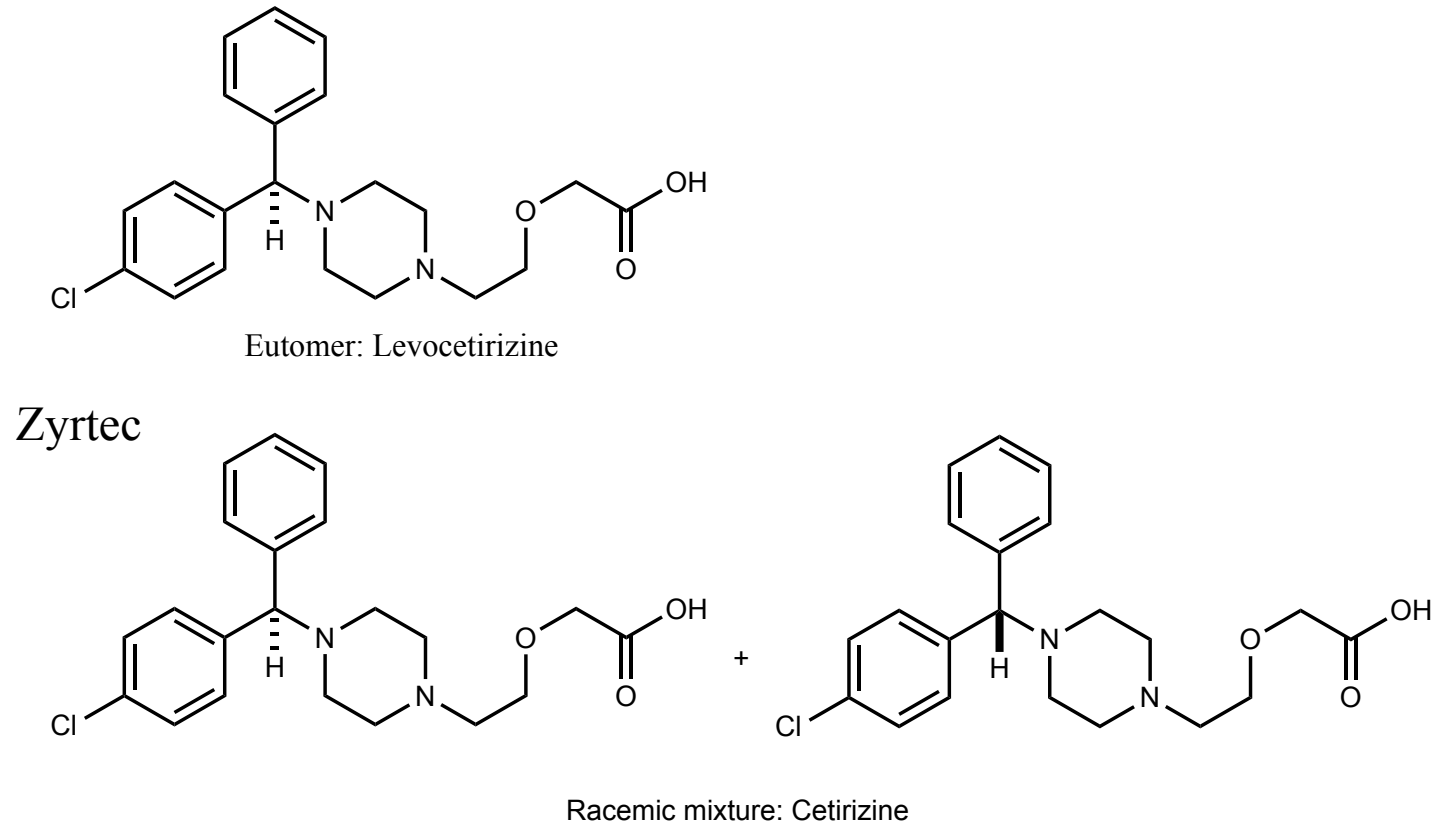

This is merely one example of how an enantiomerically pure synthesis is beneficial to drug production. Similar enantiomerically pure asymmetric synthesis of amines could be applied to other drug applications, thus the development of such a synthesis is of interest. The next section describes some of the synthetic methodologies that have been developed to achieve the goal of the asymmetric synthesis of chiral amines.

\section{Chiral amines: synthetic methods}

A variety of methods exist for the preparation of chiral amines. These methods include the use of a functional group family known as the sulfinyl group which includes sulfinyl chlorides (RSOCl), sulfoxides (RSOR'), sulfinate esters ( $\left.\mathrm{RSO}_{2} \mathrm{R}^{\prime}\right)$, and sulfinamides $\left(\mathrm{RSONH}_{2}\right) .{ }^{4}$ Among these compounds, sulfinate esters and sulfinamides are versatile synthetic 
tools that have previously been employed in amine synthesis. Ellman and coworkers utilized $(R)-$ tert-butylsulfinamide to synthesize chiral amines in a three-step process involving condensation of ketones and aldehydes, Grignard addition, and hydrolysis (Scheme 2). ${ }^{5}$ From this three-step method they were able to synthesize $\alpha$-amino acids, $\beta$-amino acids, amino alcohols, metalloamines, and pavine alkaloids with high enantioselectivity. ${ }^{5}$

Scheme 2: Amine synthesis depicted in literature

\section{Ellman and Coworkers}

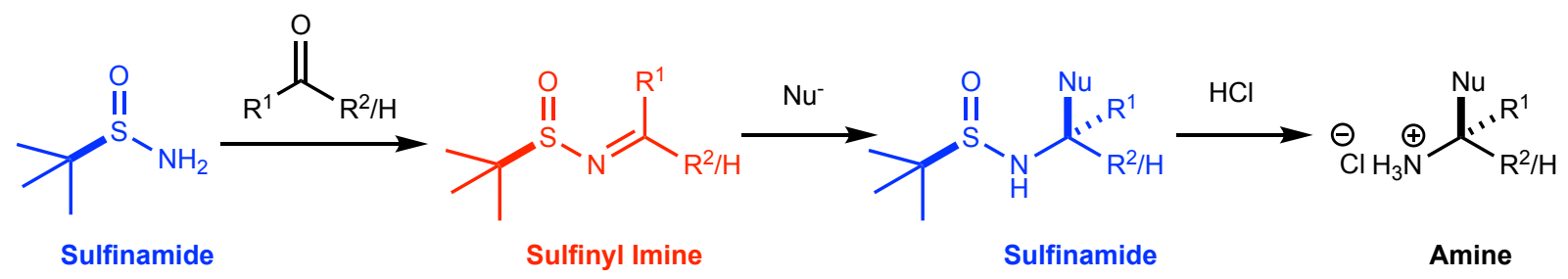

\section{Sun and Coworkers}

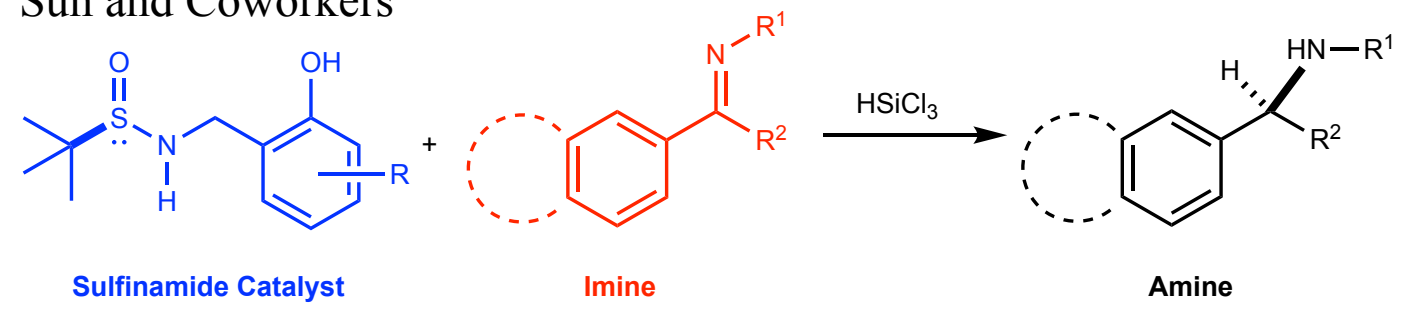

In another example, Sun and coworkers developed a method for amine synthesis by utilizing a sulfinamide catalyst for the asymmetric reduction of imines to give enantioselectivity (Scheme 2). ${ }^{6}$ While the Ellman methodology has been more widely applied, it is limited in that it is a stoichiometric methodology that requires that the sulfinamide chiral auxiliary is employed in full stoichiometric amounts. In contrast, the Sun methodology involves using sulfinamides as chiral catalyst. The development of catalytic asymmetric methods in organic chemistry continues to grow and is gaining ground in the synthetic toolbox every day. ${ }^{7}$ Based on this knowledge, it is 
proposed that a new catalytic method based on the Sun methodology could be developed that employs chiral catalytic amounts of structurally novel sulfinamides for the enantioselective synthesis of amines by the asymmetric reduction of imines as depicted in Scheme 2. Also, it is further proposed that sulfinate esters will be utilized as an entry point into the synthesis of the requisite chiral sulfinamides. This would be an attractive route as the synthesis of enantiomerically pure sulfinate esters has been readily accomplished more so than the synthesis of enantiomerically pure sulfinamides. ${ }^{8}$ In this light, sulfinamides can be directly synthesized from sulfinate esters through the process of nucleophilic substitution. Much of the work in this thesis is dedicated to developing the synthesis of sulfinate esters in terms of their general structures $\left(\mathrm{RSO}_{2} \mathrm{R}^{\prime}\right)$ and their diastereomerically and enantiomerically pure forms. The next section reviews some of the applications of sulfinate esters.

\section{Sulfinate esters: synthetic and biological applications}

Sulfur-containing compounds play a central role in the development of novel synthetic methods in synthetic organic chemistry. For example, sulfonium compounds (e.g., the CoreyChaykovsky reagent, 1), ${ }^{9}$ sulfones (e.g., the Julia-Lythgoe and the Julia-Kocienski olefination reaction, 2), ${ }^{10}$ and sulfoxides (e.g., Pummerer rearrangement, 3$)^{11}$ are common sulfur-based reagents that have found wide-spread utility in modern organic synthesis (Scheme 3). In contrast, the sulfur-containing compounds known as sulfinate esters (4) have not received as much attention. These compounds represent an important class of sulfur-containing compounds that are becoming more recognized for their value. Sulfinate esters may serve as entry points into the synthesis of sulfoxides and sulfinamides (Scheme 4). Of particular importance for this thesis is the transformation of sulfinate esters into sulfinamides for amine synthesis. 
Scheme 3. Sulfur-containing reagents in organic synthesis

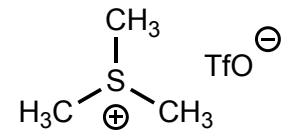

1

Corey-Chaykovsky Reagent

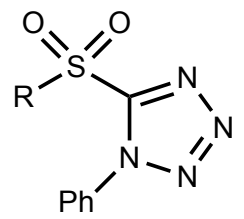

2

Julia-Kocienski Reagent

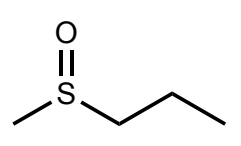

3<smiles>[R]OS([R])=O</smiles>

4

Pummerer Reagent Sulfinate Ester

Scheme 4. Synthesis of sulfoxides and sulfinamides from sulfinate esters

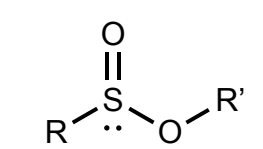

Sulfinate alkyl ester
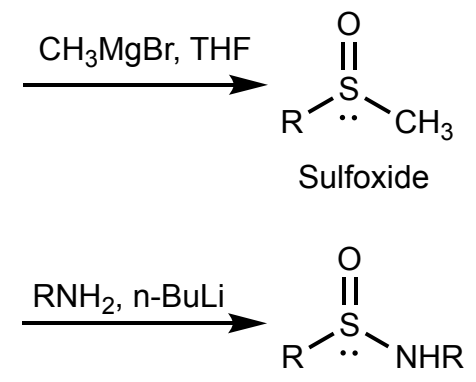

Sulfinamide

Beyond their synthetic applications, sulfinate esters are increasingly being employed in biological studies where the development of molecular probes is of value. Chakrapani and coworkers developed a highly selective sulfinate ester probe for thiol imaging. ${ }^{12}$ Thiols are tightly regulated within cells as they mediate many cellular processes, and when a cell is under distress the amount of thiols present will deviate from normal levels. ${ }^{12} \mathrm{~A}$ sulfinate ester probe can be administered and react with thiols present in the cell and fluoresce to reveal if there are abnormal levels or not. ${ }^{12}$ Distress of a cell could be caused by diabetes, neurodegenerative diseases, cancers, immunodeficiency syndromes, etc. Thus, an efficient sulfinate ester thiol probe to give diagnosis of such diseases is of interest. ${ }^{12}$ Chakrapani group synthesized a sulfinate ester through a three-step process beginning with a sulfinyl chloride and a phenol (Scheme 5). This synthesized sulfinate esters was reacted with a thiol to give a thiosulfinate and alcohol. The 
alcohol produced was a fluorophore that was detected through fluorescence. Levels of thiols present within a cell was detected by this fluorescence, which would only occur upon the sulfinate ester and thiol reaction. Sulfinate esters are of interest for biological studies such as described here, but also for transformation into sulfinamides for amine synthesis and other organocatalytic processes. ${ }^{13}$ The next section reviews some of the current literature methods that exists for sulfinate ester synthesis and discusses their effectiveness and limitations.

Scheme 5: Chakrapani and coworkers sulfinate ester as a thiol probe ${ }^{12}$

Sulfinate Ester Synthesis

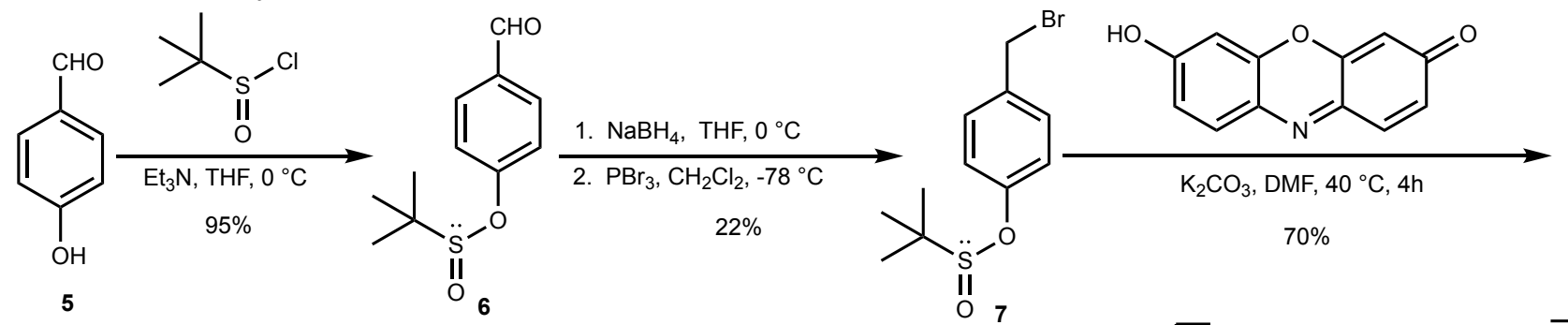

Sulfinate Ester as Thiol Probe<smiles>CC(C)(C)S(=O)Oc1ccc(COc2ccc3c(c2)OCC=N3)cc1</smiles>

8<smiles></smiles>

Fluorescent 


\section{Modern methods for the synthesis of sulfinate esters}

In 2017, Menezes and Oliveira disclosed an acid catalyzed synthesis of sulfinate esters that is analogous to the classic Fischer esterification (Scheme 6). ${ }^{14}$ The methodology is operationally simple and involved treating sulfinic acids with alcohols with catalytic amounts of sulfuric acid in dichloromethane with $4 \AA$ molecular sieves. The process afforded a series of sulfinate esters in isolated chemical yields ranging from 50 to $84 \%$. While the procedure offers a direct method for the synthesis of sulfinate esters, it is limited by the use of the acid catalyzed pathway. In this context, tert-butyl alcohol failed to generate a product. Phenols also proved to be unsuitable for the transformation, perhaps due to the sensitivity of the corresponding sulfinate phenyl ester products. ${ }^{14}$ Ultimately, acid sensitive substrates are not a viable option for this procedure. Despite these limitations, this is still a very effective method for the synthesis of simple sulfinate esters.

Scheme 6: Acid catalyzed synthesis of sulfinic acids ${ }^{14}$

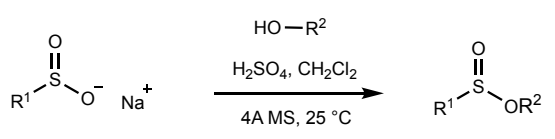
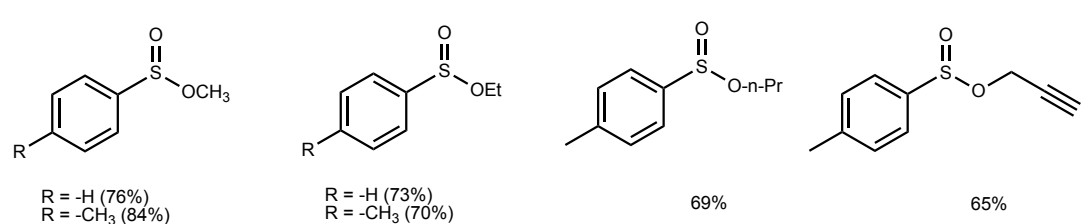

$\mathrm{R}=-\mathrm{CH}_{3}(84 \%)$

$R=-H(73 \%)$
$R=-C H$

$69 \%$

$65 \%$

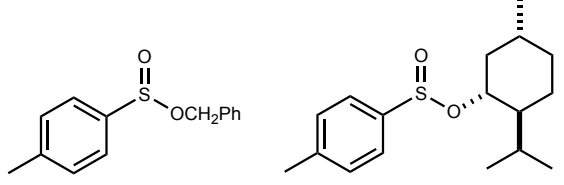

$65 \%$

$50 \%$

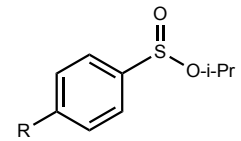

$\mathrm{R}=-\mathrm{H}(71 \%)$
$\mathrm{R}=-\mathrm{CH}_{3}(67 \%)$<smiles>C=CCOS(=O)c1ccc(C)cc1</smiles><smiles>CC(=O)CCS(=O)O</smiles>

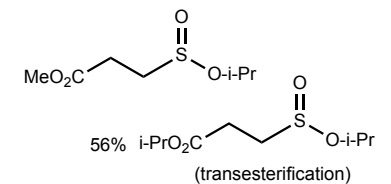


In the same year, Prapurna and coworkers developed a synthetic methodology for the preparation of sulfinate esters via reaction of alcohols with $p$-tolylsulfonylmethyl isocyanide (TosMIC) and boron trifluoride etherate $\left(\mathrm{BF}_{3}-\mathrm{Et}_{2} \mathrm{O}\right)$ as seen in Table 1.

Table 1. Synthetic approach to sulfinate esters via $p$-tolylsulfonylmethyl isocyanide ${ }^{15}$

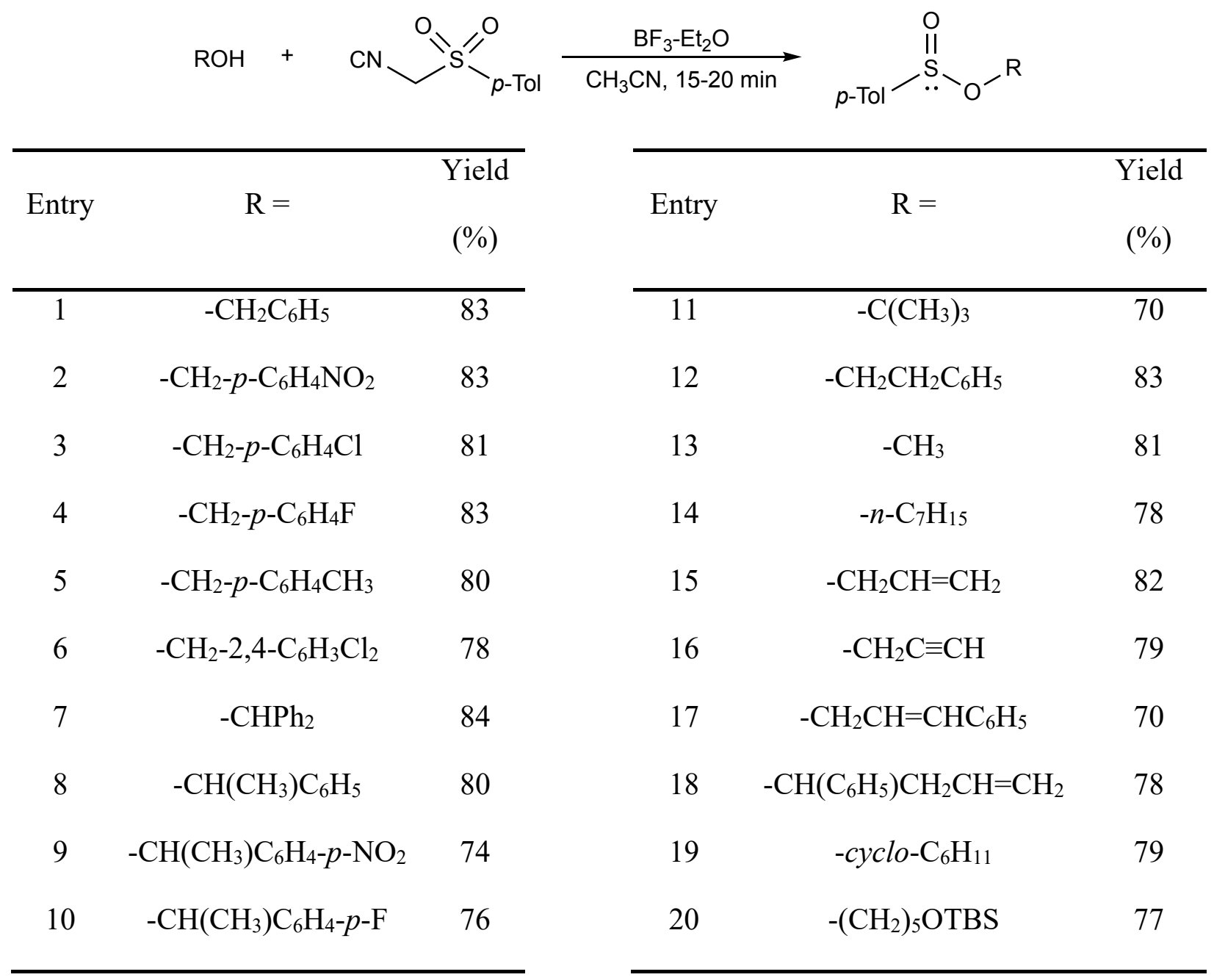

The process afforded a series of sulfinate esters in isolated chemical yields ranging from 70 to $84 \% .{ }^{15}$ While the procedure offers a direct method for the synthesis of sulfinate esters, it is limited by the use of the acid $\mathrm{BF}_{3}$ as substrates prone to carbocation rearrangements would not be suitable. This is a similar limitation as the Menezes and Oliveira methodology. 
In 2018, Zhang and coworkers had developed a sustainable oxidative formation of sulfinate esters via the oxidative esterification of thiols in the presence of cobalt nano-catalyst supported on doped carbon. ${ }^{16}$ This procedure provided a direct formation of sulfinate esters synthesis and afforded a series in isolated chemical yields ranging from 45 to $91 \%$ (Scheme 7 ). ${ }^{16}$ These results were a significant innovation within surface chemistry, but it is limited in the scalability for industrial purposes.

Scheme 7: Synthetic approach to sulfinate esters via oxidative formation ${ }^{16}$

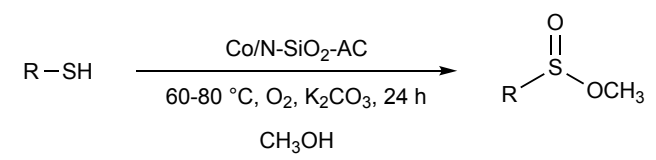<smiles>COS(=O)c1ccc(C)cc1S(=O)OC</smiles><smiles>COS(=O)c1ccccc1</smiles><smiles>COS(=O)c1ccc(C(C)(C)C)cc1</smiles><smiles>COc1ccc(S(=O)OC)cc1</smiles><smiles>COS(=O)c1ccc2ccccc2c1</smiles><smiles>COS(=O)c1ccc(F)cc1</smiles><smiles>COS(=O)c1ccc(Br)cc1</smiles><smiles>COS(=O)c1ccc(Cl)cc1</smiles><smiles>COS(=O)c1ccccc1Cl</smiles><smiles>COS(=O)c1cccc(Cl)c1</smiles><smiles>COS(=O)c1cc(Cl)cc(Cl)c1</smiles><smiles>COS(=O)c1ccc(C(F)(F)F)cc1</smiles><smiles>COS(=O)c1ccc(N)cc1</smiles><smiles>COS(=O)c1ccc(NC(C)=O)cc1</smiles><smiles>COS(=O)c1ccoc1C</smiles><smiles>COS(=O)c1ccsc1C</smiles><smiles>CCCCCCS(=O)OC</smiles> 
Basak and coworkers developed a Wittig ylide mediated synthesis of N-sulfonyl hydrazones to sulfinates. ${ }^{17}$ This process afforded a series of sulfinate esters in isolated chemical yields ranging from $0-76 \%$ (Scheme 8 ). However, this method was limited due to the sulfone

Scheme 8. Acid catalyzed Basak diazonium cation ${ }^{17}$

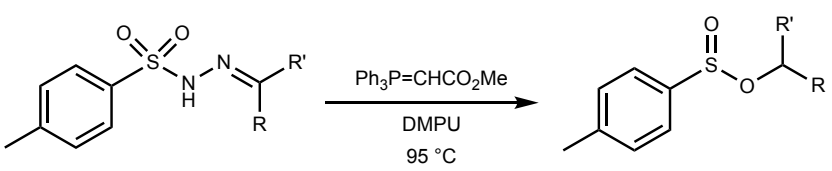<smiles>Cc1ccc(S(=O)OCc2ccccc2)cc1</smiles>

$66 \%$

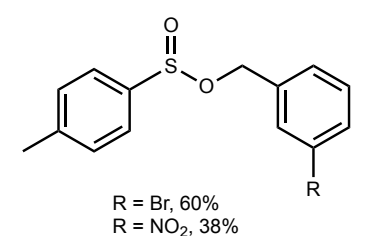
$\mathrm{R}=\mathrm{NO}_{2}, 38 \%$<smiles>Cc1ccc(S(=O)OCc2cccc3ccccc23)cc1</smiles>
$68 \%$<smiles></smiles>

$64 \%$<smiles>COc1cc(COS(=O)c2ccc(C)cc2)ccc1O</smiles><smiles>COc1cc(COS(=O)c2ccc(C)cc2)cc(OC)c1OC</smiles><smiles>Cc1ccc(S(=O)OCc2ccc(P)cc2)cc1</smiles><smiles>Cc1ccc(S(=O)OCc2cccc(C)c2F)cc1</smiles>

$56 \%$<smiles>COc1ccc(C(C)OS(=O)c2ccc(C)cc2)cc1</smiles>

$68 \%$<smiles>Cc1ccc(S(=O)OC(c2ccccc2)c2ccccc2)cc1</smiles>

$60 \%$<smiles>Cc1ccc(S(=O)OCc2cccnc2)cc1</smiles>

$66 \%$<smiles>Cc1ccc(S(=O)OCc2ccco2)cc1</smiles>

$68 \%$<smiles>Cc1ccc(S(=O)OCc2cn(C(=O)c3ccccc3)c3ccccc23)cc1</smiles>

$54 \%$<smiles>CC(=O)COc1c(COS(=O)c2ccc(C)cc2)cc(C(C)(C)C)cc1C(C)(C)C</smiles><smiles>O=S(OCc1ccccc1O)c1ccc(I)cc1</smiles>

$0 \%$<smiles>C=CCOc1ccccc1COS(=O)c1ccc(C)cc1</smiles>

$74 \%$<smiles>Cc1ccc(S(=O)OCc2ccccc2OCC#Cc2ccccc2)cc1</smiles>

$76 \%$ 
starting material requiring a multiple step synthesis. Also, this method used excess reagents that required extensive chromatographic separation to be removed. Such long and inefficient process could not be applied to industrial processes.

In 2020, Wei and coworkers developed a methodology for the preparation of sulfinate esters via electrochemical process (Scheme 9). ${ }^{18}$ This method is a great recent innovation but-

Scheme 9: Electrochemical synthesis of sulfinate esters ${ }^{18}$
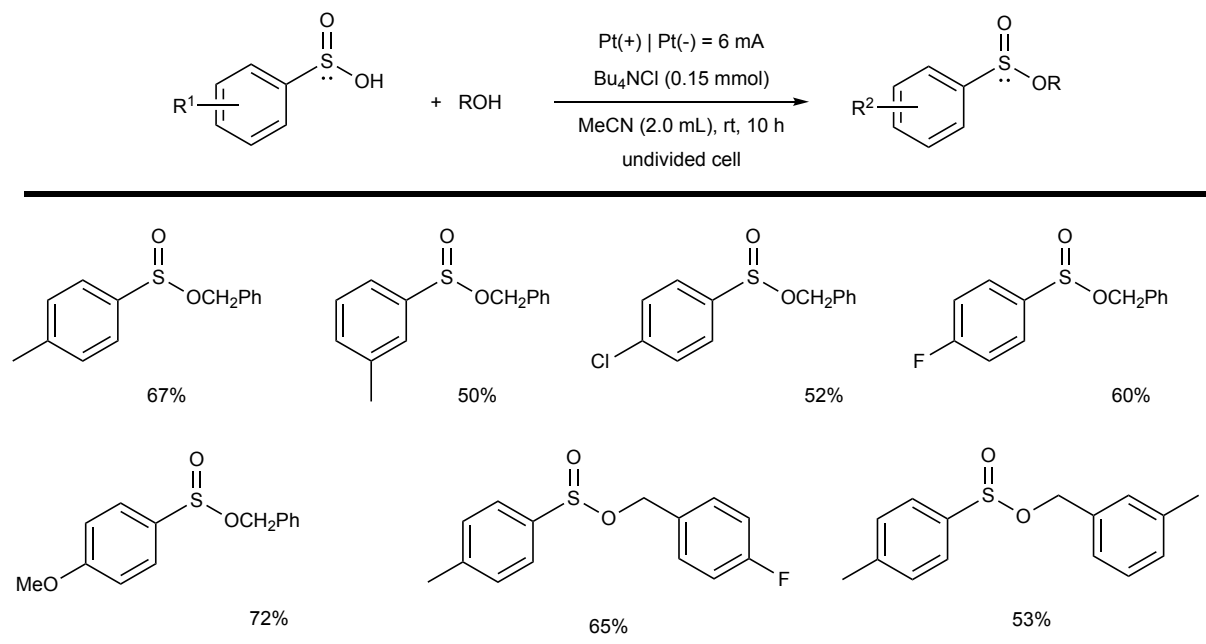<smiles>Cc1ccc(S(=O)OCc2ccc(C(F)(F)F)cc2)cc1</smiles>

$70 \%$<smiles>Cc1ccc(S(=O)OCc2cccc(Cl)c2)cc1</smiles><smiles>COc1ccc(S(=O)OC)cc1</smiles>

$60 \%$<smiles>CC(C)OS(=O)c1ccc(Cl)cc1</smiles><smiles>COc1ccc(S(=O)OC(C)C)cc1</smiles>

$65 \%$<smiles>CCOS(=O)c1ccc(OC)cc1</smiles>

\section{$75 \%$}

$63 \%$

$63 \%$<smiles>CCCCCCCCOS(=O)c1ccc(Cl)cc1</smiles><smiles>CCCCCOS(=O)c1ccc(OC)cc1</smiles><smiles>Cc1ccc(S(=O)OCCc2ccccc2)cc1</smiles><smiles>Cc1ccc(S(=O)OCCc2ccccc2)cc1</smiles>

$58 \%$

$63 \%$

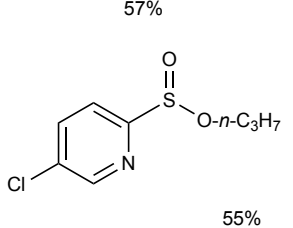


applying it to an industrial scale would be inefficient. A more efficient and simplistic organosynthetic method is desirable for industry.

\section{A novel methodology for sulfinate ester synthesis via activated phenoxy sulfinate esters}

The focus of this thesis is dedicated to the development of a novel methodology for the synthesis of sulfinate esters in terms of their general structures $\left(\mathrm{RSO}_{2} \mathrm{R}^{\prime}\right)$ and their diastereomerically and enantiomerically pure forms. It is proposed that the utilization of activated esters can assist in this development, and of interest is phenoxy sulfinate esters. This proposed method for synthesis of sulfinate esters through activated phenoxy sulfinate esters would allow for scalability in industrial processes and allow for inclusion of acid sensitive compounds. Ultimately, making this proposed method a more viable option than previously discussed literature methods. Pre-existing methods for the synthesis of such phenoxy sulfinate esters can be seen in Scheme 10. ${ }^{19}$

Scheme 10: Pre-existing phenoxy sulfinate ester syntheses

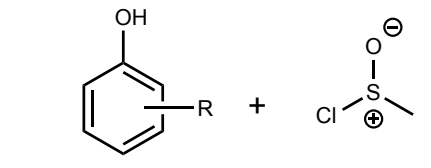

Ciuffarin et al., 1973 and Janda et al., 2016

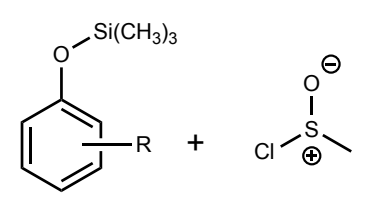

Kozuka and Higashino, 1980
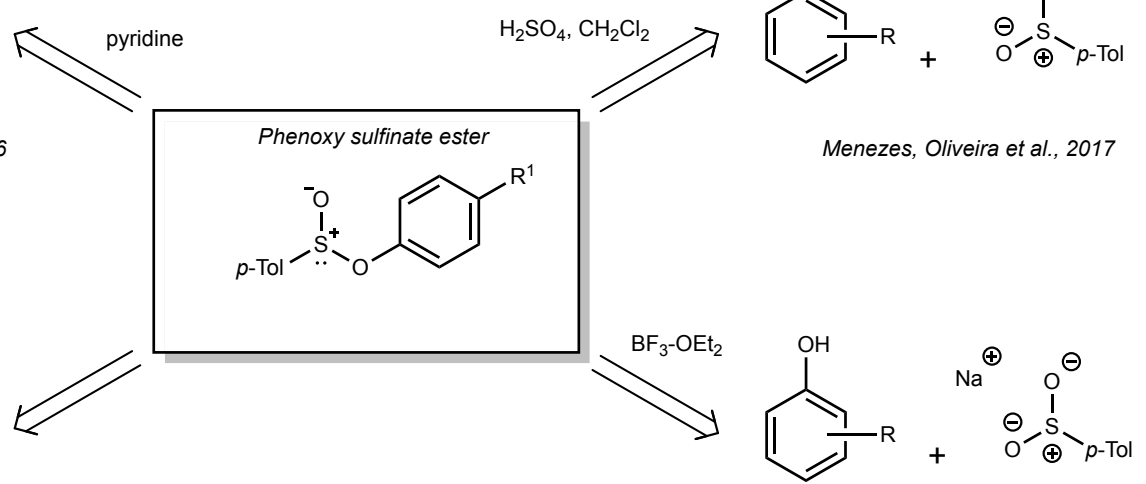

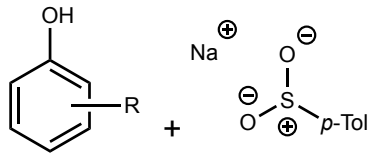

Menezes, Oliveira et al., 2017

Xiong et al., 2016 
In 2018 Hitchcock and coworkers developed a method for sulfinate ester synthesis that utilized 1-ethyl-3-(3-dimethylaminopropyl)carbodiimide (EDC) with $p$-toluenesulfinic acid and an alcohol. ${ }^{20}$ This method is to be used for the synthesis of the phenoxy sulfinate esters by the addition of a phenol, as seen in Scheme 11.

Scheme 11: Phenoxy sulfinate ester synthesis via EDC method ${ }^{20}$
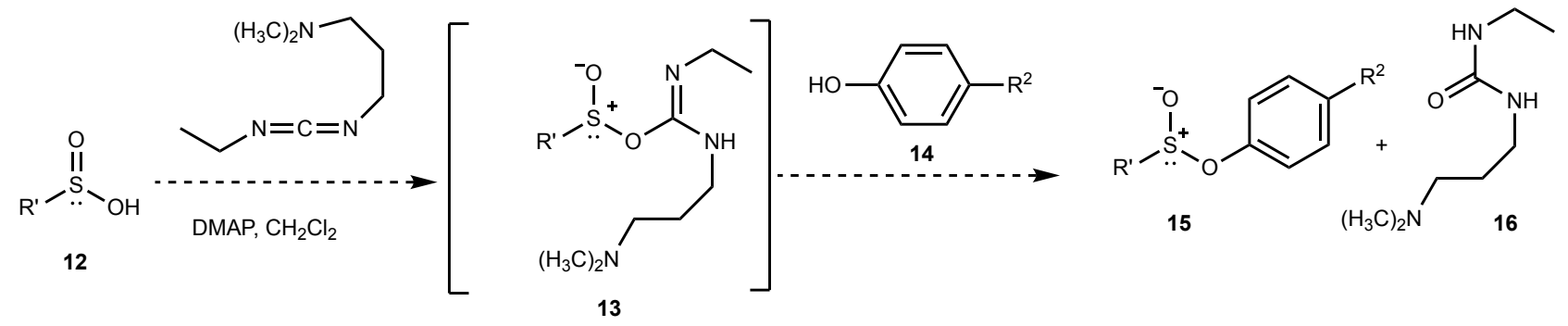

Upon the completion of the phenoxysulfinate ester (PSE, (15)) synthesis these compounds will be subjected to another EDC synthesis with an alcohol to produce a sulfinate ester, Scheme 12. This produced sulfinate ester is the compound of interest for biological application and indirect amine synthesis. It is proposed that the indirect sulfinamide synthesis can be achieved from sulfinate esters through a process known as dynamic kinetic resolution.

Scheme 12: Sulfinate ester synthesis via PSE<smiles>[R]OS(=O)O[R]</smiles> 


\section{Dynamic kinetic resolution: Can phenoxysulfinate esters achieve kinetic resolution?}

The process of dynamic kinetic resolution (DKR) was considered as a potential means of achieving a stereoselective synthesis of the desired sulfinamide substrates (20, 20') (Scheme 13). Dynamic kinetic resolution involves the use of rapidly equilibrating enantiomers $\left(\mathrm{E}_{1}(\mathbf{1 5})\right.$ and $\mathrm{E}_{2}$ (15') as the starting material. It is proposed that phenoxysulfinate esters may exhibit such a propensity for enantiomeric equilibration. For such enantiomers, they can be reacted with a foreign chiral substrate such as a chiral alcohol. Upon the addition of a chiral alcohol to this equilibrated mixture, product formation will be favorable towards one diastereomer, 18 or 18', due to a higher reaction rate caused by preferential bonding of the enantiomers via stereochemical considerations. This will ultimately lead to a potential diastereoselective synthesis of a sulfinate esters. These sulfinate esters in turn can then be converted into the requisite sulfinamide upon the addition of an amine.

Scheme 13: Dynamic kinetic resolution

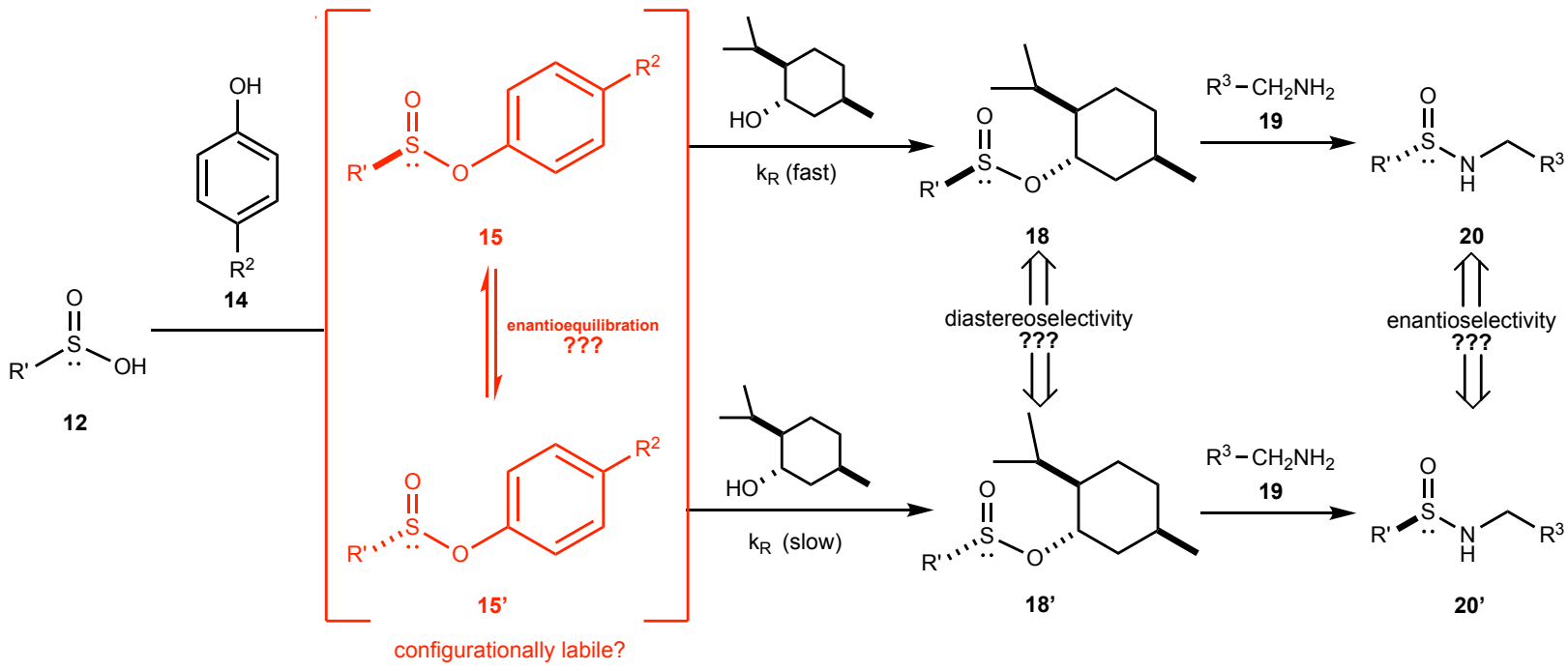


The nature of DKR with the sulfinyl group $(\mathrm{R}-\mathrm{S}=\mathrm{O})$ depends on the chemical properties of the leaving group, and it is proposed that a phenoxy leaving group could influence DKR to be a diastereoselective. Thus, phenoxy sulfinate ester (PSE) compounds are proposed to be a possible tool in the DKR investigations. The next chapter is focused on the development on the PSE derivatives as tools for the synthesis of sulfinate esters and tools for DKR. 


\section{CHAPTER II: THE DESIGN, SYNTHESIS, AND APPLICATION OF PHENOXY \\ SULFINATE ESTERS AS PREPARATIVE TOOLS FOR THE SYNTHESIS \\ OF SULFINATE ESTERS AND SULFINAMIDES}

\section{Introduction}

Sulfinate esters and sulfinamides have been employed as important synthetic agents for catalytic asymmetric synthesis and biological applications. ${ }^{21}$ In a recent study by Sun and coworkers developed a sulfinamide catalysis for the process of the catalytic asymmetric reduction of imines with trichlorosilane (Scheme 14). ${ }^{6}$ The sulfinamide that was employed relied on a chiral sulfinyl group bound to a nitrogen that was substituted with a series of phenolic derivatives. The use of these derivatives in the catalytic reduction of imines yielded the reduced amines in enantioselectivities ranging from 49 to $84 \%$. Ideally, the synthesis of enantiomerically pure pharmaceutical agents should be conducted with very high enantioselectivities by chemical means. While Sun and coworkers' catalytic asymmetric catalysis was limited in terms of the enantioselectivities, the process is open to the development of new and more effective sulfinamide catalysts.

Scheme 14: Sun and coworkers catalytic asymmetric reduction

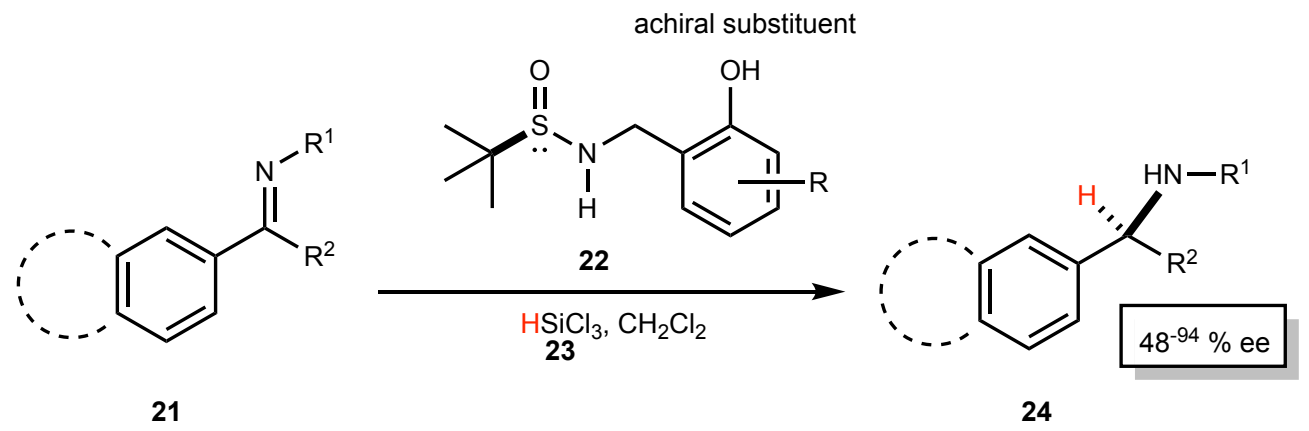


Based on Sun and coworkers leading work in this field, it is proposed that the sulfinamide catalyst can be designed to yield improved enantioselectivities by the introduction of structurally demanding chiral substituents on the sulfinamide core (Scheme 15). The additional chiral framework would potentially create a more rigorous steric environment for the catalysis to occur in and thereby increase the enantioselective formation of the target amine product. Such an approach would potentially lead to improved selectivities in the chemical synthesis and the potential application of this methodology to the synthesis of the drug cinacalcet (25). Cinacalcet is a drug that is designed for those persons with hypothyroidism who are experiencing elevated levels of serum calcium. ${ }^{22}$ It is known that the $(R)$-enantiomer is known to be at least ten times more responsive that the $(S)$-enantiomer in clinical trials. ${ }^{23}$ Thus, an efficient synthesis of the $(R)$-enantiomer would be of value and this would be a long-term goal of the proposed research. Thus, the overall proposed research program would be initially focused on the design and synthesis of a new class of chiral sulfinamides with additional chiral scaffolding and the application of these compounds to the synthesis to the pharmaceutical agent cinacalcet.

Scheme 15: Proposed new sulfinamide catalyst

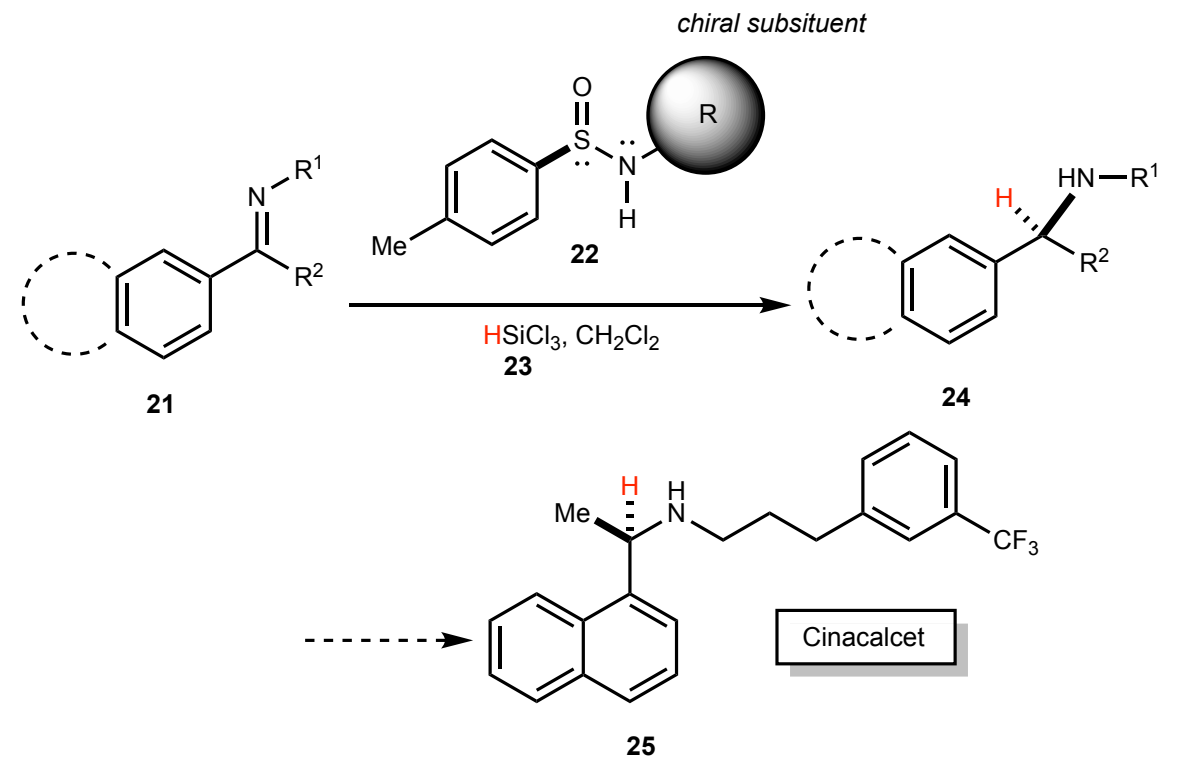




\section{Synthesis of a L-phenylglycine based sulfinamide: The diastereomer dilemma}

The synthesis of a structurally new sulfinamide with additional chiral scaffolding was launched with the use of the alpha-amino acid ester, L-phenylglycine methyl ester. This chiral molecule has been successfully employed in asymmetric synthesis in conjugate addition reactions. ${ }^{24}$ Using the carbodiimide approach developed by Hitchcock and coworkers, the Lphenylglycine methyl ester was coupled with $p$-toluenesulfinic acid using EDC and catalytic DMAP in dichloromethane (Scheme 16).

Scheme 16: Synthesis of the L-phenylglycine methyl ester sulfinamide<smiles>Cc1ccc(S(=O)O)cc1</smiles>

26

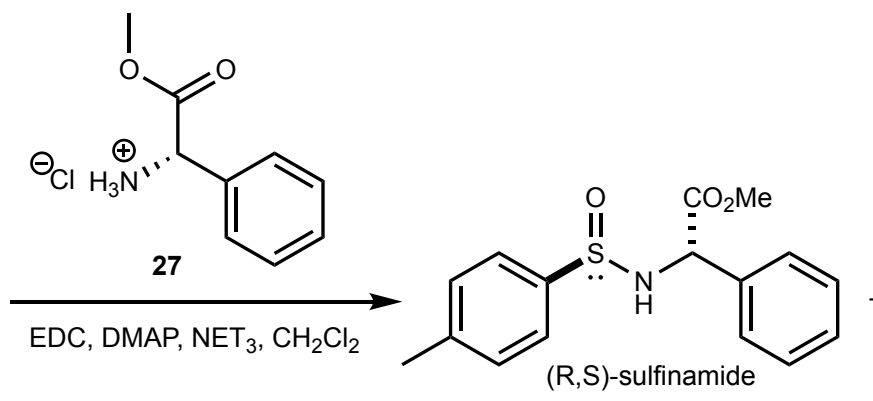

28a<smiles></smiles>

$28 b$

The reaction yielded a mixture of diastereomers (the $\left(R_{S}, S\right)$-sulfinamide $28 \mathbf{a}$ and the $\left(S_{S}, S\right)$-sulfinamide $\mathbf{2 8 b}$ ) in a 54:46 ratio as determined by $400 \mathrm{MHz}{ }^{1} \mathrm{H}$ NMR spectroscopy (Figure 1). The ratio of the diastereomers was determined by the analysis of the crude reaction mixture. The signal that was evaluated was the diagnostic methyl group appended to the toluenesulfinyl ring. The methyl group of the major diastereomer appeared at $2.34 \mathrm{ppm}$ and the minor diastereomer appeared at $2.42 \mathrm{ppm}$. 
Figure 1: Crude ${ }^{1} \mathrm{H}$ NMR diastereomeric mixture of sulfinamide diastereomers 28a \& $\mathbf{2 8 b}$

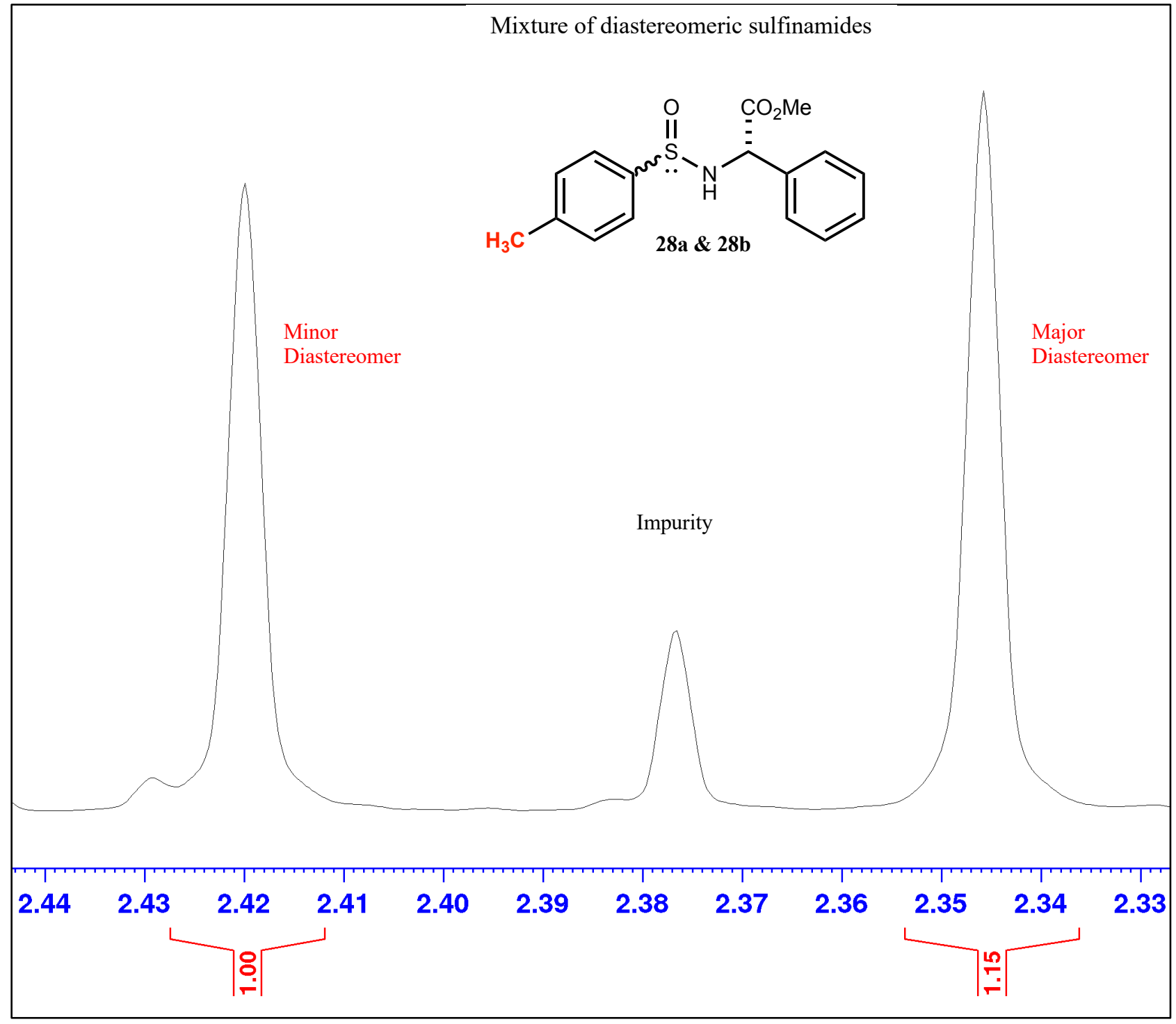

It was important that the diastereomers be separated as the chiral sulfinamide catalyst needed for the asymmetric catalyst had to exist as a single isomer. Thus, the crude mixture was purified via flash column chromatography on silica gel using hexanes and ethyl acetate (75:25) as the mobile phase. The chromatographic separation of the two diastereomers (the $\left(R_{S}, S\right)$ sulfinamide 28a and the $\left(S_{S}, S\right)$-sulfinamide $\left.\mathbf{1 8 b}\right)$ yielded three separate collections of fractions. The first fraction collected contained mostly minor diastereomer and a small amount (less than 
$10 \%$ ) of major diastereomer, the second fraction collected was a near 50:50 mixture of the minor and major diastereomers, and the third fraction collected was mostly the major diastereomer contaminated with the minor isomer. It was determined by $400 \mathrm{MHz}{ }^{1} \mathrm{H}$ NMR spectroscopy that the third fraction was composed of an 88:12 mixture favoring the major diastereomer (Figure 2).

Figure 2: $400 \mathrm{MHz}{ }^{1} \mathrm{H}$ NMR spectrum of the third fraction derived from chromatography

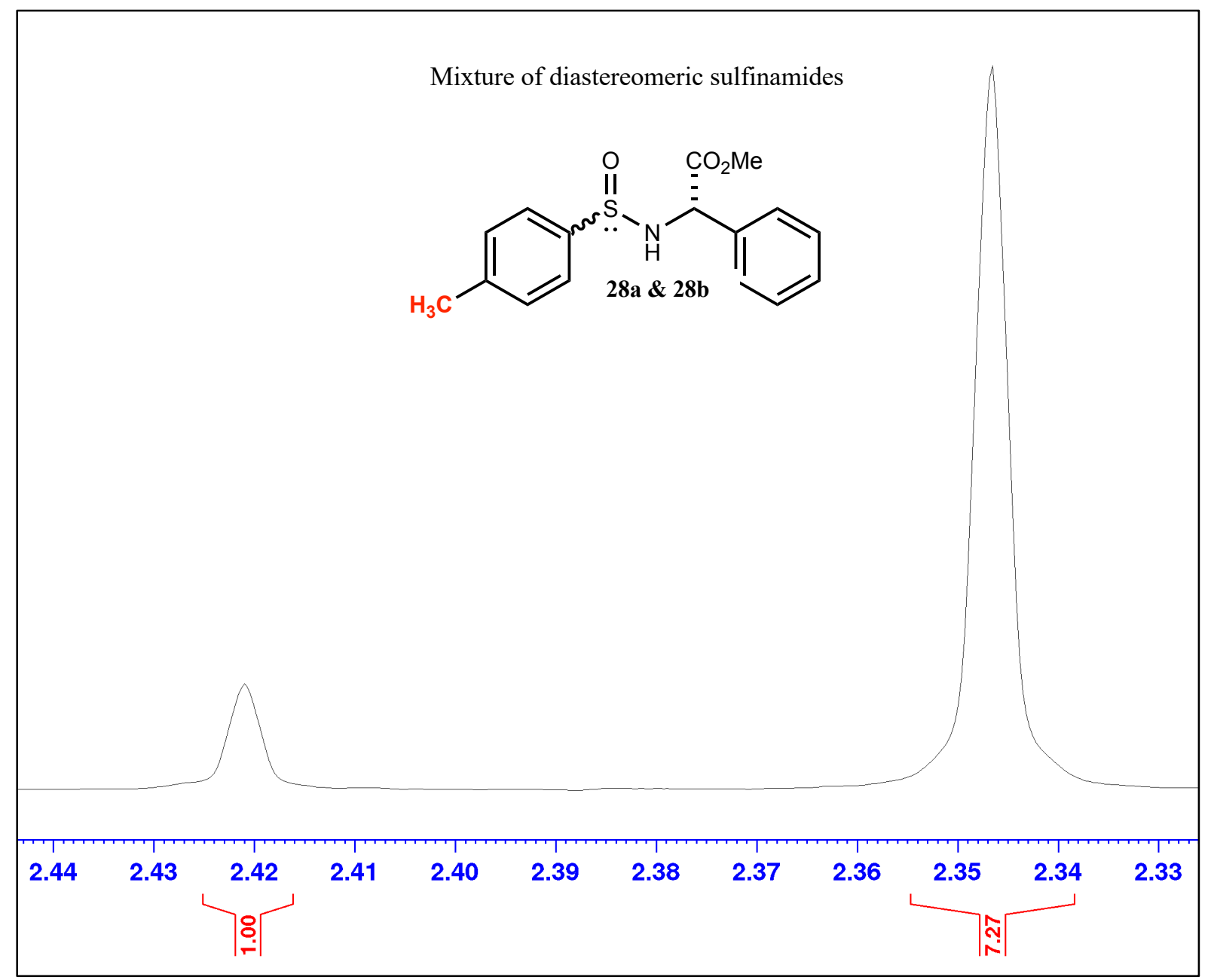

The diastereomeric ratio of 88:12 was not considered to be pure enough for application in the catalytic asymmetric reduction that was earlier proposed. In an attempt to isolate the major diastereomer as a single purified diastereomer, the mixture of diastereomers from the third 
fraction was subjected to recrystallization from ethyl acetate and hexanes. The recrystallized product was analyzed by $400 \mathrm{MHz}{ }^{1} \mathrm{H}$ NMR spectroscopy and the diastereomeric purity determined to be 97:3 favoring the major diastereomer over the minor diastereomer (Figure 3). The structural identity of the isolated sulfinamide was determined by single crystal X-ray crystallography to be the $\left(S_{S}, \mathrm{~S}\right)$-diastereomer (Figure 4$){ }^{25}$

Figure 3: Recrystallized pure $400 \mathrm{MHz}{ }^{1} \mathrm{HNMR}$ of sulfinamide target product

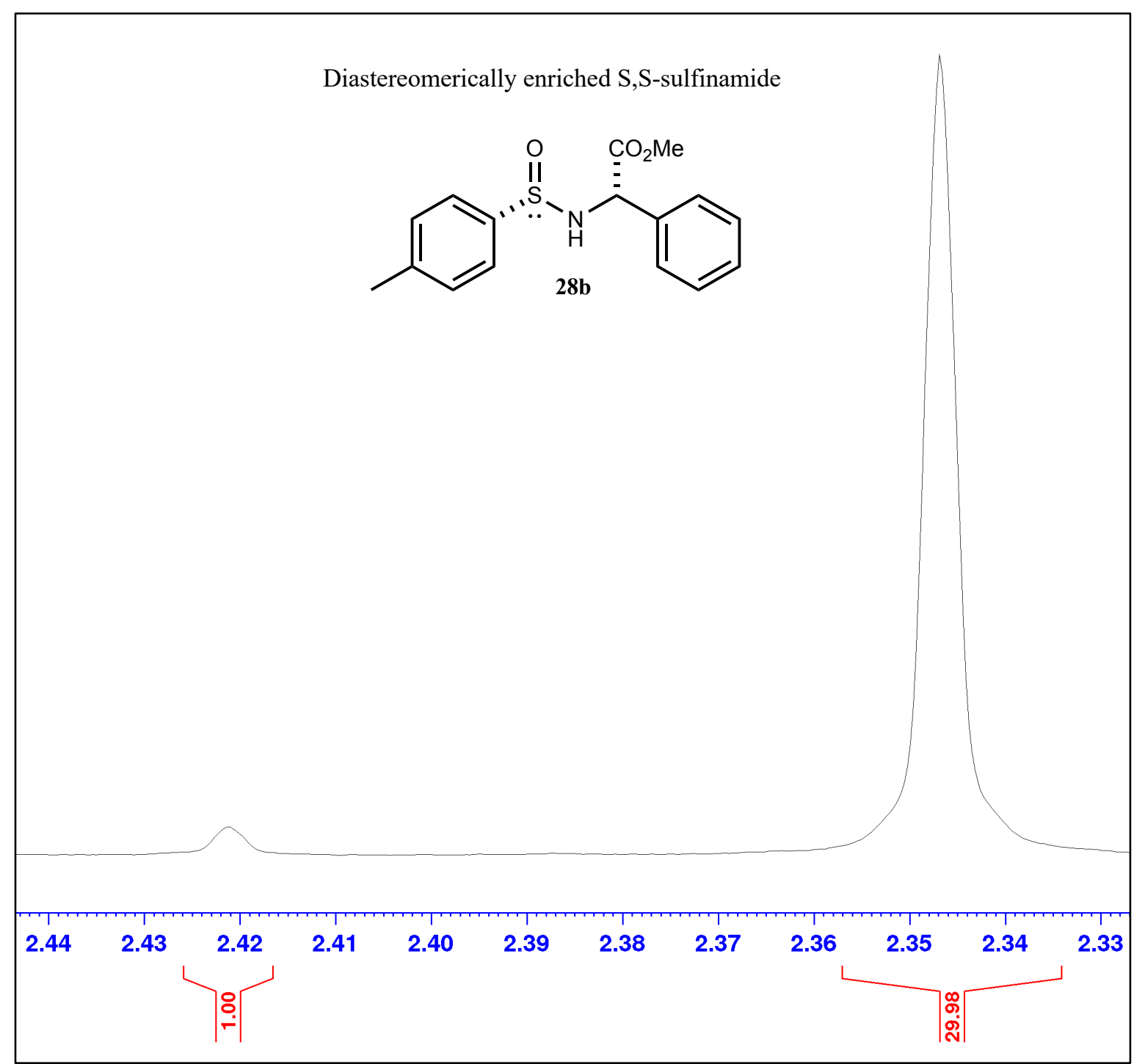


Figure 4: X-ray crystal structure of the sulfinamide $(S, S)$-diastereomer $\mathbf{2 8 b}^{25}$

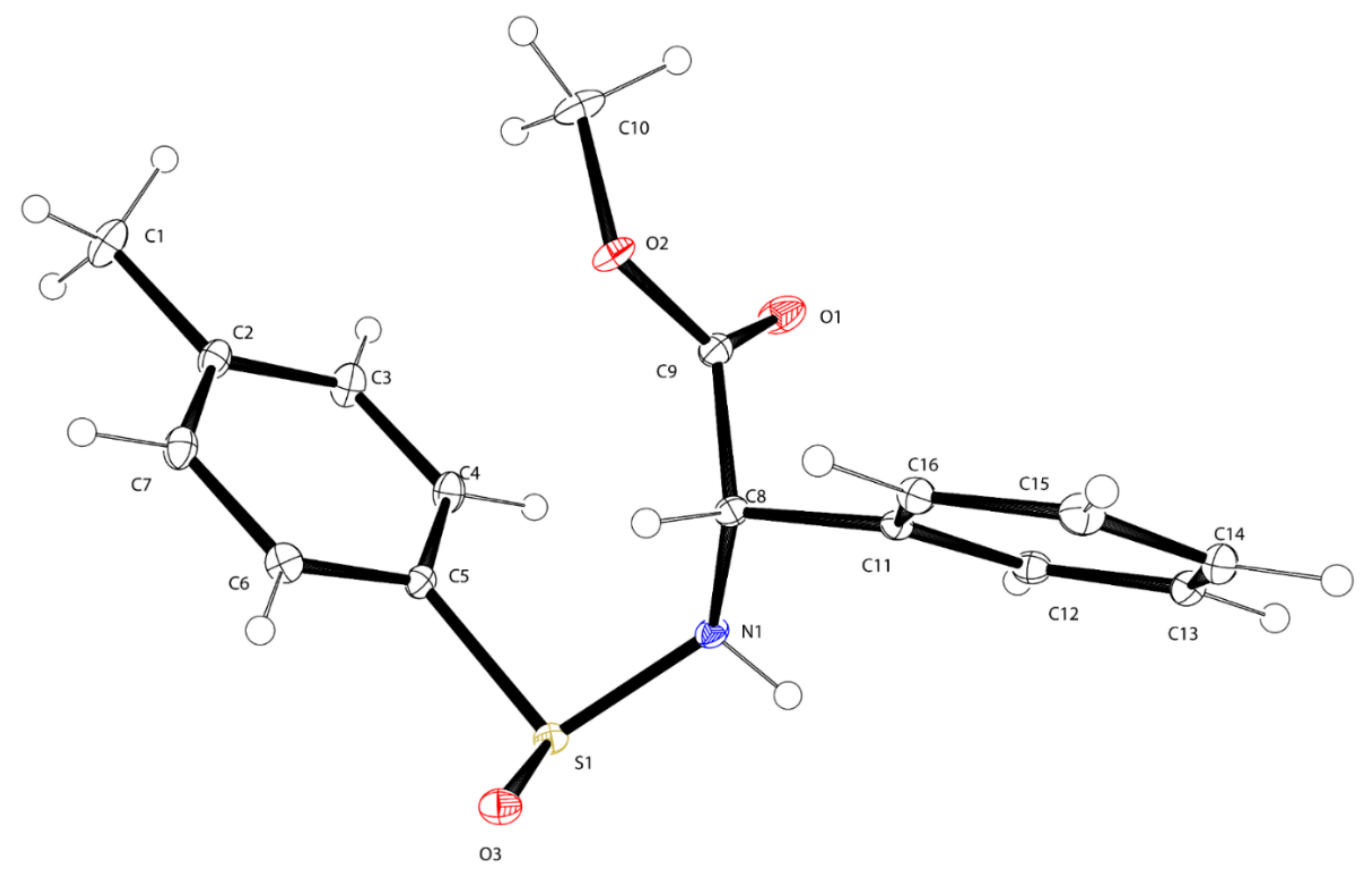

While the recrystallized ratio represented a significant improvement over the initial 54:46 ratio that was obtained from the crude reaction, it was still not the ideal pure single isomer that was being sought. Despite this dilemma of having the isolate a single diastereomer through chromatography and recrystallization, the $97: 3$ ratio was determined to be suitable for usage in the catalytic asymmetric reduction process. With a single diastereomer of the sulfinamide possessing a chiral scaffold bound to the nitrogen, the next stage of this work was the synthesis of imine substrates for the asymmetric reduction. 


\section{Synthesis of a series of imines for the catalytic asymmetric reduction}

The imine synthesis was conducted using the method of White and coworkers. ${ }^{26}$ This methodology involved reacting a series of ketones with titanium tetrachloride $\left(\mathrm{TiCl}_{4}\right)$, triethylamine $\left(\mathrm{Et}_{3} \mathrm{~N}\right)$, and aromatic amines together to synthesize the desired imines (Scheme 17).

Scheme 17: Imine synthesis using the method of White and coworkers ${ }^{26}$
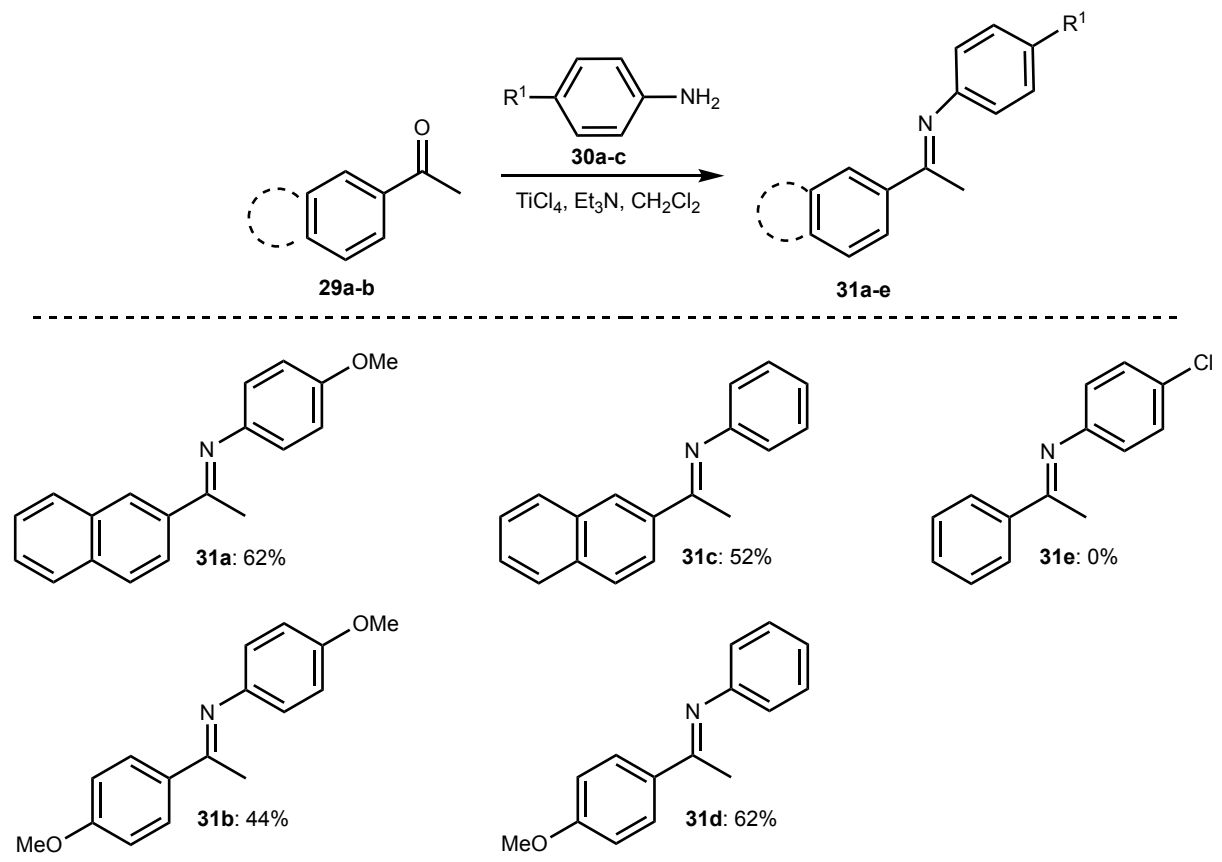

The synthesis of the imines 31a-e was successful with the exception of 31e. The failure of the synthesis of imine 31e was attributed to the electronic nature of the $p$-chloroaniline employed. Despite this minor setback, the remaining imines were isolated and purified by flash chromatography on silica gel with a mobile phase of hexanes and ethyl acetate $(75: 25)$. The formation and final isolation of the pure imines was deemed to be successful based on the analysis of the $400 \mathrm{MHz}{ }^{1} \mathrm{H}$ NMR spectra. 


\section{Application of the imines in the synthesis of racemic amine standards}

The plan of action for research ultimately involved using the imines in the catalytic asymmetric reduction illustrated in Scheme 18. The analysis of the enantioselective efficiency of these reactions would involve the use of chiral stationary phase HPLC. In turn, this would require the use of racemic standards of the reduction products to ensure that the measured enantioselectivities are accurate representations of the reaction mixtures.

Scheme 18. Rationale for the synthesis of the racemic amines
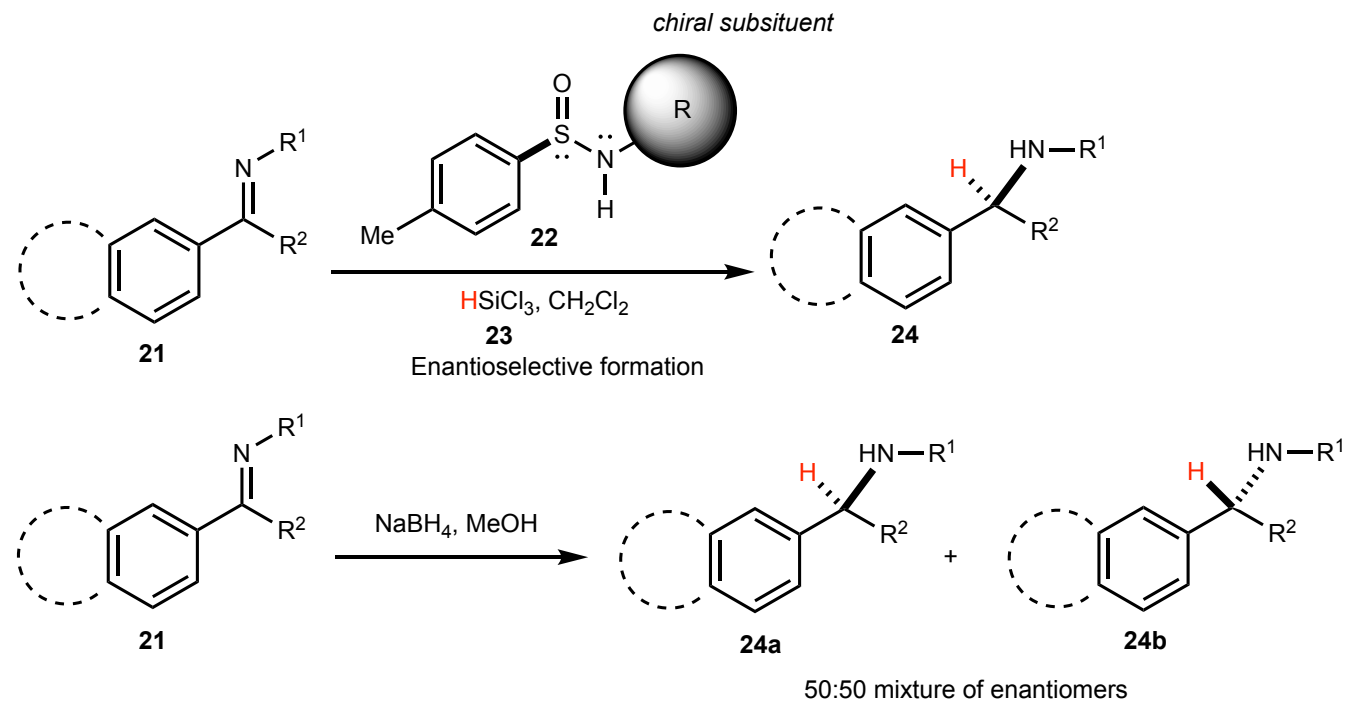

A series of racemic amine standards (32a-d) were prepared by a known method of reacting imines with sodium borohydride $\left(\mathrm{NaBH}_{4}\right)$, as seen in Scheme 19. Analysis of the ${ }^{1} \mathrm{H}$ NMR spectrum of the crude mixtures revealed the target amines had formed and they were directly carried onto analysis via HPLC. 
Scheme 19: Synthesis of racemic standards for HPLC

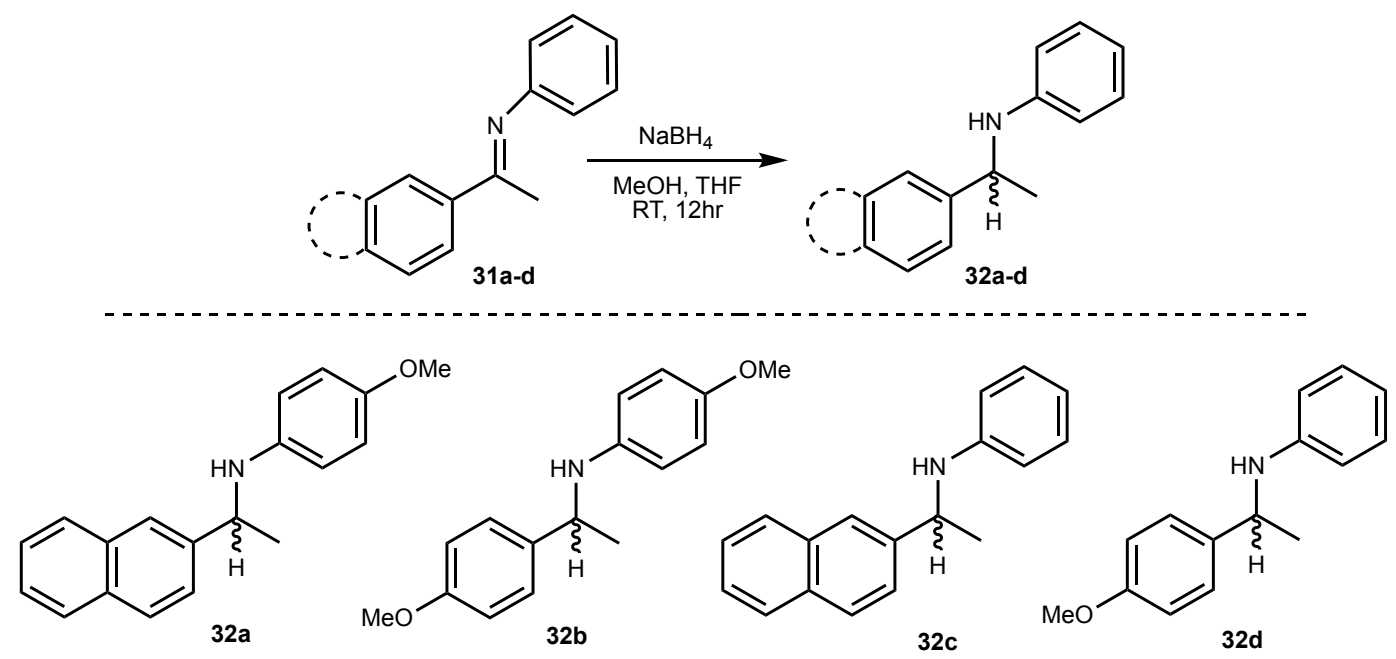

The optimization of HPLC as a method of analysis for enantioselectivity was conducted. Variables that underwent optimization consisted of the mobile phase, injection sample size, and flow rate. These variables were manipulated in order to observe a clear baseline separation of the chiral amine enantiomers. The column used for this optimization was the commercially available Chiralcel OD-H chiral stationary phase column. This is an HPLC column that is packed with cellulose bound to silica gel. The hydroxy groups of the cellulose modified stationary phase have been capped with a carbamate functional group thus creating a unique chiral environment. In the course of a chiral separation of a mixture of enantiomers, this unique environment that will interact with the two individual enantiomers in two unique ways. ${ }^{27}$ Ultimately, this leads to separation of those enantiomers as they will have individual retention times on the column. ${ }^{27}$ The chosen column, Chiralcel OD-H, was packed with cellulose tris(3,5-dimethylphenylcaramate) coated on $5 \mu \mathrm{m}$ silica-gel. ${ }^{28}$ The racemic standards 32a-d were analyzed on this column with mobile phases 98:2 and 99:1 hexanes:ethyl acetate, injection sample sizes $1 \mu \mathrm{L}, 3 \mu \mathrm{L}$, and $4 \mu \mathrm{L}$, and the flow rates of $1.0 \mathrm{~mL} / \mathrm{min}$ and $1.5 \mathrm{~mL} / \mathrm{min}$. The closest baseline separation observed was with racemic standard 32a under the conditions of 99:1 hexanes: ethyl acetate mobile phase, 3 
$\mu \mathrm{L}$ injection sample size, and a $1.5 \mathrm{~mL} / \mathrm{min}$ flow rate. Upon the analysis of this HPLC chromatographic trace data, it was determined that the enantioselectivity of the chiral amines would have to be deduced by ${ }^{1} \mathrm{H}$ NMR spectroscopy only.

It was at this stage that the imines and catalytic sulfinamide had been synthesized and prepared for application in the catalytic asymmetric reductive synthesis of chiral amines. The proposed synthesis of chiral amines via a sulfinamide catalyst designed to improve enantioselectivity was conducted. Imine substrate 31c was reacted with the L-phenylglycine methyl ester sulfinamide $\mathbf{2 8 b}$, and trichlorosilane $\left(\mathrm{Cl}_{3} \mathrm{SiH}\right)$ (Scheme 20$)$. The crude product was then analyzed by $1 \mathrm{H}$ NMR spectroscopy to confirm product formation. The use of chiral stationary phase HPLC was not able to resolve the individual peaks of the enantiomers, but it was possible to determine that the enantioselectivity was no greater than a ratio of 60:40 favoring the major enantiomer.

Scheme 20: Synthesis of chiral amines via catalytic asymmetric reduction

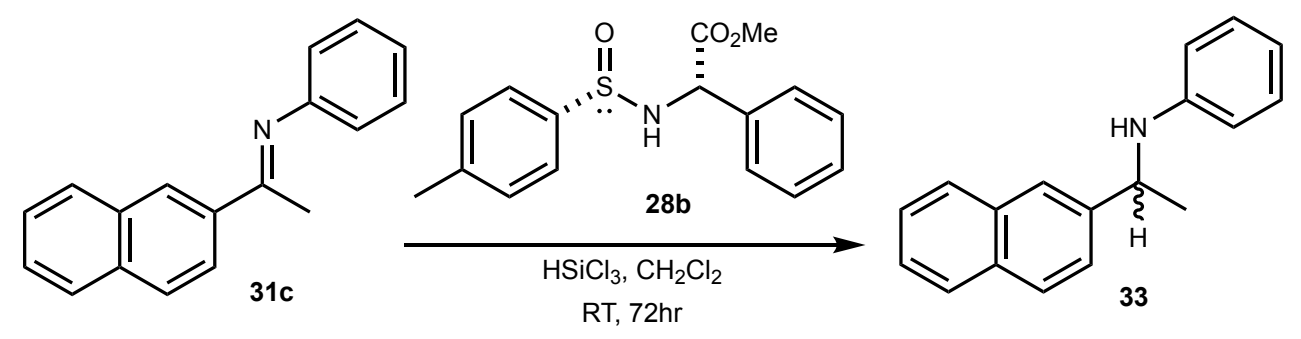

It was decided that the catalysis reaction needed to be optimized in order to achieve an improved enantioselectivity. The first optimization was to observe the effect of a base. Two reactions were set up side by side in which the imine 31c was reacted with the synthesized sulfinamide $\mathbf{2 8 b}$, and one reaction contained the base $N, N$-diisopropylethylamine (Hünig's base) 34 (Scheme 21). Analysis of the crude ${ }^{1} \mathrm{H}$ NMR spectra suggested that the reaction had worked 
to create the desired amine, but again, the chiral stationary phase HPLC analysis revealed that the enantioselectivity had not improved but remained effectively the same.

Scheme 21: Synthesis of racemic amines via catalytic asymmetric reduction, version two<smiles>CC(=O)N(C(C)C)C(C)C(C)C</smiles>

Reaction time and temperature for amine synthesis without base underwent optimization next. It was proposed that the catalytic asymmetric reduction could be optimized by decreasing the temperature thus decreasing reaction rate in which the formation of one enantiomer is favored, increased enantioselectivity. A trial consisting of four reactions with varying time and

Table 2: Optimization of the synthesis of racemic amines via catalytic asymmetric reduction

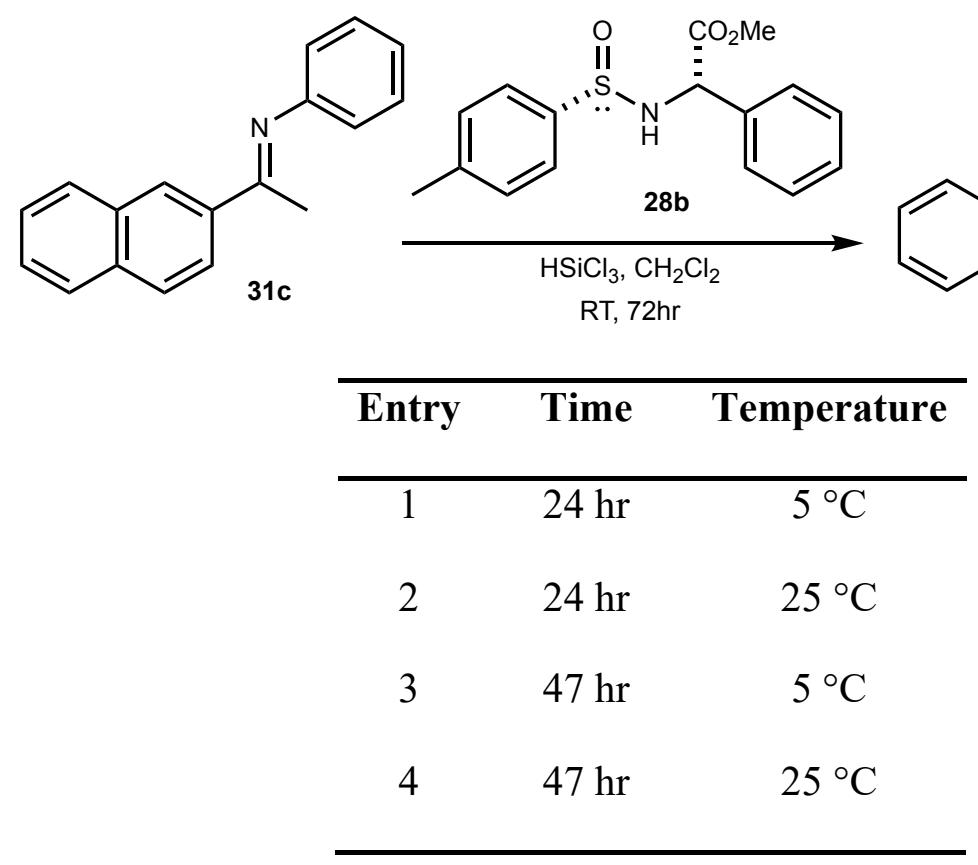


temperature was conducted, Table 2 . The analysis of these three reactions by ${ }^{1} \mathrm{H}$ NMRspectroscopy and HPLC revealed that the reactions were successful, but the enantioselectivity had not increased. Furthermore, more attempts at improving the baseline separation of the enantiomeric peak signals in the HPLC still remained as a challenge.

\section{Conclusion of the catalytic asymmetric reduction of imines with sulfinamide catalysts}

In addition to the difficulty of developing a method for chiral separation there was also the limitation in the amount of catalyst available for this study. The limitation of not having enough catalyst would be detrimental to the overall project and had to be addressed as the more important issue. The carbodiimide EDC approach was limited to only yielding nearly equimolar quantities of the sulfinamide diastereomers. Isolation of a single diastereomer from the 50:50 crude mixture became extensive and time consuming. Thus, an alternate approach to the selective synthesis of the diastereomer sulfinamides was considered. The process of dynamic kinetic resolution (DKR) was considered as a potential means of achieving selective synthesis as was discussed in Chapter I with Scheme 13. 


\section{CHAPTER III: THE SYNTHESIS, STABILITY, APPLICATION OF \\ PHENOXYSULFINATE ESTERS}

\section{Introduction}

As was stated in Chapter II, the pursuit of phenoxysulfinate esters (PSE) was rooted in the desired to develop an effective methodology for the preparation of sulfinate esters and sulfinamides. More importantly, the pursuit of the phenoxysulfinate esters was of interest as synthetic tools for achieving diastereoselective synthesis of sulfinamides for the sake of the catalytic asymmetric reduction (Scheme 22).

Scheme 22. Synthesis of the L-phenylglycine methyl ester sulfinamide

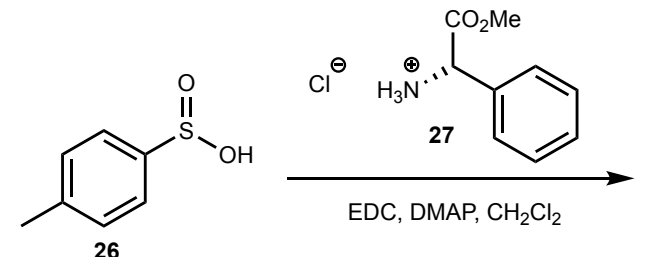

nearly equal formation of diastereomers

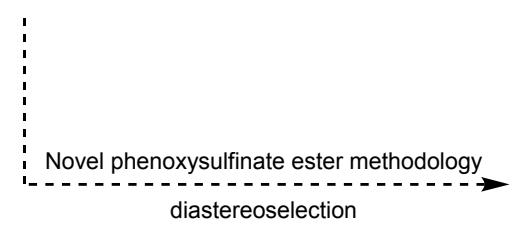

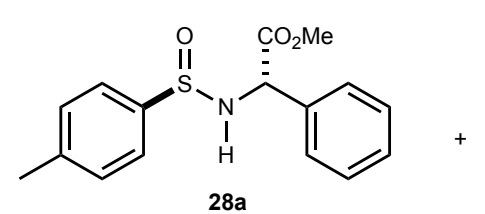

(RS,S)-sulfinamide

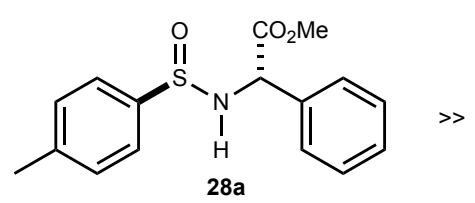

(RS,S)-sulfinamide $X$<smiles>CC(=O)[C@@H](C)C(=O)N[C@@H](C(C)=O)c1ccccc1</smiles>

(SS,S)-sulfinamide<smiles>CC(=O)[C@H](c1ccccc1)N([14CH3])[13C](=O)c1ccc(C)cc1</smiles>

(SS,S)-sulfinamide $X$

The initial synthesis of the $\alpha$-amino acid ester sulfinamide described in the previous chapter was limited by the fact that it generated a nearly 50:50 mixture of diastereomers, and consequently made the isolation of a single diastereomer inefficient. The development of a diastereoselective method that greatly favored the formation of one diastereomer over the other 
would be far more practical. It was proposed in the introduction that phenoxysulfinate esters may exhibit a propensity for enantiomeric equilibration of $\mathbf{1 5}$ and $\mathbf{1 5}$ ' within the DKR process for the transformation of sulfinate esters into sulfinamides for selective amine synthesis (Scheme 23). If the DKR process gives moderate stereoselectivity of a single major diastereomer (18 or 18') with measurable amounts of the minor diastereomer, then the major diastereomer is to be isolated.

However, if high stereoselectivity occurs in the formation of either $\mathbf{1 8}$ or $\mathbf{1 8}$ ' resulting in a single diastereomer then no isolation is needed, and amine addition can occur within a one-pot synthesis to produce a single chiral amine enantiomer.

Scheme 23: Phenoxysulfinate esters for dynamic kinetic resolution

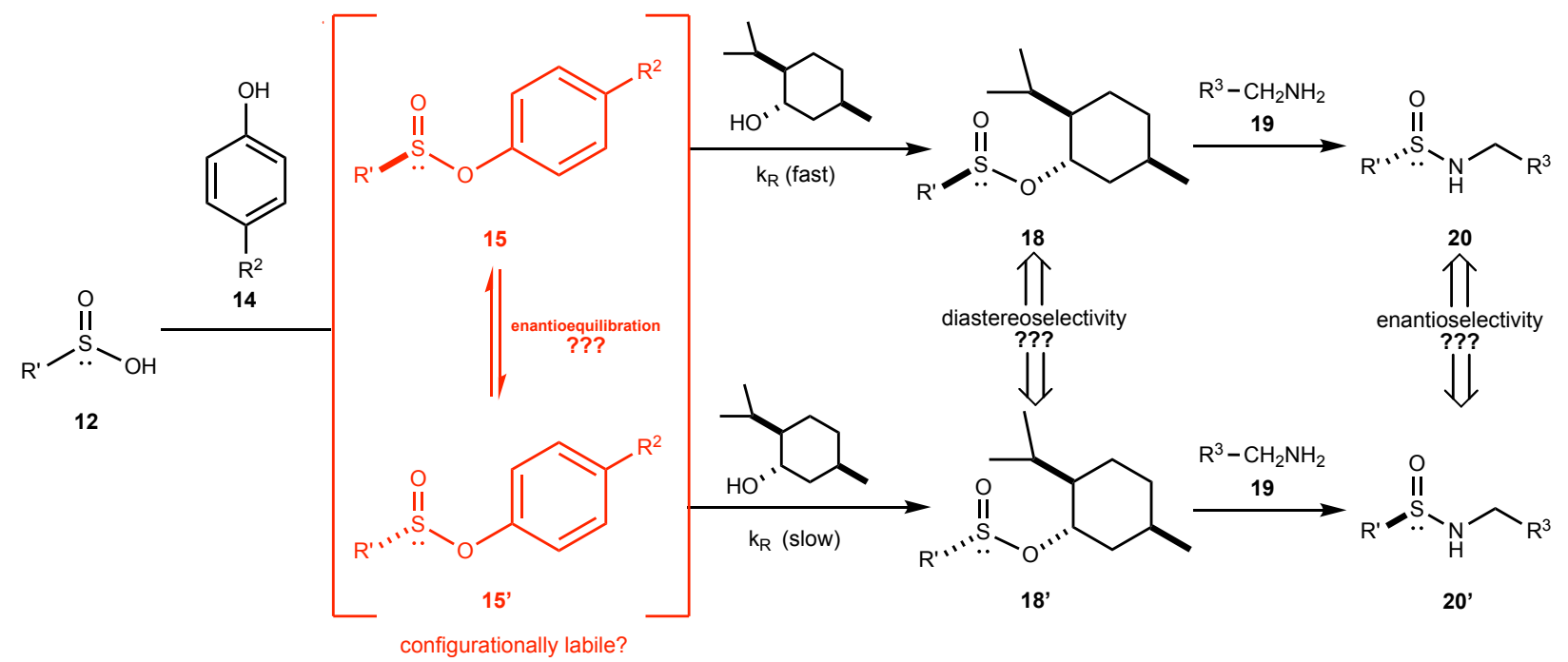

In terms of their synthesis and application, phenoxysulfinate esters have only received limited attention in the chemical literature. ${ }^{29}$ There are only two known examples of the synthesis of these compounds: (a) by reaction of sulfinyl chlorides with phenolic substrates ${ }^{30}$; (b) and by attempted reaction of sodium $p$-toluenesulfinate with catalytic sulfuric acid and phenolic substrates as originally reported by Menezes, Oliveira, and coworkers. ${ }^{31}$ 
The sulfinyl chloride method is limited by the fact that sulfinyl chloride compounds can be expensive, have limited availability, and limited stability. With regard to the method developed by Menezes, Oliveiria, and coworkers, it is proposed that the phenoxysulfinate esters formed were not isolable likely due to the acidic conditions used. Such conditions would likely cause the acid catalyzed hydrolysis of the phenoxysulfinate ester either during the course of the reaction or during the extractive work-up.

\section{A New Synthetic Paradigm for the Synthesis of Sulfinate esters and Sulfinamides: Synthesis of Phenoxy Sulfinate Esters}

Due to the limitations of the sulfinyl chloride method and the catalytic acid method, a new methodology was employed to achieve the goal of the synthesis of the phenoxysulfinate esters. Using the previously developed carbodiimide method explored within the Hitchcock research group, it was possible to obtain the desired sulfinate esters. This method consisted of reacting $p$-toluenesulfinic acid with EDC, DMAP, and a phenol substrate in dichloromethane $\left(\mathrm{CH}_{2} \mathrm{Cl}_{2}\right)$ for 12 hours. Utilizing this method, a series of four para-substituted phenolic substrates with varying electronic properties were selected as candidates for the synthesis of a series of phenoxysulfinate esters, Table 3. The $p$-bromophenyl-PSE (35a), $p$-tert-butylphenyl-PSE (35b), and the $p$-methoxyphenyl-PSE (35c) were all successfully isolated via flash chromatography and characterized by $400 \mathrm{MHz}{ }^{1} \mathrm{H}$ NMR spectroscopy, $100 \mathrm{MHz}$ C-13 NMR spectroscopy, infrared spectroscopy, and electrospray ionization high resolution mass spectrometry. In contrast, the $p$ nitrophenoxysulfinate derivative ( $p$-nitrophenyl-PSE) (35d) was not isolated. 
Table 3: Initial Synthesis of phenoxysulfinate esters 35a-d

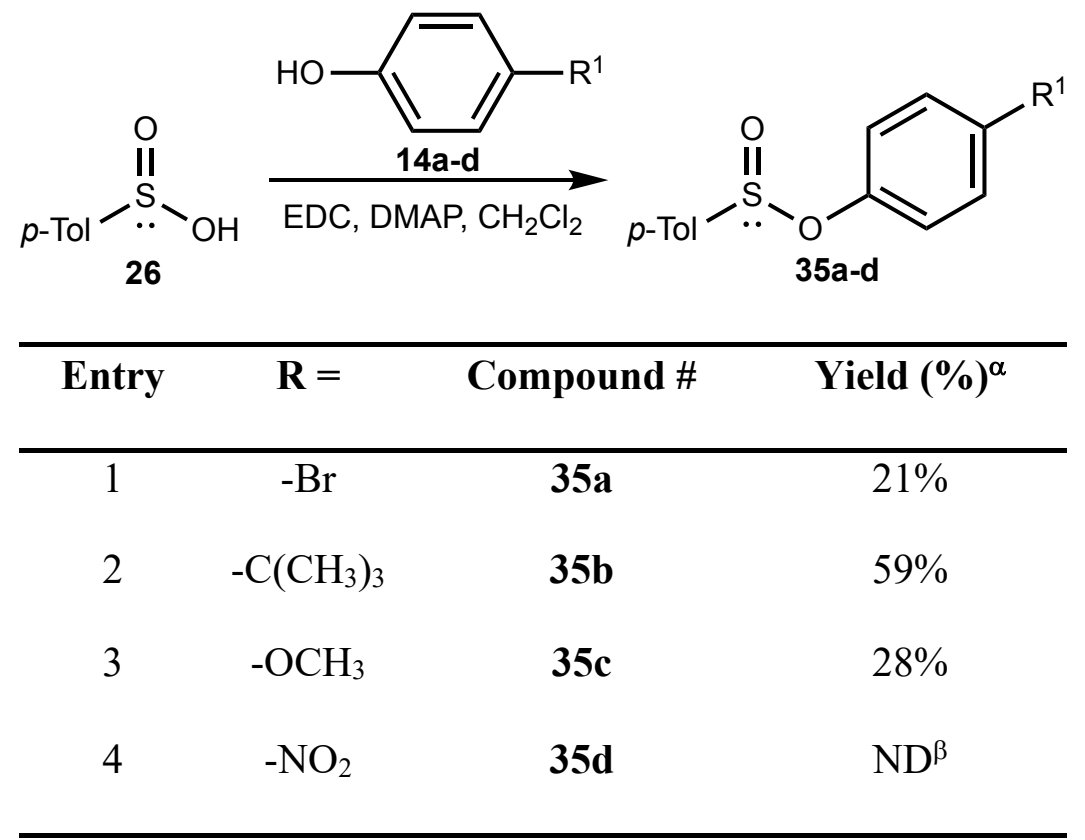

${ }^{\alpha}$ The reported yield was determined after silica gel column

chromatography. ${ }^{\beta}$ The yield could not be determined due to the formation of multiple by products.

Analysis of the ${ }^{1} \mathrm{H}$ NMR spectrum of the crude reaction mixture of the $p$-nitrophenyl-PSE derivative revealed the presence of the target compound along with a complex mixture of the starting material $p$-nitrophenol and unidentified byproducts. Analysis of the crude reaction mixture by thin layer chromatography (tlc) suggested that the isolation of the target compound would not be possible. The failure of the synthetic attempt to make the $p$-nitrophenoxysulfinate ester is attributed to the electron withdrawing nature of the nitro- group (Scheme 24). This substituent is very electron withdrawing, inductively and through the resonance effect. These combined effects have a negative impact in terms of the $p$-nitrophenol serving a nucleophile early in the reaction. In addition to this, the $p$-nitrophenoxy group is activated toward enhanced nucleophilic displacement, making it susceptible to hydrolysis in water. 
Scheme 24. Attempted synthesis of the $p$-nitrophenoxysulfinate ester<smiles>CCN=C(NCCCN(C)C)OS(=O)c1ccc(C)cc1</smiles><smiles>Cc1ccc(S(=O)Oc2ccc([N+](=O)[O-])cc2)cc1</smiles>

Once the other three PSE derivatives were isolated (35a-d), a very distinct color change was observed when the products were stored at $25{ }^{\circ} \mathrm{C}$ (Figure 6). This drastic color change from clear/white appearance to a dark brown/amber color was suggestive of the decomposition of the PSE derivatives. This observation led to a systemic investigation into the relative stabilities of the PSE derivatives.

Figure 5: Observed decomposition of the standalone PSE derivatives after 48 hours at $25^{\circ} \mathrm{C}$
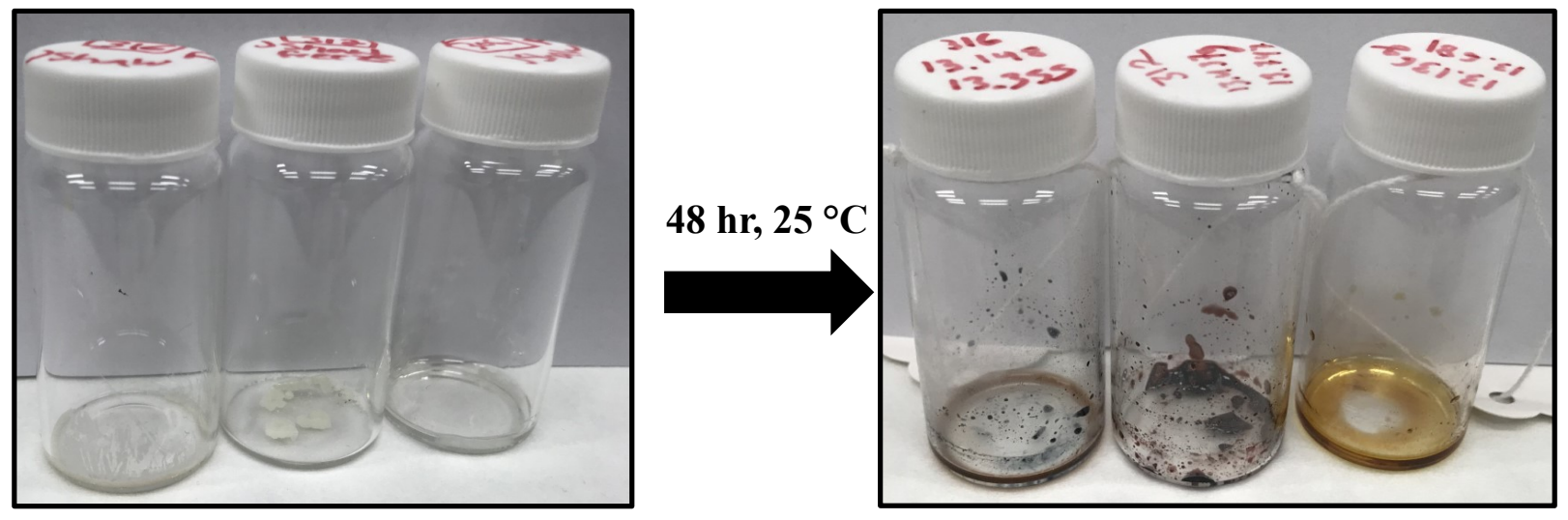


\section{Time Trials of Phenoxysulfinate Esters}

Upon discovery of the observed decomposition of the PSE compounds an interest was developed in determining the rate of decomposition. The course of action that was taken involved establishing a series of time trials. By understanding the rate of decomposition an assessment could be made of the relative stabilities of these standalone PSE compounds and their potential usefulness in synthetic work. For the time trials, the three standalone PSE derivatives were analyzed at time zero $\left(\mathrm{t}_{\mathrm{o}}\right)$ which was directly after purification via flash column chromatography on silica gel using solvent system hexanes: ethyl acetate (90:10). From this point, each sampled was evaluated by $400 \mathrm{MHz}{ }^{1} \mathrm{H}$ NMR spectroscopy at 24 hours, 48 hours, and 72 hours. At each time mark of demarcation of analysis three samples were prepared for each of the three standalone PSE derivatives. The first sample prepared (" $\alpha$ ") was the original PSE product kept in a sealed vial at room temperature $\left(25^{\circ} \mathrm{C}\right)$. The second sample prepared (“ $\beta$ ”) was the retained ${ }^{1} \mathrm{H}$ NMR tube sample dissolved in deuterated chloroform and kept at room temperature $\left(25^{\circ} \mathrm{C}\right)$. The third sample prepared " $\gamma$ " was the PSE product stored in a sealed vial at $-17^{\circ} \mathrm{C}$. Collectively, these three prepared samples $(\alpha, \beta, \gamma)$ were analyzed by $400 \mathrm{MHz}{ }^{1} \mathrm{H}$ NMR spectroscopy at three different time marks of 24 hours, 48 hours, and 72 hours after the initial time zero $\left(\mathrm{t}_{\mathrm{o})}\right.$. At each time mark there were nine individual samples analyzed in total as each of the three PSE derivatives ( $p$-bromophenyl, $p$-tert-butylphenyl, and $p$-methoxyphenyl) had their own three samples $(\alpha, \beta, \gamma)$. It was suspected that the primary mode of decomposition of standalone PSE compounds was the reversion back to starting materials, namely, the starting $p$-toluenesulfinic acid and the corresponding phenol. A quantitative assessment of the decomposition of the standalone PSE derivatives was observed by ${ }^{1} \mathrm{H}$ NMR spectral analysis by comparing the amount of target product to starting phenol via the integration of their 
corresponding diagnostic signals. Specifically, the data analysis of the ${ }^{1} \mathrm{H}$ NMR spectra for all three standalone PSE derivatives was carried out by either analyzing the aromatic region containing the protons on the phenolic ring system (comparison method A) or by analyzing the alkyl region with the methyl proton on the toluene ring, of both the PSE product and starting phenolic substrate (comparison method B), Scheme 25. The entire time trial consisting of the 400 $\mathrm{MHz}{ }^{1} \mathrm{H}$ NMR spectroscopic analysis all three PSE derivatives with their associated three samples $(\alpha, \beta, \gamma)$ over the span of 72 hours are collected in Table 4.

Scheme 25: Quantitative assessment of the relative amounts of PSE derivative and phenol Comparison method A<smiles>[X]c1ccc(OS(=O)c2ccc(C)cc2)c([R])c1</smiles>

vs.<smiles>[X]c1cc([R])cc(O)c1</smiles>
Comparison method $B$<smiles>[X]c1ccc(OS(=O)c2ccc(C)cc2)cc1</smiles>

vs.<smiles>Cc1ccc(S(=O)O)cc1</smiles> 
Table 4: Entire time trial ${ }^{1} \mathrm{H}$ NMR spectra analysis of the standalone PSE derivatives (4a-d) with their associated three samples $(\alpha, \beta, \gamma)$ at each time mark

\begin{tabular}{ccccccc} 
& & & & \\
\hline
\end{tabular}

All product: starting material ratios determined by ${ }^{1} \mathrm{H}$ NMR.

${ }^{\alpha}$ Sample stored at room temperature in fume hood.

${ }^{\beta}$ Sample stored in NMR tube with $\mathrm{CDCl}_{3}$ at room temperature in fume hood.

${ }^{\gamma}$ Sample stored in freezer. 


\section{The time trial study for the degradation of the p-Bromophenylphenoxysulfinate ester}

The bromo-PSE time trial data can be seen in Table 5 which contains the ${ }^{1} \mathrm{H}$ NMR spectral analysis and Figure 6 contains the spectral comparison. Within Table 5 is the ${ }^{1} \mathrm{H}$ NMR spectral analysis of each of the three samples $(\alpha, \beta, \gamma)$ at each time demarcation to compare the amount of target bromo-PSE product to the starting phenol as the time trial was carried out. It can be seen in the Figure 6 the ${ }^{1} \mathrm{H}$ NMR spectra comparison method A of the aromatic region, entry 1 is outlined in red representing time zero and entry 4 is outlined in blue representing the time mark of 72 hour at $-17^{\circ} \mathrm{C}$.

Table 5: Time trial ${ }^{1} \mathrm{H}$ NMR spectrum analysis of the bromo-PSE derivative

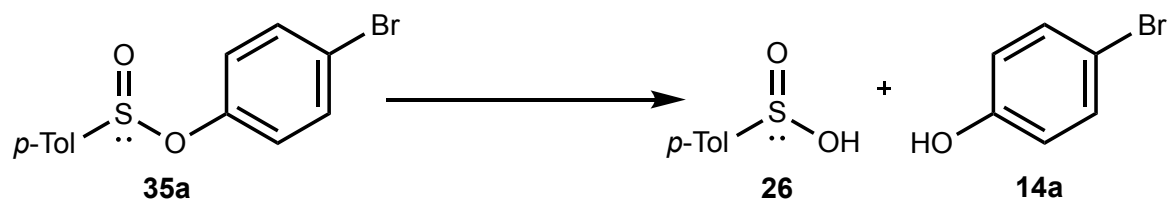

\begin{tabular}{ccccc}
\hline \multirow{2}{*}{ Entry } & $\begin{array}{c}\text { Product: Starting Material } \\
\text { (7.06ppm:6.77ppm) }\end{array}$ & $\mathbf{2 5}^{\circ} \mathbf{C}^{\boldsymbol{\alpha}}$ & $\mathbf{2 5}^{\circ} \mathbf{C ~ \& ~} \mathbf{C D C l}_{\mathbf{3}}{ }^{\boldsymbol{\beta}}$ & $\mathbf{- 1 7}^{\circ} \mathbf{C}^{\gamma}$ \\
\hline 1 & $0 \mathrm{hr}$ & $\mathbf{7 4 : 2 6}$ & & \\
2 & $24 \mathrm{hr}$ & $7: 93$ & $3: 97$ & $11: 89$ \\
3 & $48 \mathrm{Hr}$ & $3: 97$ & $0: 100$ & $14: 86$ \\
4 & $72 \mathrm{Hr}$ & $0: 100$ & $0: 100$ & $\mathbf{3 : 9 7}$ \\
\hline
\end{tabular}

${ }^{\alpha}$ Sample stored at room temperature in fume hood.

${ }^{\beta}$ Sample stored in NMR tube with $\mathrm{CDCl}_{3}$ at room temperature in fume hood.

${ }^{\gamma}$ Sample stored in freezer. 
Proton NMR spectroscopic data was collected directly after the purification of the bromoPSE. Analysis of the ${ }^{1} \mathrm{H}$ NMR spectrum revealed that the purified product was a mixture consisting of $74 \%$ product and $26 \%$ starting phenol and is known as Entry 1 in Table 5. Data collected from ${ }^{1} \mathrm{H}$ NMR spectra for the time trial gave evidence that the bromo-PSE 35a was very unstable and underwent complete decomposition. The ${ }^{1} \mathrm{H}$ NMR analysis of the $\alpha$ sample showed product decreasing between Entry 1 and Entry 2 as the amount of starting material increasing. This trend of decreased PSE product and increased phenol continued on for the $\alpha$ sample at each time mark and by Entry 4 there was zero product remaining and the sample contained significant amounts of the starting phenol. For the $\beta$ sample, which was the retained ${ }^{1} \mathrm{H}$ NMR tube from $\mathrm{t}_{\mathrm{o}}$, the ${ }^{1} \mathrm{H}$ NMR spectrum analysis between Entry 1 and Entry 2 in Table 5 showed significant decrease in PSE product and significant increase in the starting phenol. By Entry 3 there was no remaining PSE product. For the $\gamma$ sample, ${ }^{1} \mathrm{H}$ NMR spectrum analysis for the time trial also showed a decrease in PSE product and increase in starting phenol, but at a slower rate than the $\alpha$ or $\beta$ sample. Entry 4 of the $\gamma$ sample contained small amounts of products meaning that the decomposition occurred at a slower rate. A slower rate of decomposition for the $\delta$ sample was expected as the sample was store at low temperature of $-17^{\circ} \mathrm{C}$. Upon the ${ }^{1} \mathrm{H}$ NMR spectra comparison of Entry $1 \alpha$ sample and Entry $4 \gamma$ sample as seen in Figure 6 it was observed that an undesired byproduct seen in the aromatic region of the $\gamma$ sample spectrum, outlined in blue, had formed. The undesired byproduct remained unknown and did not undergo further investigation. Due to the finding of the undesired byproduct and the observed significant decomposition of the $\alpha, \beta, \gamma$ samples throughout the time trial it was proposed that the cause was the bromine R-substituent. Electronic properties of the R- substituent have a heavy influence on the leaving-group capabilities of the phenolic system. Bromine is a very strong electron- 
withdrawing group causing a significant increase in the leaving group ability of the phenolic system. The electron withdrawing effect caused an increased reaction rate as the phenolic system was more susceptible to decomposition or catalysis by trace water or acid within the reaction system.

Figure 6: Time trial spectra comparison of the bromo-PSE derivative Entry 1 outlined in red and Entry 4 outlined in blue
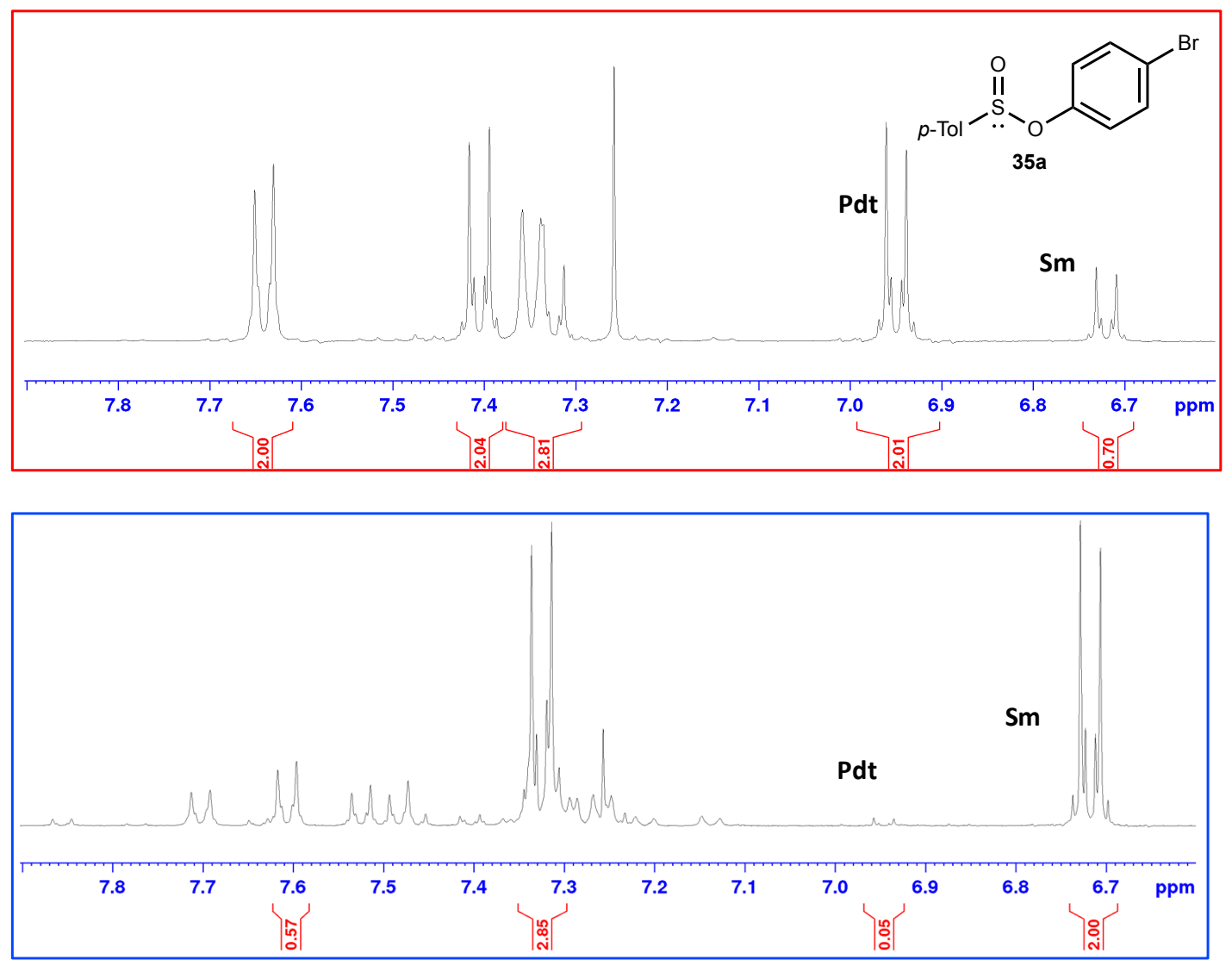

Ultimately, the increased reaction rate induced by the bromine substituent led to the termination of the bromo-PSE derivative studies as the observed instability and undesired byproducts deemed it a non-useful synthetic tool. 


\section{The time trial study for the degradation of the p-tert-butylphenoxysulfinate ester}

Time trial data for the tert-butyl-PSE (35b) time trial was collected in the same manner as the bromo-PSE data, and can be seen in Table 6 which contains the ${ }^{1} \mathrm{H}$ NMR spectral analysis and Figure 7 contains the spectral comparison. Within Table 6 is the ${ }^{1} \mathrm{H}$ NMR spectral analysis of each of the three samples $(\alpha, \beta, \gamma)$ at each time demarcation to compare the amount of target tert-butyl-PSE product to the starting phenol as the time trial was carried out.

Table 6: Time trial ${ }^{1} \mathrm{H}$ NMR spectrum analysis of the tert-butyl-PSE derivative

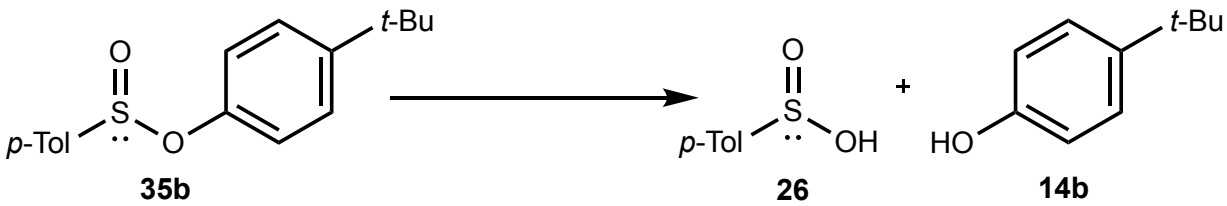

\begin{tabular}{ccccc}
\hline Entr & $\begin{array}{c}\text { Product: Starting Material } \\
\mathbf{y}\end{array}$ & $\mathbf{2 5}^{\circ} \mathbf{C}^{\boldsymbol{\alpha}}$ & $\mathbf{2 5}^{\circ} \mathbf{C ~ \& ~} \mathbf{C D C l}_{3}{ }^{\beta}$ & $\mathbf{- 1 7}^{\circ} \mathbf{C}^{\gamma}$ \\
\hline 1 & $0 \mathrm{hr}$ & $\mathbf{9 7 : 0 6}$ & & \\
2 & $24 \mathrm{hr}$ & $23: 77$ & $97: 3$ & $97: 3$ \\
3 & $48 \mathrm{Hr}$ & $0: 100$ & $97: 3$ & $97: 3$ \\
4 & $72 \mathrm{Hr}$ & $0: 100$ & $15: 85$ & $\mathbf{9 7 : 3}$ \\
\hline
\end{tabular}

${ }^{\alpha}$ Sample stored at room temperature in fume hood.

${ }^{\beta}$ Sample stored in NMR tube with $\mathrm{CDCl}_{3}$ at room temperature in fume hood.

${ }^{\gamma}$ Sample stored in freezer.

It can be seen in the Figure 7 the ${ }^{1} \mathrm{H}$ NMR spectra comparison method A of the aromatic region, entry 1 is outlined in red representing time zero and entry 4 is outlined in blue 
representing the time mark of 72 hour at $-17{ }^{\circ} \mathrm{C}$. Proton NMR spectroscopic data was collected directly after the purification of the tert-butyl-PSE derivative. Analysis of the ${ }^{1} \mathrm{H}$ NMR spectrum revealed that the purified product was a mixture consisting of $97 \%$ product and $3 \%$ starting phenol and is known as Entry 1 in Table 6. Data collected from ${ }^{1} \mathrm{H}$ NMR spectra for the time trial gave evidence that the tert-butyl-PSE derivative (4b) was more stable than previously observe bromo-PSE derivative (4a). The ${ }^{1} \mathrm{H}$ NMR analysis of the $\alpha$ sample showed product decreasing between Entry 1 and Entry 2 as the amount of starting material increased, as seen in Table 6. More importantly, there was complete decomposition between Entry 2 to Entry 3 which contained no PSE product and significant amounts of the starting phenol, this was only after 48 hours at $25^{\circ} \mathrm{C}$. For the $\beta$ sample, which was the retained ${ }^{1} \mathrm{H}$ NMR tube from $\mathrm{t}_{\mathrm{o}}$, the ${ }^{1} \mathrm{H}$ NMR spectrum analysis showed stability as there was no decrease in the PSE product between Entry 1 and Entry 2. Between Entry 2 and Entry 3 there was significant decrease in the PSE product and significant increase in the starting phenol, by Entry 3 there was no remaining PSE product. For the $\gamma$ sample, ${ }^{1} \mathrm{H}$ NMR spectrum analysis showed significant stability as there was no observation of decomposition at any point of the time trial. This observation is due to a slower rate of decomposition for the $\gamma$ sample caused by low storage temperature of $-17^{\circ} \mathrm{C}$. Upon the ${ }^{1} \mathrm{H}$ NMR spectra comparison of Entry $1 \alpha$ sample and Entry $4 \gamma$ sample, as seen in Figure 7, it was observed that the two spectrums were identical to one another meaning that over 72 hours at -17 ${ }^{\circ} \mathrm{C}$ the standalone tert-butyl-PSE derivative did not undergo any decomposition or undesired side reactions. The observed stability can be attributed to the electronic properties of the tert-butyl Rsubstituent on the phenolic system. This substituent is a weak electron donating group, allowing for electron donation into the phenol and stabilizing it. Stabilization of the phenolic system decreases its leaving group capabilities, thus decreasing the reaction rate. Ultimately, the rate of decomposition and/or catalysis by excess water or acid within the reaction system is significantly 
decreased. It is to be noted that although the $\gamma$ sample shows no decomposition there is observed decomposition for the $\alpha$ sample and the $\beta$ sample, so the tert-butyl-PSE derivative is only stable at low temperatures. This gives evidence that the tert-butyl-PSE derivative can be a useful synthetic tool when it is kept at a low storage temperature of $-17^{\circ} \mathrm{C}$.

Figure 7: Time trial spectra comparison of the tert-butyl-PSE derivative Entry 1 outlined in red and Entry 4 outlined in blue
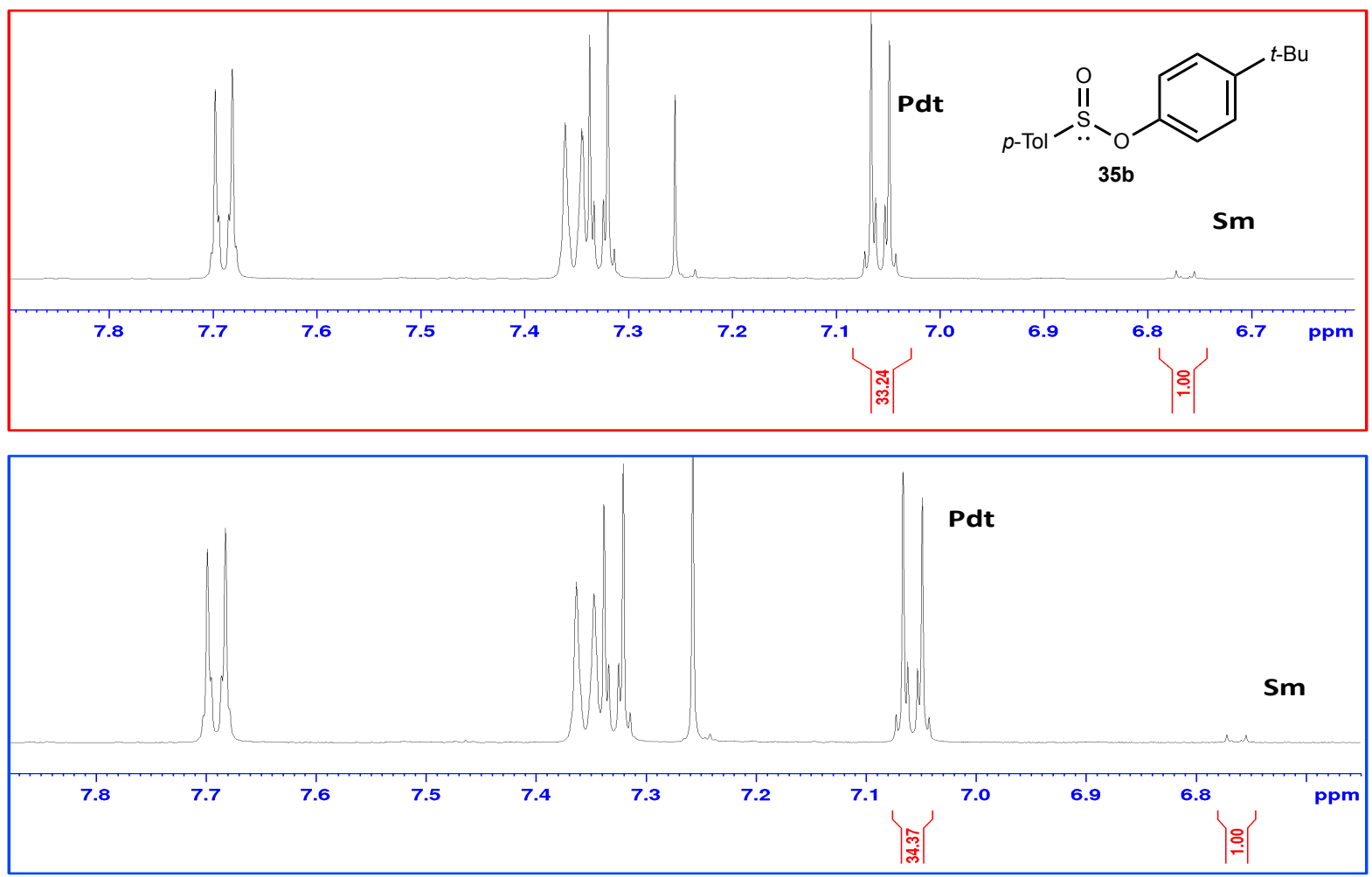

The time trial study for the degradation of the p-methoxyphenoxysulfinate ester

Time trial data for the methoxy-PSE derivative (4c) time trial was collected in the same manner as the bromo- and tert-butyl-PSE data. The collected data can be seen in Table 7 which contains the ${ }^{1} \mathrm{H}$ NMR spectral analysis and Figure 8 contains the spectral comparison. Within 
Table 7 is the ${ }^{1} \mathrm{H}$ NMR spectral analysis of each of the three samples $(\alpha, \beta, \delta)$ at each time demarcation to compare the amount of target methoxy-PSE product to the starting phenol as the time trial was carried out. It can be seen in the Figure 8 the ${ }^{1} \mathrm{H}$ NMR spectral comparison method B of the alkyl region, entry 1 is outlined in red representing time zero and entry 4 is outlined in blue representing the time mark of 72 hour at $-17^{\circ} \mathrm{C}$. The ${ }^{1} \mathrm{H}$ NMR analysis within the aromatic region for the methoxy-PSE derivative was not viable due to significant overlap of signals within the region.

Table 7: Time trial ${ }^{1} \mathrm{H}$ NMR spectrum analysis of the methoxy-PSE<smiles>COc1ccc(O[GeH2]S(=O)(=O)Oc2ccc(OC)cc2)cc1</smiles>

\begin{tabular}{ccccc}
\hline \multirow{2}{*}{ Entry } & $\begin{array}{c}\text { Product: Starting Material } \\
\text { (7.06ppm:6.77ppm) }\end{array}$ & $\mathbf{2 5}^{\circ} \mathbf{C}^{\boldsymbol{\alpha}}$ & $\mathbf{2 5}^{\circ} \mathbf{C ~ \& ~} \mathbf{C D C l}_{\mathbf{3}}{ }^{\boldsymbol{\beta}}$ & $\mathbf{- 1 7}^{\circ} \mathbf{C}^{\gamma}$ \\
\hline 1 & $0 \mathrm{hr}$ & $\mathbf{9 7 : 3}$ & & \\
\hline 2 & $24 \mathrm{hr}$ & $30: 70$ & $95: 5$ & $97: 3$ \\
3 & $48 \mathrm{Hr}$ & $25: 75$ & $36: 64$ & $97: 3$ \\
4 & $72 \mathrm{Hr}$ & $0: 100$ & $0: 100$ & $\mathbf{9 7 : 3}$
\end{tabular}

${ }^{\alpha}$ Sample stored at room temperature in fume hood.

${ }^{\beta}$ Sample stored in NMR tube with $\mathrm{CDCl}_{3}$ at room temperature in fume hood.

${ }^{\gamma}$ Sample stored in freezer. 
Proton NMR spectroscopic data was collected directly after the purification of the methoxy-PSE derivative. Analysis of the ${ }^{1} \mathrm{H}$ NMR spectrum revealed that the purified product was a mixture consisting of $97 \%$ product and 3\% starting phenol and is known as Entry 1 in Table 7. Data collected from ${ }^{1} \mathrm{H}$ NMR spectra for the time trial gave evidence that the methoxyPSE derivative (xc) was most stable of the three PSE derivatives analyzed. The ${ }^{1} \mathrm{H}$ NMR analysis of the $\alpha$ sample showed product slightly decreasing between Entry 1 and Entry 2 as the amount of starting material increased, as seen in Table 7. More importantly, there was remaining PSE product in Entry 3 and the complete decomposition of PSE product wasn't observed until Entry 4. For the $\beta$ sample, which was the retained ${ }^{1} \mathrm{H}$ NMR tube from $t_{o}$, the ${ }^{1} \mathrm{H}$ NMR spectrum analysis showed PSE product decomposition between Entry 1 and Entry 2. Complete decomposition was observed by Entry 3, which had no remaining PSE product and significant starting phenol. For the $\gamma$ sample, ${ }^{1} \mathrm{H}$ NMR spectrum analysis showed significant stability as there was no observation of decomposition at any point of the time trial. This observation is due to a slower rate of decomposition for the $\delta$ sample caused by low storage temperature of $-17^{\circ} \mathrm{C}$. Upon the ${ }^{1} \mathrm{H}$ NMR spectra comparison of Entry $1 \alpha$ sample and Entry $4 \gamma$ sample, as seen in Figure 8 , it was observed that the two spectrums were identical to one another meaning that over 72 hours at $-17^{\circ} \mathrm{C}$ the standalone methoxy-PSE derivative did not undergo any decomposition or undesired side reactions. 
Figure 8: Time trial spectra comparison of the methoxy-PSE derivative Entry 1 outlined in red and Entry 4 outlined in blue
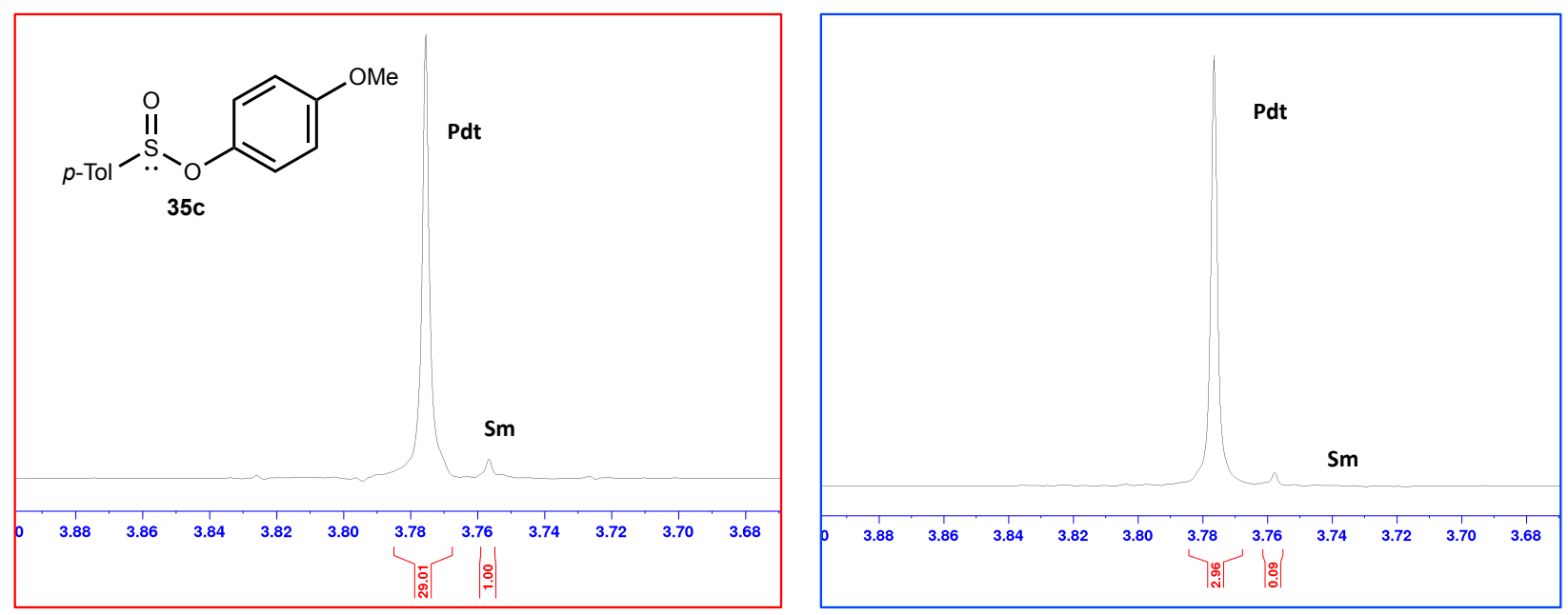

It's proposed that the methoxy-PSE derivative is more stable than the tert-butyl-PSE.

This is due to the methoxy-PSE $\alpha$ sample containing PSE product through Entry 3 and the tertbutyl-PSE $\alpha$ sample showing complete decomposition by Entry 3. The observed stability of the methoxy-PSE is attributed to the electronic effect of the methoxy R-substituent. The strong electron donating effect of methoxy influences the phenolic system making it immensely stable and having very low leaving group ability. This significantly decreases the reaction rate of any decomposition and/or catalysis via excess water or acid within the reaction system. In conclusion of the time trial the methoxy-PSE derivative was proposed to be the most stable due to the $\alpha$ sample results, and gives evidence that it can be a useful synthetic tool when it is kept at a low storage temperature of $-17^{\circ} \mathrm{C}$. 


\section{Two-step alcohol pathway synthesis of alkoxy sulfinate esters}

A comprehension review of the ${ }^{1} \mathrm{H}$ NMR spectral data of the time trial for the three PSE derivatives (bromo-, tert-butyl, and methoxy-) revealed that the methoxy-PSE was the most stable derivative over a series of temperatures. The tert-butyl-PSE derivative had comparable but slightly lower stability than the methoxy-PSE derivative. The next course of action was to develop the PSE derivatives as a useful synthetic tool. Initial investigations began with the PSE derivatives as in-situ intermediates (35a-c) for alkoxy sulfinate ester synthesis, Scheme 25. The alkoxy sulfinate esters were prepared via a two-step EDC method that required a 24 hour reaction time with the use of a phenol (14a-c), $p$-toluenesulfinic acid, EDC, DMAP, an alcohol (36a-j), and $\mathrm{NEt}_{3}$. The first step consisted of the phenol, $p$-toluenesulfinic acid, EDC, and DMAP stirred at to form the in-situ PSE intermediate. The second step was an addition of an alcohol and $\mathrm{NEt}_{3}$ stirred at room temperature for an additional 12 hours to form the desired alkoxy sulfinate ester product.

Scheme 25: PSE derivatives as in-situ intermediate for alkoxy sulfinate ester synthesis

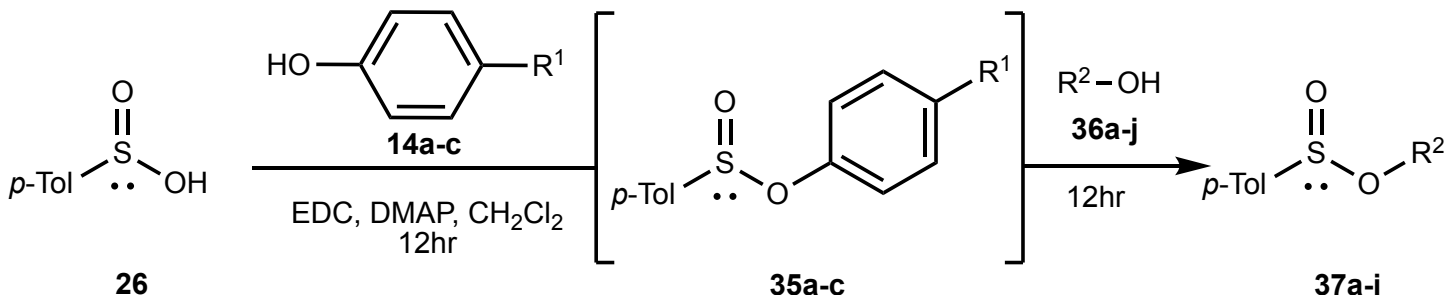

Initial investigations began with a small series using the in-situ bromo-PSE derivative with the alcohols $p$-nitrobenzyl alcohol and $p$-chlorobenzyl. These alcohols were not used for any specific reason other than being commercially available and in-stock within the laboratory at 
the time of the experiments. In the conducted time trial of the bromo-PSE derivative, there was significant evidence of weak stability. It was proposed the two-step alcohol reactions utilizing the bromo-PSE would not be successful due to this weak stability. However, the reactions were carried out as a second verification of this proposal. The crude mixture of these reactions was analyzed by ${ }^{1} \mathrm{H}$ NMR spectra. The collected data for this series can be seen in Scheme 26.

Scheme 26: Two-step synthesis via in-situ bromo-PSE intermediate with two structurally diverse alcohols
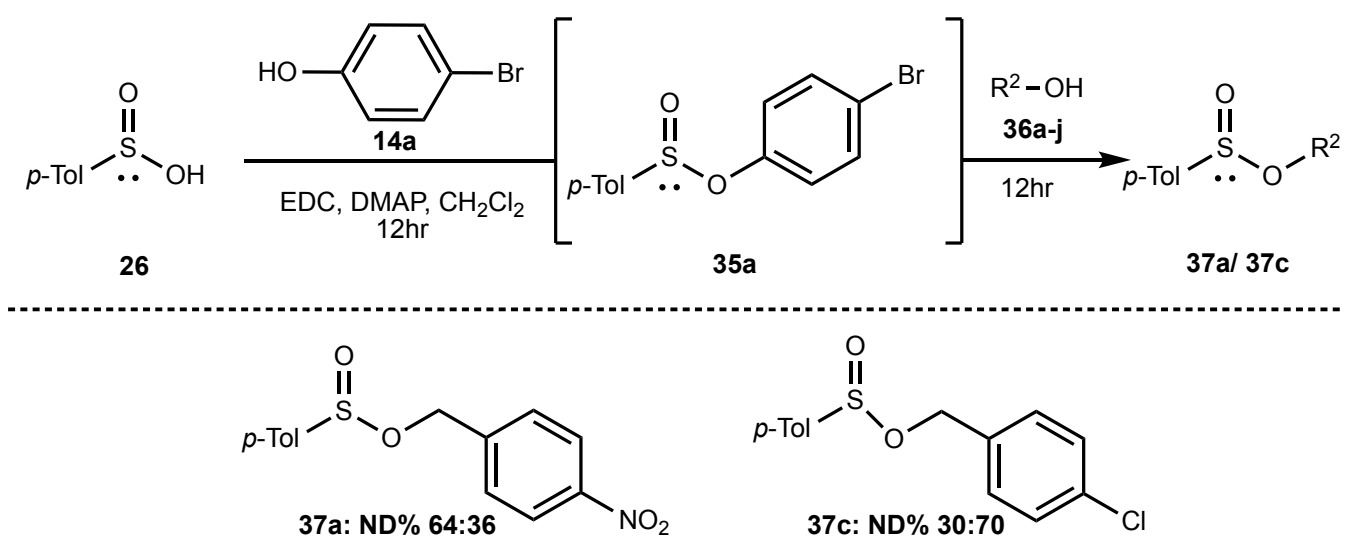

Analysis of the ${ }^{1} \mathrm{H}$ NMR spectrum for crude mixture 37 a revealed that the sulfinate ester product and the starting phenol were within the crude mixture at a 64:36 ratio, nearly a 50:50 mixture. Crude mixtures of 50:50 are undesirable because the reaction is not going to completion. Such a result can be caused by a lack of reactivity between starting materials, leading to a low product yield but high unreacted starting material. Another probable cause is the decomposition of the insitu bromo-PSE intermediate into starting phenol having a higher reaction rate than the rate for bromo-PSE intermediate to react with the alcohol. Analysis of the ${ }^{1} \mathrm{H}$ NMR for crude mixture $37 \mathbf{c}$ revealed a ratio of the sulfinate ester product to starting phenol of 30:70, arguably an even more undesired result than a 50:50 ratio due to that starting phenol being the dominant 
compound in the mixture. Synthesis of alkoxy sulfinate esters requires a more desirable crude ratio of product to starting material were the target product is the dominant compound in the mixture. Neither of the bromo-PSE reactions gave ideal ratios, and within each ${ }^{1} \mathrm{H}$ NMR analysis of $37 \mathbf{a}$ and $37 \mathbf{c}$ there was undesired byproduct seen in the aromatic region. Undesired byproduct was seen in the standalone bromo-PSE derivative time trial and was expected to occur in the two-step synthesis as well. At this point, the undesired byproduct was analyzed via ${ }^{1} \mathrm{H}$ NMR spectral data and determined to be the $p$-toluenethio- $p$-toluenesulfonate dimer caused by the $p$ toluenesulfinic acid. This specific dimerization process was previously discussed in chapter one as the dimer is a very common byproduct of all syntheses of sulfinate esters. Dimer formation within in any method is suggestive of a poor nucleophile or a poor base. Essentially, it is a strong indicator that the chosen method or reagents used within that synthesis are not a viable option. Such dimerization is seen in the 2ppm region as two sharp singlet peaks in ${ }^{1} \mathrm{H}$ NMR spectrum, as seen in Figure 9. The outcome of undesired byproducts forming from the synthesis with the insitu bromo-PSE was predicted to happen due to the low stability discovered in the time trials. The two "failed" syntheses of compounds $\mathbf{3 7 a}$ and $\mathbf{3 7} \mathbf{c}$ were second confirmation of this prediction, due to poor ratios and the formation of the dimer byproduct. The bromo-PSE derivative is a highly reactive intermediate causing undesirable side reactions, ultimately leading to its termination in this project and discontinuation in any future studies. 
Figure 9: ${ }^{1} \mathrm{H}$ NMR of the $p$-toluenesulfinic acid "dimer" byproduct

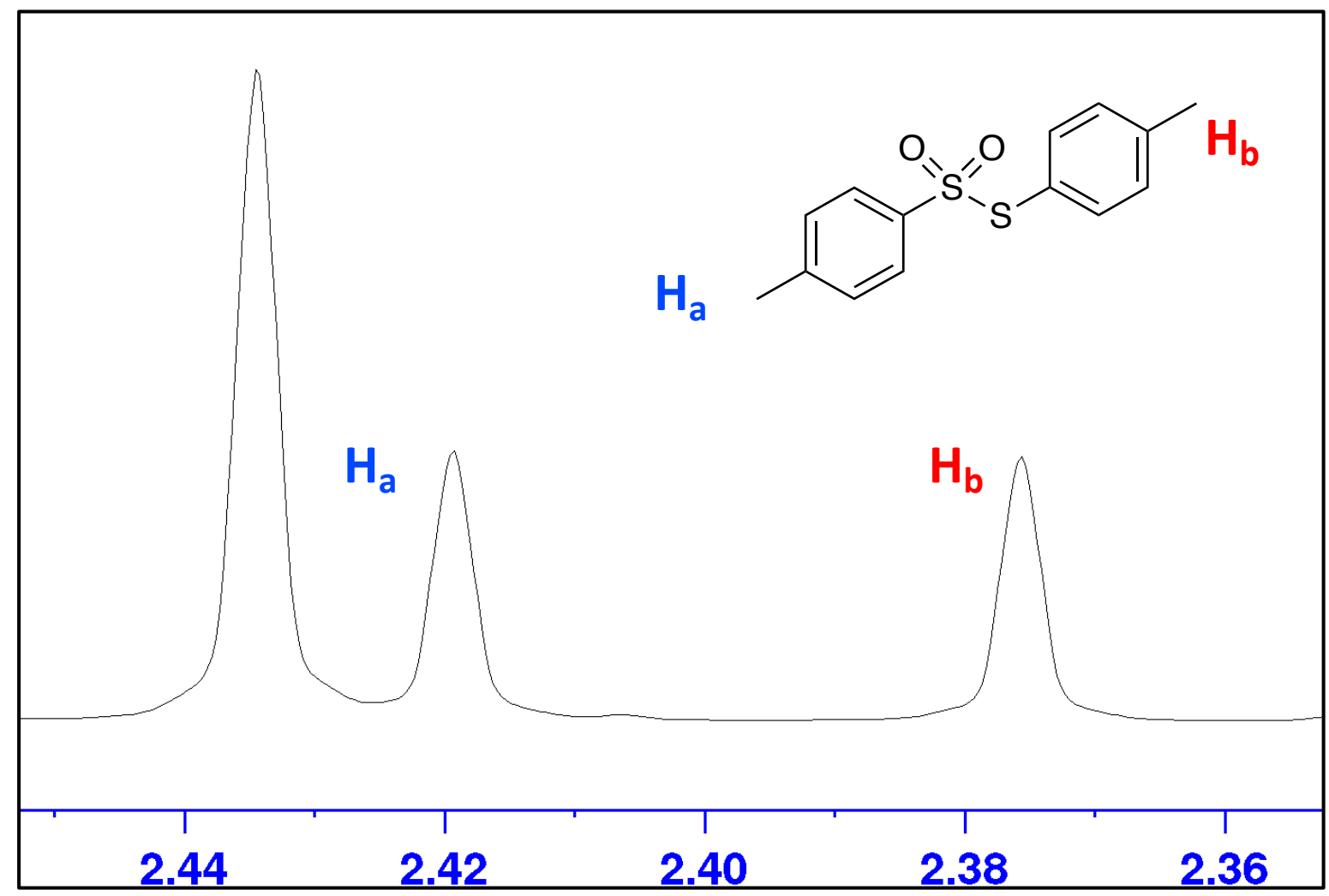

In contrast to the bromo-PSE (35a), the tert-butyl-PSE (35b) and the methoxy-PSE (35c) were moved forward in experimentation. Time trials of these PSE derivatives revealed they were stabilized when stored at low temperatures. Now it was to be investigated if they could be useful synthetic tools. Similar to the bromo-PSE, investigations began with a two-step alcohol coupling pathway synthesis were the PSE derivatives act as an in-situ intermediate for the synthesis of alkoxy sulfinate esters.

To start, the in-situ tert-butyl-PSE derivative was explored by its utilization in the twostep EDC method which was identical to the two-step bromo-PSE set-up. The first step of this method is the 24 hour reaction of $p$-toluenesulfinic acid, DMAP, tert-butyl-PSE, and $\mathrm{CH}_{2} \mathrm{Cl}_{2}$ and then the second step which is the addition of $\mathrm{NEt}_{3}$ and an alcohol. The tert-butyl-PSE was exposed to varying degrees of substituted alcohols to demonstrate the versatility of the in-situ 
tert-butyl-PSE intermediate. For this series ten structurally diverse alcohols were used which included seven primary alcohols, two secondary alcohols, and one tertiary alcohol to obtain ten sulfinate ester target products. Upon reaction completion the target products underwent purification via flash column chromatography on silica gel with mobile phase hexanes: ethyl acetate (90:10), then analyzed by ${ }^{1} \mathrm{H}$ NMR spectroscopy, and percent yield was recorded. Data collected post purification for the ten target products can be seen in Scheme 27.

Scheme 27: Two-step synthesis via in-situ tert-butyl-PSE intermediate with ten structurally diverse alcohols
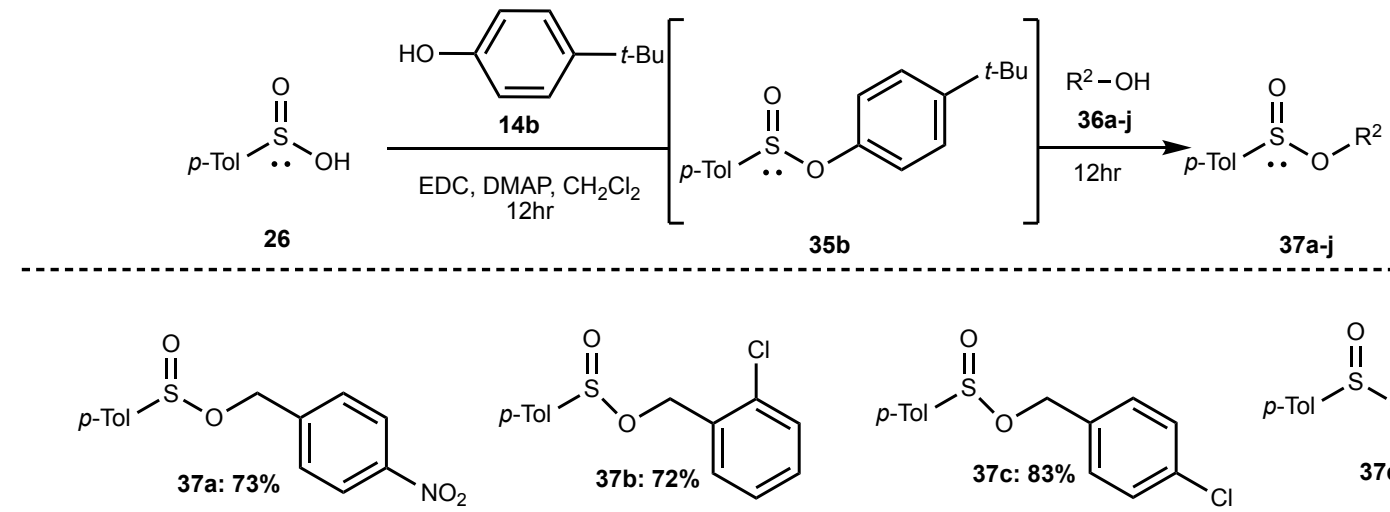

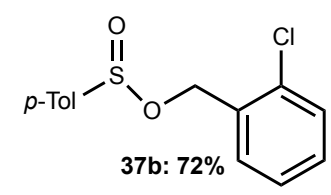<smiles>[13CH]S(=O)OCc1ccc(Cl)cc1</smiles><smiles>O=S([GeH2])OCc1ccc(Br)cc1</smiles><smiles>Cc1ccc(COS(=O)[GeH2][Ba][Ba])cc1</smiles>

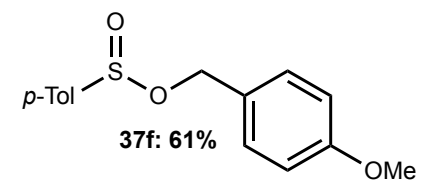<smiles>O=S([SeH])[SeH]OCCc1ccccc1</smiles>

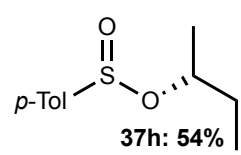<smiles></smiles><smiles>CC(C)(C)OS(=O)[18O]</smiles>

Within the data of Scheme 27 it's revealed that the primary alcohols had the highest percent yield, including compound 37c with the highest yield out of the entire series. The lowest yield observed was compound $\mathbf{3 7 h}$, which the chiral alcohol sec-butanol was used. It was 
suspected that the steric volume of sec-butanol was the cause of the low percent yield. Bulky steric volume can decrease the possible interactions with the in-situ tert-butyl-PSE intermediate, ultimately lowering the reaction rate and which decreasing the yield compared to other alcohols used. Another example of the steric volume issue was evident in the compound 37i, were the chiral alcohol menthol was used. L-Menthol has a large bulky steric volume that can lower the reaction rate due to decreased reactivity with other reagents in solution. The two chiral alcohols, sec-butanol and L-menthol are the only secondary alcohols used for the series and were revealed to have the lowest yields which was attributed to their steric volume. Compounds $\mathbf{3 7 i}$ and $\mathbf{3 7} \mathbf{j}$ had 50:50 diastereomeric mixtures, suggestive that the PSE's have low selectivity in the enantioequilibration of the DKR process (Scheme 23). Within this series there was only one tertiary alcohol example, $\mathbf{3 7} \mathbf{j}$, it was not isolable and determined that there was only trace product. Target products within the series were all isolable and purifiable thus demonstrating the ability of the tert-butyl-PSE to act as an in-situ intermediate for a two-step alcohol pathway synthesis of alkoxy sulfinate esters.

Next efforts were directed towards the investigation of the methoxy-PSE as an in-situ intermediate in the two-step alcohol pathway synthesis of alkoxy sulfinate esters. The alcohol series for the tert-butyl-PSE contained a large series of structurally diverse alcohols. Since the time trials revealed that the tert-butyl-PSE and the methoxy-PSE had comparable stabilities, a more condensed series was conducted for the methoxy-PSE as similar results were expected. Within this condensed series five struturally diverse alcohols consisting of three primary, one secondary, and one tertiary alcohol were used. For this series the synthesis method used was identical to the method described for the tert-butyl-PSE, were the alcohol was added within the second step of synthesis. Upon reaction competition the target products underwent purification via flash column chromatography on silica gel with a mobile phase of hexanes: ethyl acetate 
(90:10), then analyzed by ${ }^{1} \mathrm{H}$ NMR spectra, and percent yield was recorded. Data collected post purification for the five target products are listed in Scheme 28, a similar trend to the tert-butylPSE derivative was revealed.

Scheme 28: Two-step synthesis via in-situ Methoxy-PSE intermediate with five structurally diverse alcohols
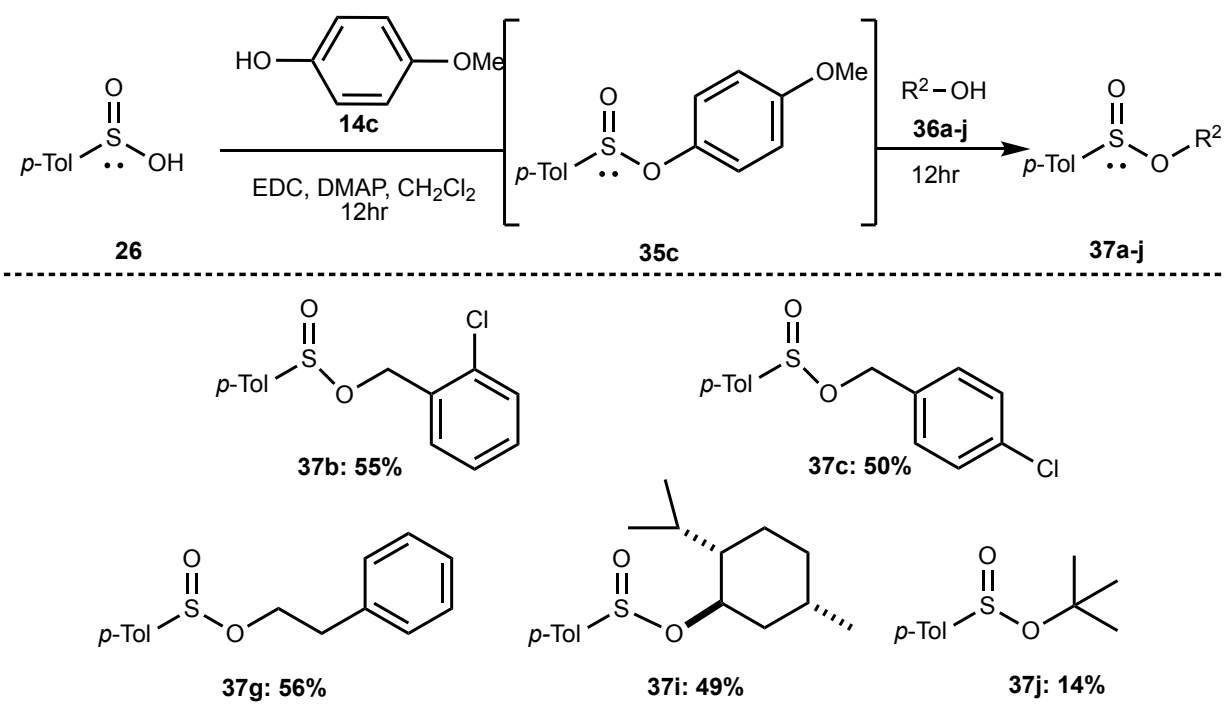

Products $\mathbf{3 7 b} / \mathbf{c} / \mathbf{g}$, synthesized by primary alcohols gave the highest yields, product $\mathbf{3 7 i}$ and 37j produced from a secondary alcohol gave 50:50 mixtures of diastereomers with a low yield due to steric volumes, product $\mathbf{3 7} \mathbf{j}$ produced from a tertiary alcohol had the lowest yield. However, the methoxy-PSE series gave significantly lower percent yields for all five products than the tert-butyl-PSE series. The results raised a suspicion of the methoxy-PSE ability to perform as an in-situ intermediate. Previously, the time trial showed the standalone methoxyPSE maintained stability for a longer time at $25^{\circ} \mathrm{C}$ than the standalone tert-butyl-PSE suggesting that the stability of the PSE is not in question, but reactivity of the in-situ methoxy-PSE is in question. The methoxy functional group is a strong donating group (via resonance contribution) 
due to the lone pairs on the oxygen of the methoxy, which donate into the phenolic system causing the PSE intermediate to be more "stable" and thus less reactive. This explanation is hypothesized to be the reason why the methoxy-PSE showed more stability in the time trial. Also, the stabilizing resonance effect from the methoxy R substituent was the cause of lower percent yields, due to an immensely low reactivity. The inductively weaker electron donating group, tert-butyl, gave enough donation into the phenolic system for such a stability that doesn't lead to undesired reactions/byproducts, yet enough reactivity and "lack" of stability that the target product was produced in good yields compared to the lower methoxy series yields.

In conclusion, the two-step alcohol pathway synthesis of alkoxy sulfinate esters utilizing the in-situ bromo-PSE intermediate was not a viable tool for synthesis and was terminated. The in-situ tert-butyl-PSE and in-situ methoxy-PSE intermediate were determined to be viable tools in the two-step synthesis of alkoxy sulfinate esters. The difference in percent yields for the two in-situ PSE's is explained by the differences in the inductive effect /resonance effect caused by the R substituents. With evidence of the in-situ tert-butyl-PSE and methoxy-PSE intermediate as useful synthetic tools in a two-step synthesis, next efforts moved towards the standalone PSE's as a useful synthetic tool in a one-pot synthesis.

\section{One-pot alcohol pathway synthesis of alkoxy sulfinate esters}

Stand-alone reagents, such as the PSE, could be a time efficient option for the synthesis of alkoxy sulfinate ester synthesis by decreasing the steps in synthesis. The general stability of the standalone PSE compounds was investigated in the previous time trials and it was revealed that tert-butyl-PSE and methoxy-PSE had stability while bromo-PSE did not. Although bromoPSE lacked stability in the time trial it was confirmed in the two-step alcohol coupling synthesis 
and was terminated from the one-step synthesis. However, the methoxy-PSE was carried on into the investigation of the one-pot synthesis due to demonstrated stability in both the time trial and two-step synthesis. The stability of the methoxy-PSE compound suggested that it may be used as shelf-stable tool for synthesis. Within this one-pot synthesis the methoxy-PSE acts as a standalone "shelf stable" reagent and therefore synthesized beforehand. Standalone methoxyPSE was synthesized by reacting $p$-toluenesulfinic acid with EDC, DMAP, and $p$ methoxyphenol in $\mathrm{CH}_{2} \mathrm{Cl}_{2}$ for 12 hours, purified via flash column chromatography on silica gel with a mobile phase of hexanes: ethyl acetate (90:10), and stored at $-17{ }^{\circ} \mathrm{C}$ directly after purification.

Initial investigations began with the optimization of the standalone PSE derivatives reacting with an alcohol for alkoxy sulfinate ester synthesis. For this optimization the methoxyPSE derivative and $p$-chlorobenzyl alcohol were used. The methoxy-PSE derivative was used as it was readily available in the laboratory, and tert-butyl-PSE was not. Within this optimization the stoichiometry of the DMAP catalyst, methoxy-PSE derivative stoichiometry, and solvent volume was probed (Table 8). The crude ${ }^{1} \mathrm{H}$ NMR spectra was analyzed for the seven entries. Within this analysis the amount of target product (37e) to starting PSE (35c) was compared. This comparison provided evidence of reaction completion. Upon analysis of ${ }^{1} \mathrm{H}$ NMR spectra (Table 8 ) it was determined that Entry 2 gave optimal results, thus these conditions of 0.2 eq DMAP, 1.1 eq methoxy-PSE, and $7 \mathrm{~mL}$ of $\mathrm{CH}_{2} \mathrm{Cl}_{2}$ were used for the one-pot synthesis of alkoxy sulfinate esters. 
Table 8: Optimization of alkoxy sulfinate ester synthesis via PSE derivative

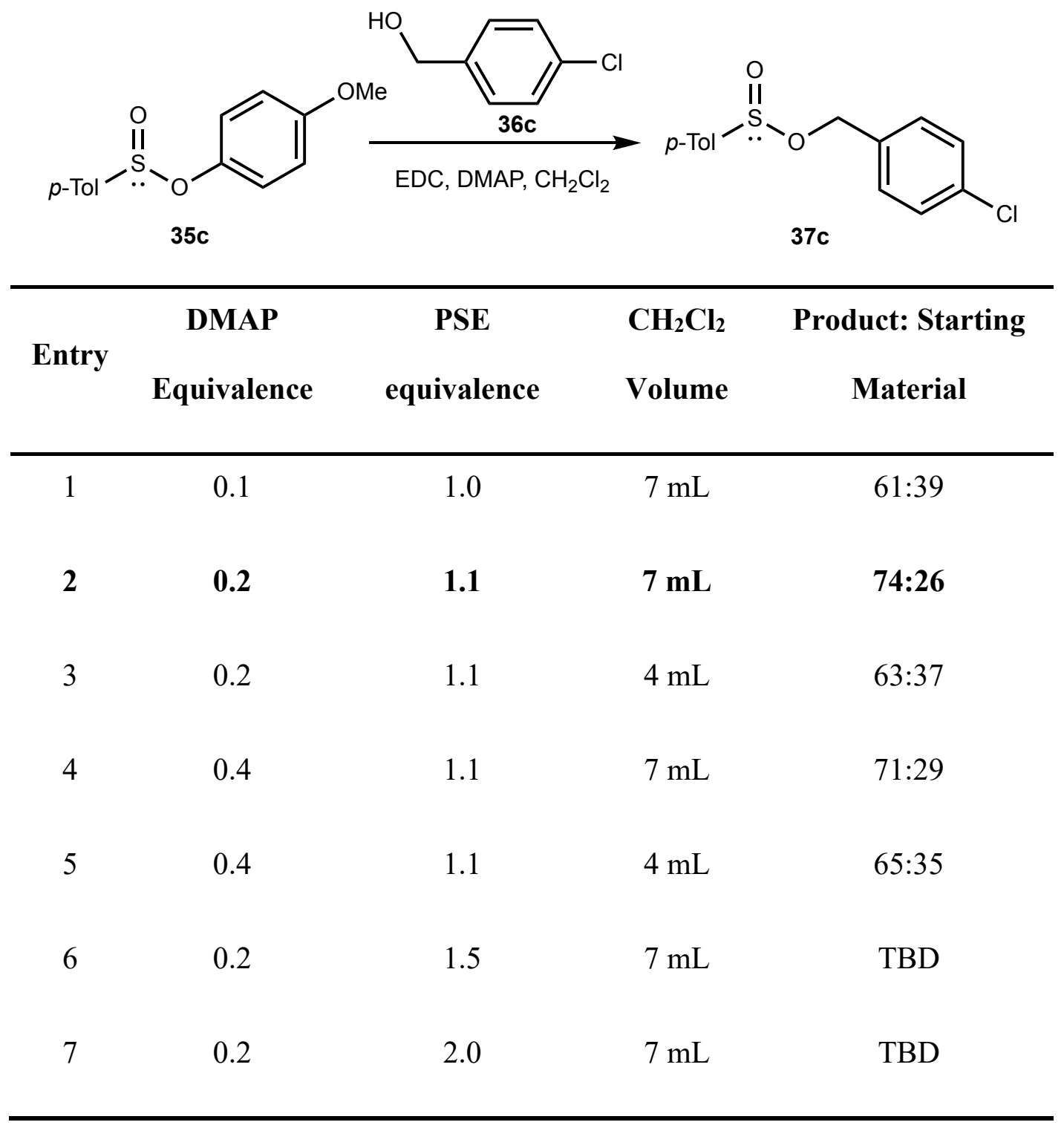

Upon the completion of the optimization of the one-pot synthesis the development of a series using the standalone methoxy-PSE derivative with structurally diverse alcohols was conducted. The five alcohols consisted of three primary, one secondary, and one tertiary alcohol were used. Upon reaction competition the target products underwent purification via flash column chromatography on silica gel with a mobile phase of hexanes: ethyl acetate (90:10), then 
analyzed by ${ }^{1} \mathrm{H}$ NMR spectra, and percent yield was recorded. Data collected post purification for the five target products can be seen in Scheme 29. Analysis of the collected data showed that the target alkoxy sulfinate esters via standalone methoxy-PSE one-pot synthesis had significantly higher yields than seen for the two-pot in-situ methoxy-PSE synthesis.

Scheme 29: One-step synthesis using stand-alone Methoxy-PSE with five structurally diverse alcohols

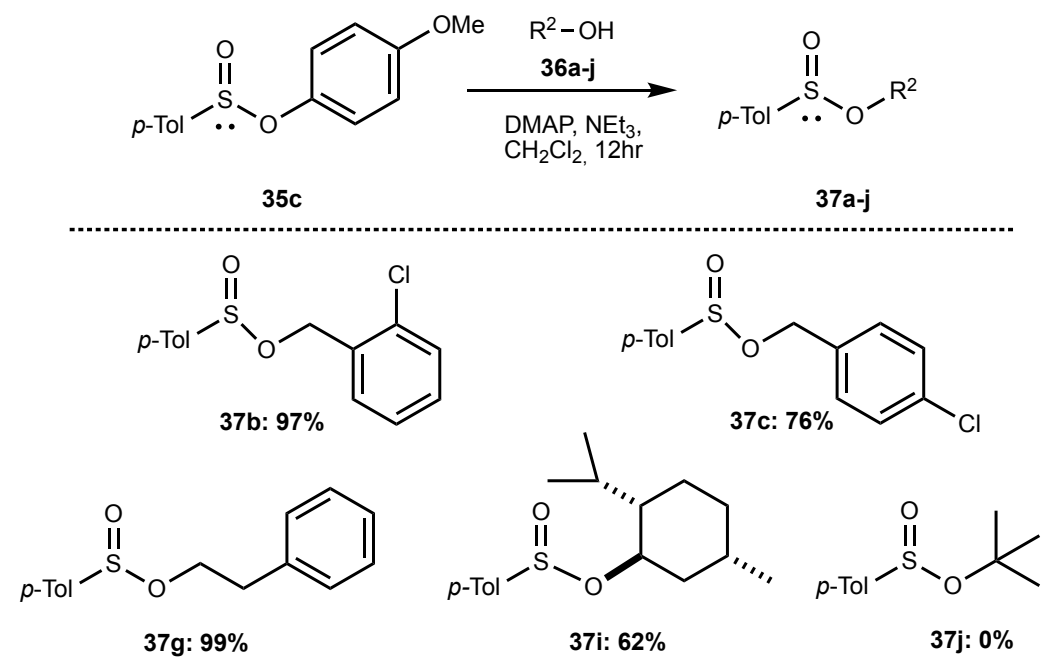

It is proposed that the low yields obtained for the two-step synthesis was caused by excess acid in solution. Increased acid in-situ can catalyze undesired side reactions or catalyze the decomposition of target product into starting materials. This excess acid issue can be attributed to the long duration of the first step, where $p$-toluenesulfinic acid and/or trace water are within solution and decomposing the in-situ methoxy-PSE intermediate into starting materials. Ultimately this would lead to very little $i n-$ situ methoxy-PSE intermediate upon addition of the alcohol, causing the in-situ methoxy-PSE to act as the limiting reagent. This process can be compared to a reaction containing a too low equivalence of a particular reagent than required, meaning all other reagents are added in excess. Thus, the limiting reagent would 
be reacted and no longer present within the reaction mixture much sooner than the other reagents, causing significant amounts of unreacted reagent and low amounts of desired product to remain in solution. Without proper equivalence a proper yield can never be achieved. For the two-step methoxy-PSE synthesis the in-situ methoxy-PSE became the limiting reactant making it impossible to achieve high yields. In contrast to the two-step synthesis, the one-pot synthesis allowed for significant decrease in excess acid. Inherently, there was little to no trace acid in-situ as the purified standalone methoxy-PSE was used, which eliminated $p$-toluenesulfinic acid from the reaction mixture. This is plausible explanation as to why the one-pot synthesis with standalone methoxy-PSE resulted in higher yields than the two-step in-situ methoxy-PSE. Although, the tert-butanol showed no evidence of the target product $\mathbf{3 7} \mathbf{j}$ for the one-pot synthesis, which truly isn't much different than the $14 \%$ yield observed in the two-step synthesis. Ultimately, the tert-butanol had poor reactivity with the methoxy-PSE as an in-situ intermediate and as a stand-alone reagent. Steric hindrance from the tert-butyl group of tert-butanol significantly affected the reaction rate by sterically preventing any nucleophilic attack on the carbon of the alcohol. Similar to the two-step synthesis the target products $37 \mathbf{b} / \mathbf{c} / \mathbf{g}$ synthesized with primary alcohols gave the highest yields, and the product $\mathbf{3 7 i}$ from a secondary alcohol showed a mixture of diastereomers and a lower yield which can be attributed the bulky steric volume from the menthol. Regardless of yield, the methoxy-PSE proved to be a useful synthetic tool as a shelf-stable reagent in the one-pot synthesis of alkoxy sulfinate esters. 


\section{Conclusion of the Phenoxy Sulfinate Esters}

After extensive investigations into the PSE's use within the alkoxy sulfinate ester synthesis including the time trial studies, two-step synthesis, and one-pot synthesis, there were clear advantages and disadvantages. Advantages included their general capabilities as a costeffective reagent for direct sulfinylation, isolable and purifiable via simple flash column chromatography, and good-excellent yields of isolated PSE's. Disadvantages of using the PSE's in alkoxy sulfinate ester synthesis is the low temperatures of $-17^{\circ} \mathrm{C}$ required for standalone PSE storage, long reaction time of 12-24 hours, and low yields of 50-80\%. The overarching goal of the PSE's was to isolate them and apply them as an entry point into the transformation of sulfinate esters into sulfinamides for DKR selective amine synthesis. Other goals of the PSE's were to demonstrate their capability to be isolated and applied as stand-alone synthetic tools for the synthesis of alkoxy sulfinate esters and observe their reactivity with a series of structurally diverse alcohols. It became clear that the disadvantages of the PSE method were far too great to fully meet the goals of this section of research. These studies were concluded after the one-pot synthesis with the methoxy-PSE as there were not enough advantages to continue on with these investigations. Ultimately, the PSE's were isolable, stable at low temperatures, and synthetic tools for sulfinate ester synthesis but the long reaction times and lack of diastereoselectivity made the PSE method inefficient and could not be applied to industrial processes. In the next section, a more efficient method for the transformation of sulfinate esters into sulfinamides for DKR selective amine synthesis is explored. 
CHAPTER IV: THE EXPLORATION OF A NEW MOTHOD FOR ALKOXY SULFINATE

ESTER SYNTHESIS

\section{Exploration of a new method for alkoxy sulfinate ester synthesis}

Once the PSE investigations were concluded the next efforts were directed towards the development of a more efficient route to alkoxy sulfinate ester synthesis. Initial investigations were literature research into such sulfinate ester synthesis, with the hopes of developing a method that may be employed without reagents such as EDC and/or DMAP. It was found within literature that a reagent known as $N, N$-carbonyldiimidazole (CDI) was widely used with carboxylic acids to synthesize esters and amides were an activated acyl imidazole intermediate 39 was a crucial intermediate formed, as can be seen in Scheme $30 .{ }^{33}$

Scheme 30: Literature use of $N, N$-carbonyldiimidazole (CDI) with carboxylic acids<smiles>[R]NC(=O)CCC(C)C(=O)n1ccnc1</smiles>

Specifically, the research group of Vaidyanathan and Coworkers from Pfizer had conducted research utilizing the CDI reagent to synthesize amides from carboxylic acids. ${ }^{34}$ The Vaidyanathan group wrote this paper to understand why reaction times significantly decreased if such a reaction was scaled up. It was found that the byproduct $\mathrm{CO}_{2}$ gas catalyzed the reactions and the increased reaction times were caused by the attempted removal of the $\mathrm{CO}_{2}$ from the 
reaction vessel. ${ }^{34}$ Although the details of this paper were not essential to the research that was conducted in this thesis, the fact that this group was able to synthesize amides from carboxylic acids with just the use of a solvent and CDI was significant. It was proposed that the CDI may be able to serve as an activating agent that would act on sulfinic acids to create reactive sulfinyl imidazoles $\mathbf{4 0}$ as seen in Scheme 31, in the same fashion as CDI reacts with carboxylic acids to create acyl imidazoles. Conceptually, all sulfinate ester and sulfinamide syntheses from sulfinic acids require the formation of a suitable leaving group and its proposed that formation of the activated sulfinyl imidazole intermediate will allow for the imidazole to act as a good leaving group, making this a more efficient method (Scheme 31).

Scheme 31: Proposed synthesis with N-N'-Carbonyldiimidazole (CDI) and sulfinic acids

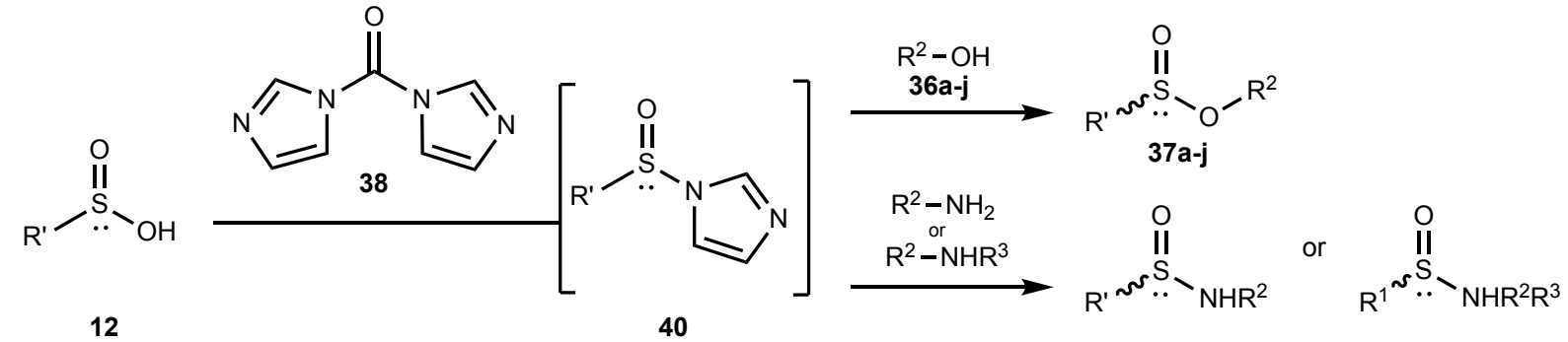

Initial investigations began with the aryl sulfinate esters, by reacting $p$-toluenesulfinic acid with $1,1^{\prime}$ carbonyl diimidazole in dichloromethane (CDI) in methylene chloride at room temperature for 30 minutes before the addition of the test alcohol $p$-nitrobenzyl alcohol and allowing the reaction mixture to stir overnight. When the sulfinic acid and CDI were combined, the reaction underwent bubbling, presumably representing the loss of carbon dioxide via a mechanistic pathway similar to that described in the case of Vaidyanathan and Coworkers research. ${ }^{34}$ The crude reaction mixture was analyzed via ${ }^{1} \mathrm{H}$ NMR spectral data. Initially this comparison was used as evidence of the viability of the newly proposed CDI method. The target 
product, 4-nitrobenzyl 4-methylbenzenesulfinate, has diagnostic geminal proton signals that would be evident in the crude ${ }^{1} \mathrm{H}$ NMR, and if they are not evident then this method would be proved a nonviable option as no target product would have been synthesized, and more literature research would be conducted. Results of the initial reaction can be seen in Figure 9, which clearly shows the diagnostic geminal proton coupling from the target product.

Figure 9: ${ }^{1} \mathrm{H}$ NMR of 4-nitrobenzyl 4-methylbenzenesilfinate crude product

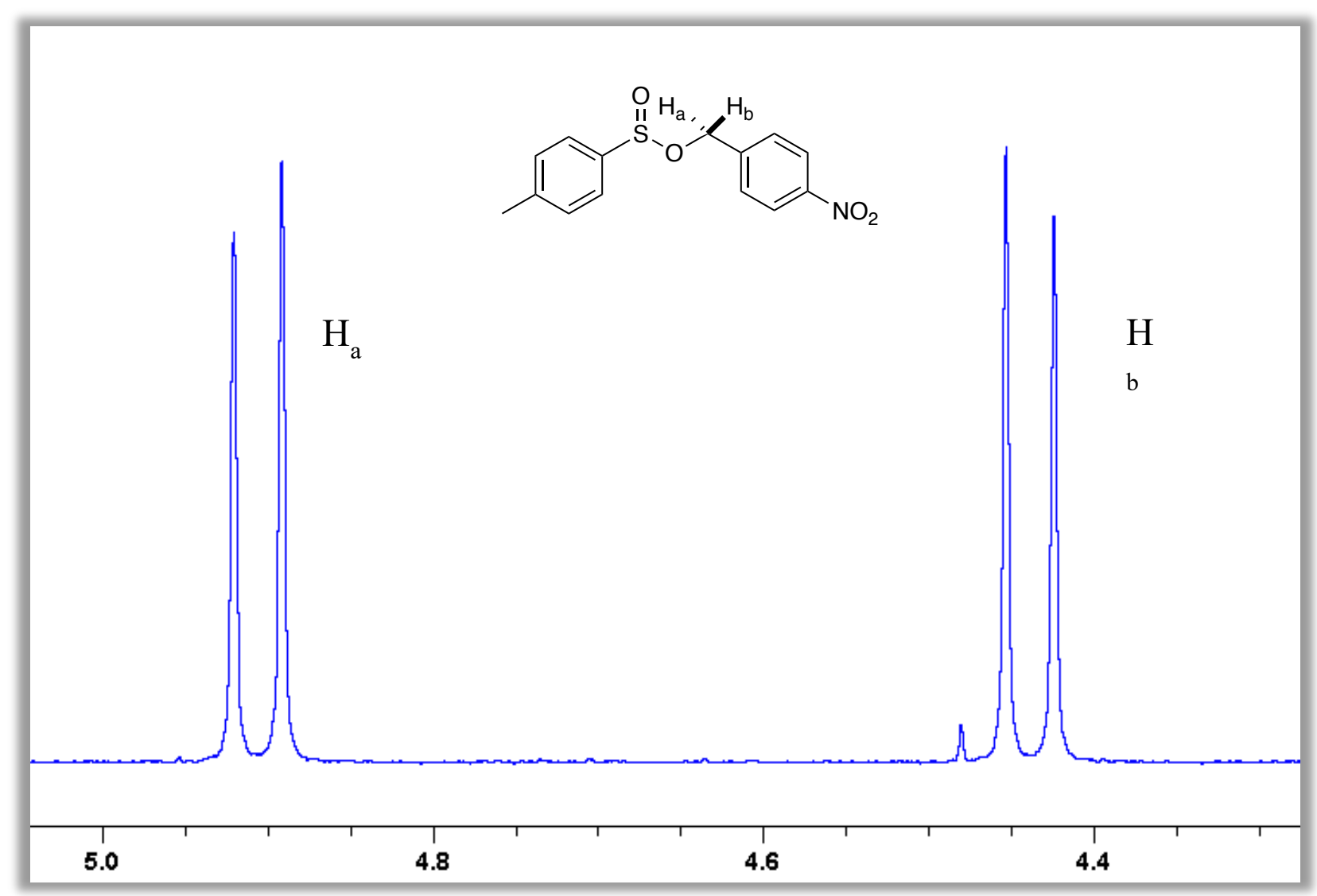

Geminal coupling for this compound is induced by the chirality of the sulfur which causes protons $\mathrm{H}_{a}$ and $\mathrm{H}_{b}$ to not be chemically equivalent to one another due to being in different chemical environments. This geminal coupling can only be see in the target product and will not 
occur for any of the starting materials, which is why it was used as an indicator for the proposed CDI method being a viable option. Once there was evidence of this product forming from the CDI method the next investigation was the optimization of the induction and reaction time. Such an optimization study allows for the determination if there would be a significant induction time and reaction time ultimately becoming a two-step synthesis similar to the PSE method. The induction period is the time needed to react the $p$-toluenesulfinic acid with CDI in order to produce the activated sulfinyl imidazole intermediate. The reaction time is the period after the addition of the alcohol into the reaction mixture. In order to optimize the CDI method a time trial was conducted with seven entries consisting of varying induction times between 0-90 minutes and reaction times between 1-18 hours, as seen in Table 9. Proton NMR spectroscopic data of the crude reaction mixtures were collected directly after the reaction time ended. Analysis of the crude ${ }^{1} \mathrm{H}$ NMR spectra revealed the amount of target product verses starting material which was used as a ratio for a comparison between each entry of this time trial. Within the collected data it was revealed that Entry one, a zero-minute induction time and an 18 hour reaction time, had the most efficient results of a crude ratio 98:2 consisting of majorly target product. It is proposed that the putative sulfinyl imidazole intermediate has a limited life-time before some mechanism of decomposition becomes prevalent, causing the entry with longer induction times to have less target product in the crude mixtures. 
Table 9: Reaction scheme for proposed CDI method for optimization investigations

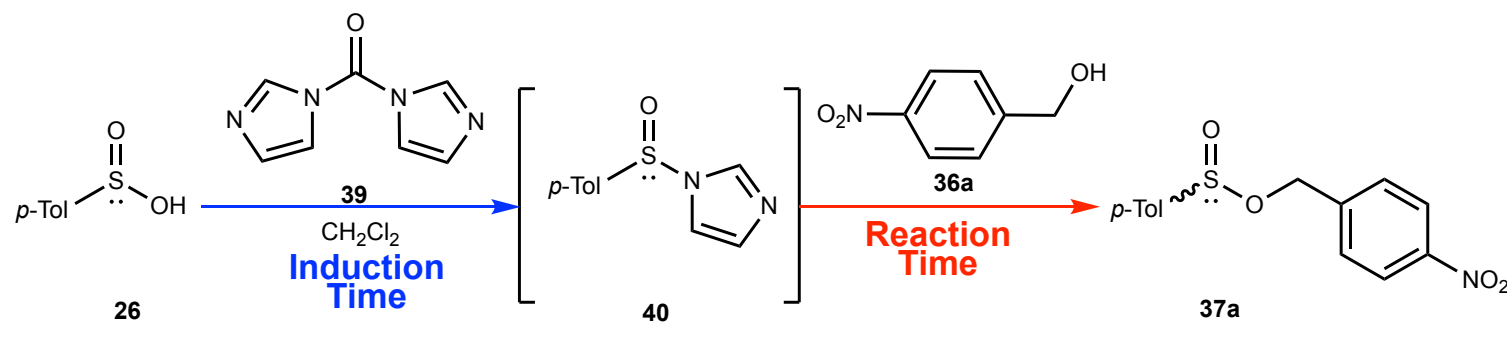

\section{Entry Induction time Reaction Time Product: Starting Material}

\begin{tabular}{lccc}
\hline 1 & $\mathbf{0 ~ m i n}$ & $\mathbf{1 8} \mathbf{~ h r}$ & $\mathbf{9 8 : 2}$ \\
2 & $0 \mathrm{~min}$ & $1 \mathrm{hr}$ & $92: 8$ \\
3 & $15 \mathrm{~min}$ & $18 \mathrm{hr}$ & $94: 6$ \\
4 & $15 \mathrm{~min}$ & $1 \mathrm{hr}$ & $95: 5$ \\
5 & $30 \mathrm{~min}$ & $18 \mathrm{hr}$ & $92: 8$ \\
6 & $60 \mathrm{~min}$ & $18 \mathrm{hr}$ & $90: 10$ \\
7 & $90 \mathrm{~min}$ & $18 \mathrm{hr}$ & $84: 16$ \\
\hline
\end{tabular}

There was a concern that the reaction was completed more quickly than the 18 hour window. Thus, another time trial was carried out wherein there was no induction time. In this set of the experiments, the amount of the $p$-toluenesulfinic acid and CDI were increased to a ratio of 1.5 equivalents relative to the alcohol to insure the completion of the reaction, as seen in Table 10. Once again, the crude mixtures were analyzed via ${ }^{1} \mathrm{H}$ NMR spectra to determine a ratio of product to starting material. With this collected data it was determined that 75 minutes was of a sufficient time to allow complete of the transformation. Interestingly, there was little or no 
apparent formation of any $p$-toluenethio- $p$-toluenesulfonate, a common byproduct in the synthesis of sulfinate esters and sulfinamides. Also, there is minimal starting material contaminants in the crude ${ }^{1} \mathrm{H}$ NMR, which is in contrast to the PSE method that had significant amounts of starting materials in the crude ${ }^{1} \mathrm{H}$ NMR spectra.

Table 10: CDI Method optimization of the reaction time

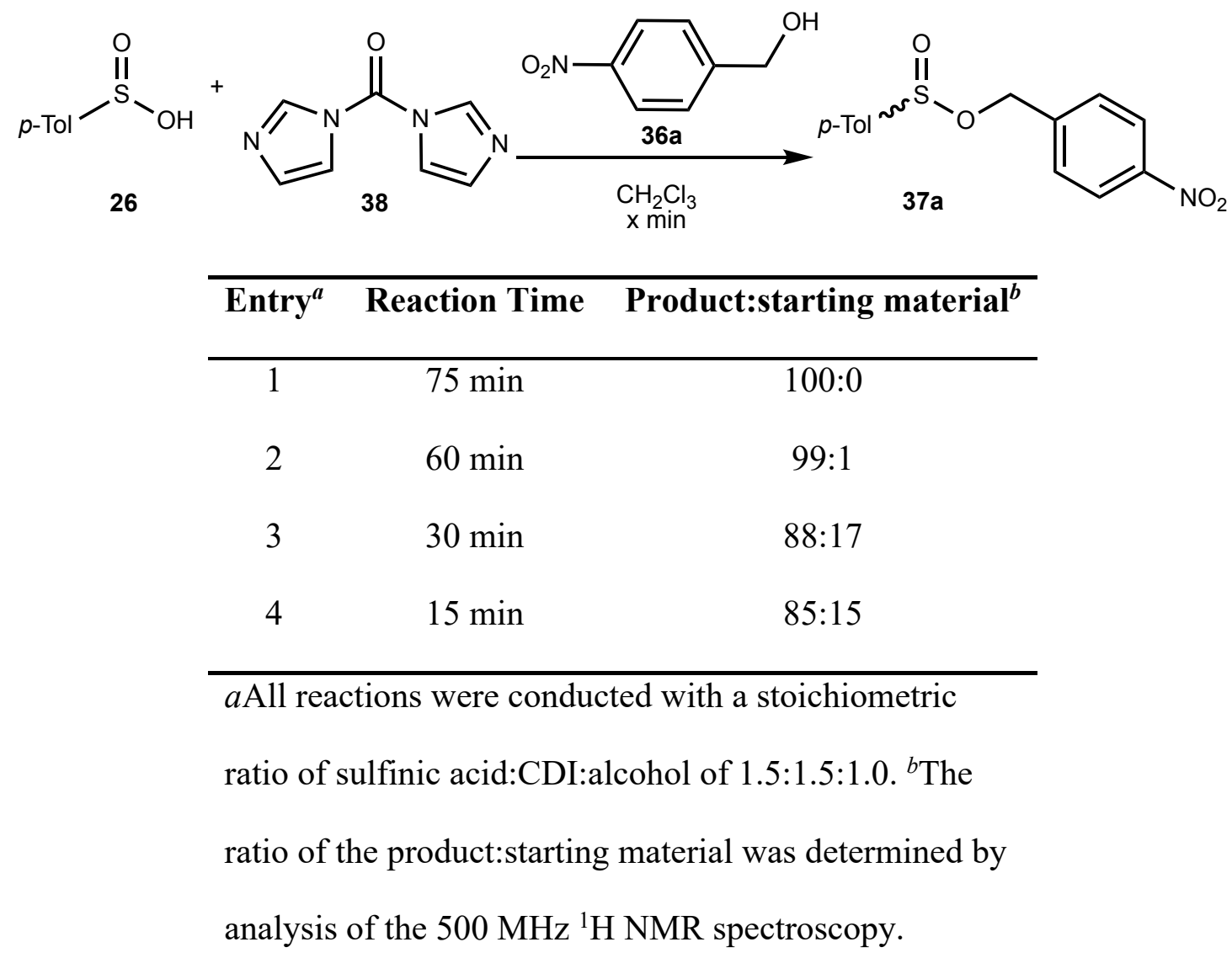




\section{Conclusion of the CDI method}

In conclusion, the CDI method has undergone optimization of the induction time and the reaction time and determined that a 75 minute one-pot synthesis is optimal. The ${ }^{1} \mathrm{H}$ NMR analysis reveals that the crude mixture has minimal contaminants, suggestive that purification may not be needed, allowing for this to be a time efficient method. The ultimate goal of the CDI method is to create an entry point into the transformation of sulfinate esters into sulfinamides for DKR selective amine synthesis, Scheme 32. Thus far the optimization trials show promising results for the application of the CDI method in the dynamic kinetic resolution process and will continued to be pursued.

Scheme 32: Sulfinyl imidazoles $\mathbf{4 0}$ for dynamic kinetic resolution

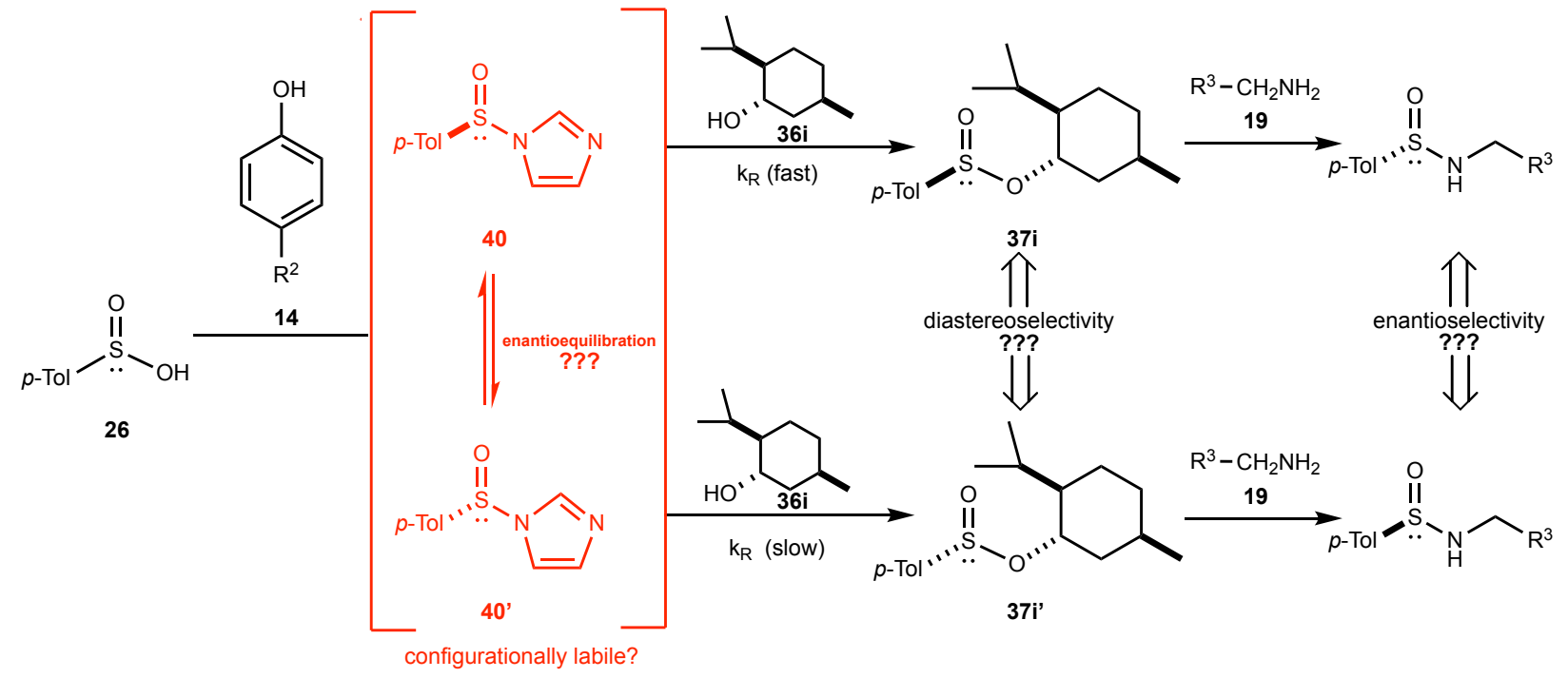




\section{CHAPTER V: THE CONCLUSION}

The focus of this thesis was dedicated to the development of a novel methodology for the synthesis of sulfinate esters in terms of their general structures $\left(\mathrm{RSO}_{2} \mathrm{R}^{\prime}\right)$ and their diastereomerically and enantiomerically pure forms. Sulfinate esters are of interest due to their biological applications and serving as an entry point into the synthesis of sulfinamides for the ultimate goal of chiral amine synthesis.

Scheme 33: PSE as an entry point into transformation of sulfinate esters into sulfinamides for the selective chiral amine synthesis
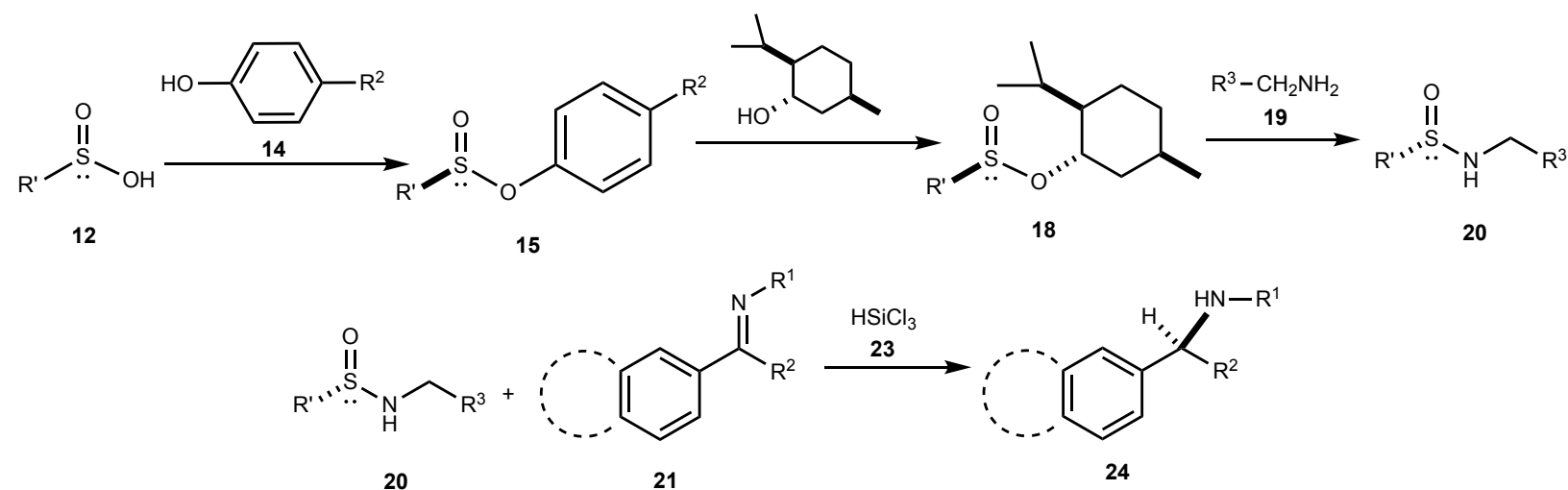

The development of a synthetic method for the asymmetric synthesis of chiral amines has been of interest due to their utility in pharmaceutical drug production. A variety of methods exist for the preparation of chiral amines. These methods include the use of a functional group family known as the sulfinyl group which includes sulfinyl chlorides (RSOCl), sulfoxides (RSOR'), sulfinate esters $\left(\mathrm{RSO}_{2} \mathrm{R}^{\prime}\right)$, and sulfinamides $\left(\mathrm{RSONH}_{2}\right)$. Among these compounds, sulfinate esters and sulfinamides were focused on for this thesis work. 
Initially, the focus was on the design and synthesis of a chiral sulfinamides with an additional chiral scaffolding. The L-phenylglycine based sulfinamide was synthesized and purified, then reacted with amines as a catalyst to yield chiral amines. Enantioselectivity of this reaction was analyzed by HPLC. Ultimately, this portion of work came to a point of temporary suspension due to poor yield and an extensive purification process for the sulfinamide synthesis along with the great difficulty in the chiral separation of the amine enantiomers.

Upon the completion of this portion of thesis work, it was proposed that activated esters could become part of a novel methodology for the synthesis of sulfinate esters. It was proposed that the activated esters could be utilized in the process of dynamic kinetic resolution (DKR) for achieving a stereoselective synthesis of the desired sulfinamide substrates. Dynamic kinetic resolution involves the use of rapidly equilibrating enantiomers as the starting material. It was thought that phenoxysulfinate esters (PSE's) may exhibit such a propensity for enantiomeric equilibration to ultimately give selectivity of chiral amines. It was investigated to see if the PSE method could act as an entry point into sulfinamide and amine synthesis, but to also act as a shelf-stable synthetic tool. Herein, the phenoxysulfinate esters (PSE's) were explored as a standalone and in-situ intermediate for sulfinate ester synthesis. A series of PSE's were synthesized and then subjected to a two-step and one-pot alcohol pathway synthesis of alkoxy sulfinate esters. After extensive investigations it was concluded that the disadvantages of the PSE were far too great to act as a shelf-stable tool and thus as an entry point into sulfinamide and amine synthesis.

Next efforts were directed towards the development of a more efficient route to alkoxy sulfinate ester synthesis. This began with the proposed CDI method in which the reagent CDI would allow for an activated sulfonyl imidazole intermediate that may exhibit a propensity for 
enantiomeric equilibration within the DKR process. Initial investigations have shown promising results of the CDI method and will continue to be investigated.

Ultimately, a novel methodology for alkoxy sulfinate ester synthesis was explored through phenoxysulfinate esters. This exploration led to the isolable PSE compounds and their application in sulfinate esters, but they could not be deemed an efficient entry point into sulfinamide synthesis or as shelf-stable tools. Thus, the CDI method was explored in place of the PSE and has undergone optimization with promising results. This method will be applied as an entry point into sulfinamide synthesis with the eventual goal of producing enantioselective chiral amines through the DKR process as seen in Scheme 32 from the previous chapter.

Scheme 32: Sulfinyl imidazoles 40 for dynamic kinetic resolution

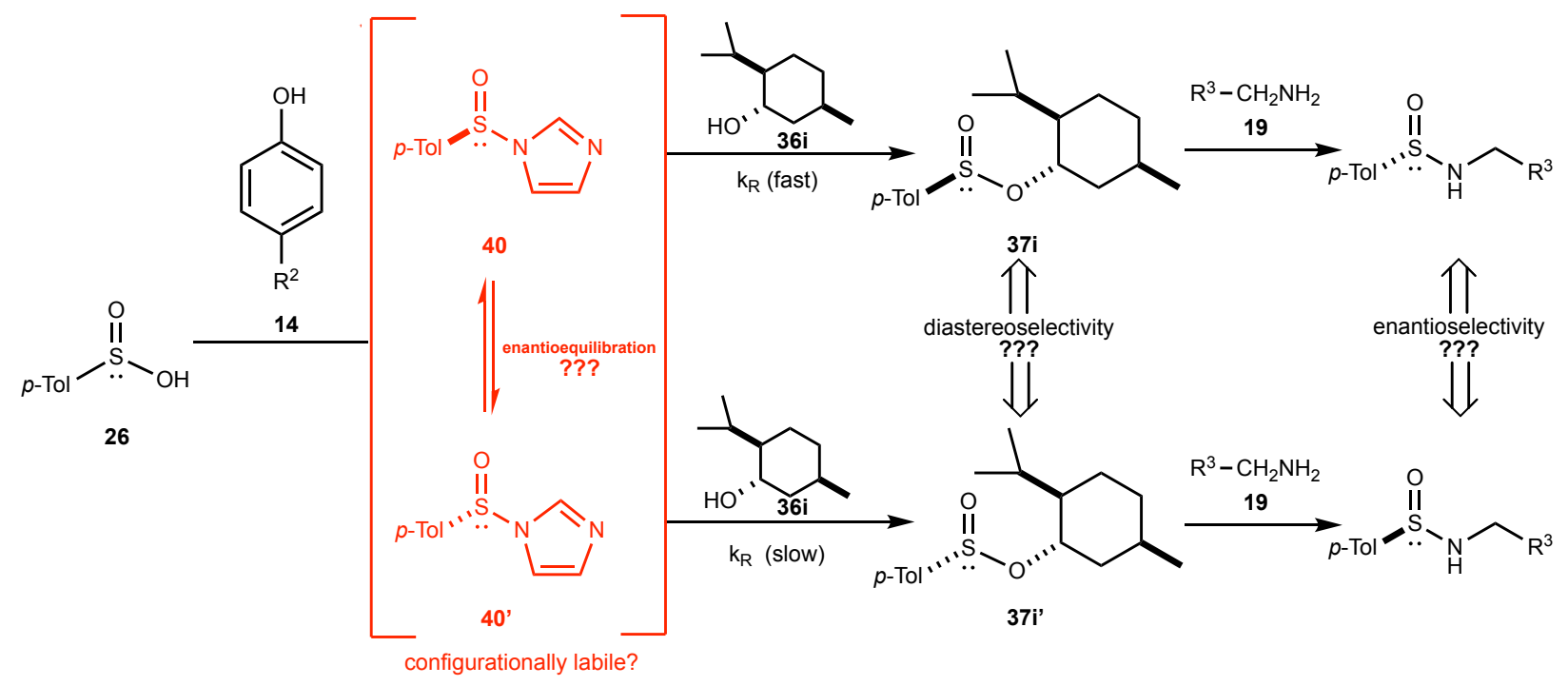




\section{WORKS CITED}

1. Ellman, J. A.; Cogan, D. A.; Liu, G. Catalytic Asymmetric Synthesis of tertButanesulfinamide. Application to the Asymmetric Synthesis of Amines. J. Am. Chem. Soc. 1997, 119, 9913-9914.

2. Shilpa, T.; Varalakshmi, D. K. Significance of stereochemistry and eudesmic ratio in chiral drug development. World J. Pharm. Res. 2017, 7, 224-233

3. Pflum, D. A.; Krishnamurthy, D.; Han, Z.; Wald, S. A.; Senanayake, C. H. Asymmetric Synthesis of Cetirizine Dihydrochloride. Tetrahedron Lett. 2002, 43, 923-926.

4. Wojaczyńska, E.; Wojaczyńska, J. Modern Stereoselective Synthesis of Chiral Sulfinyl Compounds. Chem. Rev. 2020, 120, 4578-4611.

5. Peltier, H. M.; Evans, J. W.; Ellman, J. A. Catalytic Enantioselective Sulfinyl Transfer Using Cinchona Alkaloid Catalysts. Org. Lett. 2005, 7, 1733-1736.

6. Wei, J.; Sun, Z. tert-Butyl Sulfoxide as a Starting Point for the Synthesis of Sulfinyl Containing Compounds. Org. Lett. 2015, 17, 5396-5399.

7. Xiang, S.-H.; Tan, B. Advances in asymmetric organocatalysis over the last 10 years. Nature Commun. 2020, 11, 3786.

8. Ellman, J. A. Applications of tert-butanesulfinamide in the Asymmetric Synthesis of Amines. Pure Appl. Chem. 2003, 75, 39-46.

9. (a) Davoust, M.; Brière, J.-F. ; Jaffrés, P.-A.; Metzner, P. Design of Sulfides with a Locked Conformation as Promoters of Catalytic and Asymmetric Sulfonium Ylide Epoxidation. J. Org. Chem. 2005, 70, 4166-4169. (b) Robiette, R.; Marchan-Brynaert, J. Diastereoselective synthesis of vinylcyclopropanes from dienes and sulfur ylides. Synlett 2008, 517-520. 
10. (a) Keck, G. E.; Savin, K. A.; Weglarz, M. Use of a Samarairum Diiodide as an Alternative to Sodium/Mercury Amalgam in the Julia-Lythgoe Olefination. J. Org. Chem. 1995, 60, 3194-3204. (b) Pospišil, J.; Pospisil, T.; Marko, I. E. Sulfoxides in Julia-Lythgoe Olefination: Efficient and Stereoselective Preparation of Di-, Tri-, and Tetrasubstituted Olefins. Org. Lett., 2005, 7, 2373-2376.

11. (a) Burr, S. K.; Padwa, A. The Pummerer Reaction: Methodology and Strategy for the Synthesis of Heterocyclic Compounds. Chem. Rev. 2004, 104, 2401-2432. (b) Kojima, K.; Yakushiji, F.; Katsuyama, A. ;Ichikawa, S. Total Synthesis of Echinomycin and Its Analogues. Org. Lett. 2020, 22, 4217-422.

12. Malwal, S. R.; Labade, A.; Andhalkar, A. S.; Sengupta, L.; Chakrapani, H. Chem. Commun. 2014, 50, 11533-11535.

13. Chelouan, A.; Recio, R.; Alcudia, A.; Khiar, N.; Fernández, I. DMAP-Catalysed Sulfinylation of Diacetone-D-Glucose: Improved Method for Synthesis of Enantiopure tertButyl Sulfoxides and tert-Butanesulfinamides. Eur. J. Org. Chem. 2014, 6935-6944.

14. Tranquilino, A.; Andrade, S. R. C. P.; da Silva, A. P. M.; Menezes, P. H.; Oliveira, R. A. Tetrahedron Lett. 2017, 58, 1265-1268.

15. Pogaku, N.; Krishna, P. R.; Prapurna, Y. L. Synth. Commun. 2017, 47, 1239-1249.

16. Pang, S.; Yang, X.; Cao, Z.-H.; Zhang, Y.-L.; Zhao, Y.; Huang, Y.-Y. Intermolecular [2 + 2] Cycloaddition/Isomerization of Allenyl Imides and Unactivated Imines for the Synthesis of 1-Azadienes Catalyzed by a $\mathrm{Ni}\left(\mathrm{ClO}_{4}\right)_{2} \cdot 6 \mathrm{H}_{2} \mathrm{O}$ Lewis Acid. ACS Catal. 2018, 8, 5193- 5199,

17. Choudhary, D.; Khatri, V.; Basak, A. K. Wittig Ylide Mediated Decomposition of NSulfonylhydrazones to Sulfinates. Org. Lett. 2018, 20, 1703-1706.

18. He, Y.; Zhang, J.; Xu, L.; Wei, Y. Electrochemical synthesis of sulfinic esters from alcohols and thiophenols. Tetrahedron Lett. 2020, 61, 151631. 
19. Seki, H.; Xue, S.; Pellet, S.; Silhar, P.; Johnson, E. A.; Janda, K. D. Cellular Protection of SNAP-25 against Botulinum Neurotoxin/A: Inhibition of Thioreduxin Reductase through a Suicide Substrate Mechanism. J. Am. Chem. Soc. 2016, 138, 5568-5575.

20. Gafur, S. H.; Waggoner, S. L.; Jacobsen, E.; Hamaker, C. G.; Hitchcock, S. R. Efficient Synthesis of Sulfinate Esters and Sulfinamides via Activated Esters of p-Toluenesulfinic acid. Synthesis 2018, 50, 4855-4866.

21. R7 Bentley, R. Role of Sulfur Chirality in the Chemical Processes of Biology. Chem. Soc. Rev. 2005, 34, 609.

22. Nemeth, E. F.; Fox, J. Compounds acting on the parathyroid calcium receptor as novel therapies for hyperparathyroidism and osteoporosis. Endocr. Updates 2003, 19, 173-202.

23. Ravinder, V.; Ashok, S.; Varma, M. S.; Babu, C. V. R.; Balaswamy, K. S. G. A Validated Chiral LC Method for the Enantiomeric Separation of Cinacalcet Hydrochloride. Chromatographia 2009, 70, 229-232.

24. Andersson, P. G.; Schink, H. E.; Osterlund, K. Asymmetric Total Synthesis of (+)Tolterodine, a New Muscarinic Receptor Antagonist, via Copper-Assisted Asymmetric Conjugate Addition of Aryl Grignard Reagents to 3-Phenyl-prop-enoyl-oxazolidnones. $J$. Org. Chem. 1998, 63, 8067-8070.

25. This X-ray crystal structure was provided by Professor C. G. Hamaker, Department of Chemistry, Illinois State University.

26. Weingarten, H; Chupp, J. P.; White, A. W. J. Org. Chem. 1967, 32, 3246-3249.

27. Knauer. Columns for analytical HPLC, UHPLC, preparative HPLC and GPC. https://www.knauer.net/en/Systems-Solutions/LC-Columns (accessed July 17th, 2020). 
28. Chiral Technologies Daicel group. Instruction manual for Chiralcel OD-H and Chiralcel OJH. 2013. http://chiraltech.com/wp-content/uploads/2014/07/6g-CHIRALCEL-OD-H-OJH.pdf (accessed July 17th, 2020).

29. (a) Moghaddam, F. M.; Dekamin, M. G.; Ghaffarzadeh, M. $\mathrm{FeCl}_{3}$ as an efficient and new catalyst for the thia-Fries rearrangement of aryl sulfinates. Tetrahedron Lett. 2001, 42, 81198121. (b) Wragg, A. H.; McFadyen, J. S.; Stevens, T. S. Rearrangement of sulfinic esters. J. Chem. Soc. 1958, 3603-3605.

30. Senatore, L.; Ciuffarin, E.; Fava, A.; Levita, G. Nucleophilic Substitution at Sulfur. Effect of Nucleophile and Leaving Group Basicity as Probe of Bond Formation and Breaking. J. Am. Chem. Soc. 1973, 95, 2918-2922.

31. Tranquilino, A.; Andrade, S. R. C. P.' da Silva, A. P. M.; Menezes, P. H.; Oliveira, R. A. Tetrahedron Lett. 2017, 58, 1265-1268.

32. Armstrong, A. Paquette, L. A., Ed.; John Wiley \& Sons. 1995, 2, 1006 and references therein.

33. Vaidyanathan, R.; Kalthod, V. G.; Ngo, D. P.; Manley, J. M.; Lapekas, S. P. Amidations Using N,N'-Carbonyldiimidazole: Remarkable Rate Enhancement by Carbon Dioxide. $J$. Org. Chem. 2004, 69, 25652568 


\section{APPENDIX A: EXPERIMENTALS}

General Remarks: Chemical reagents and solvents were purchased from commercial vendors and used without further purification. All reactions were conducted in flame-dried or oven dried glassware under a nitrogen atmosphere. Solvents were removed by rotary evaporation and further dried by a Welch DryFast mechanical pump. All ${ }^{1} \mathrm{H}$ and ${ }^{13} \mathrm{C}$ NMR spectra were recorded in deuterated chloroform $\left(\mathrm{CDCl}_{3}\right)$ using an NMR spectrometer operating at 500 and $400 \mathrm{MHz}$ for ${ }^{1} \mathrm{H}$ NMR and operating at 125 and $100 \mathrm{MHz}$, respectively. Chemical shifts were reported in parts per million ( $\delta$ scale) and coupling constant ( $J$ values) are listed in Hertz $(\mathrm{Hz})$. Tetramethylsilane (TMS) was used as internal standard $(\delta=0 \mathrm{ppm})$. Major isomers were reported except otherwise stated. $\mathrm{OH}$ and $\mathrm{NH}$ peaks were not reported only when they are not observed. Infrared spectra are reported in reciprocal centimeters $\left(\mathrm{cm}^{-1}\right)$ and are measured in nujol mull, regular chloroform or as a neat liquid. Melting points were recorded on a Mel-Temp apparatus and are uncorrected. All polarimetric experiments were carried out using a Jasco P-2000 polarimeter.

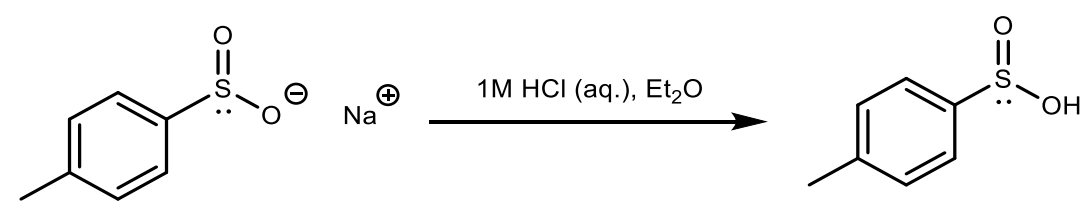

p-Toluenesulfinic acid (anhydrous): To a $500 \mathrm{~mL}$ Erlenmeyer flask was added $p$-toluenesulfinic acid sodium salt hydrate $(5.00 \mathrm{~g}, 28.1 \mathrm{mmol})$, diethyl ether $(60 \mathrm{~mL})$, and $1 \mathrm{M} \mathrm{HCl}(60 \mathrm{~mL})$. The reaction mixture was stirred at ambient temperature for 45 minutes and the aqueous layer was extracted. Organic layer was washed with brine $(2 * 20 \mathrm{~mL})$, dried with anhydrous $\mathrm{MgSO}_{4}$, gravity filtered, and concentrated to yield the p-toluenesulfinic acid. 
<smiles>Cc1ccc(S(=O)O)cc1</smiles>

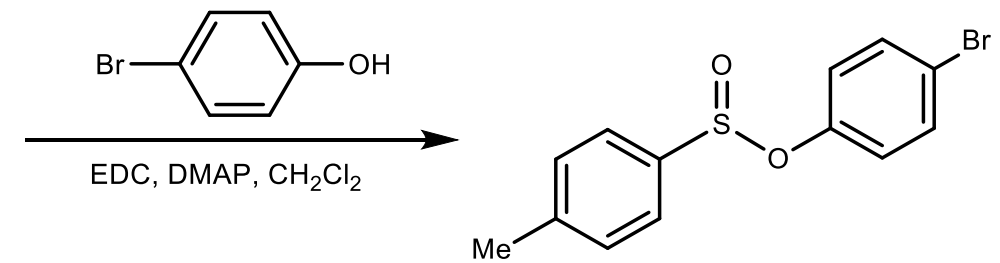

Bromo phenoxysulfinate ester (35a): To a $500 \mathrm{~mL}$ Erlenmeyer flask was added p-toluenesulfinic acid sodium salt hydrate $(5.000 \mathrm{~g}, 28.06 \mathrm{mmol})$, ether $(60 \mathrm{~mL})$, and $1 \mathrm{M} \mathrm{HCl}(60 \mathrm{~mL})$. The reaction mixture was stirred at room temperature for 45 minutes and the aqueous layer was extracted. Organic layer was washed with brine $(2 * 20 \mathrm{~mL})$, dried with anhydrous $\mathrm{MgSO}_{4}$, gravity filtered, and concentrated to yield the p-toluenesulfinic acid. Sequentially, to flame-dried round bottom flask under nitrogen atmosphere was added 4-Bromophenol (0.608 g, $3.52 \mathrm{mmol}), \mathrm{CH}_{2} \mathrm{Cl}_{2}$ (12 $\mathrm{mL})$, EDC (0.670 g, $3.52 \mathrm{mmol})$, DMAP (0.156 g, $1.28 \mathrm{mmol})$, and p-toluenesulfinic acid (0.500 $\mathrm{g}, 3.20 \mathrm{mmol}$ ). The reaction mixture was allowed to stir at room for 12 hours. The resulting mixture was diluted with $\mathrm{CH}_{2} \mathrm{Cl}_{2}(60 \mathrm{~mL})$ and washed with $1 \mathrm{M} \mathrm{HCl}(20 \mathrm{~mL})$, the aqueous layer was extracted. The collected organic layer was washed with $1 \mathrm{M} \mathrm{NaOH}(3 * 20 \mathrm{~mL})$, brine $(20 \mathrm{~mL})$, dried with $\mathrm{MgSO}_{4}$, filtered, and concentrated via reduced pressure. The crude product was purified by flash column chromatography (Hx: EtOAc, 90:10, $\mathrm{Rf}=0.36)$ to yield $0.207 \mathrm{~g}(21 \%)$ of the title compound collected.

Characterization: ${ }^{1} \mathrm{H}$ NMR (400 MHz $\left.\mathrm{CDCl}_{3}\right): \delta 2.4(\mathrm{~s}, 3 \mathrm{H}), 6.9-7.0(\mathrm{~m}, 2 \mathrm{H}), 7.33-7.34(\mathrm{~m}, 2 \mathrm{H})$, 7.39-7.42 (m, 2H), 7.6-7.7 (m, 2H) ppm. 

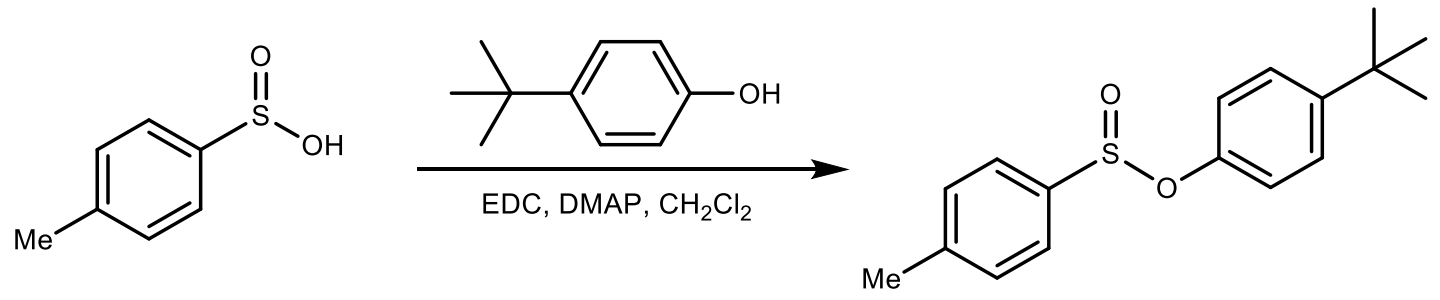

Tert-butyl phenoxysulfinate ester(35b): To a $500 \mathrm{~mL}$ Erlenmeyer flask was added ptoluenesulfinic acid sodium salt hydrate $(5.000 \mathrm{~g}, 28.06 \mathrm{mmol})$, ether $(60 \mathrm{~mL})$, and $1 \mathrm{M} \mathrm{HCl}(60$ $\mathrm{mL}$ ). The reaction mixture was stirred at room temperature for 45 minutes and the aqueous layer was extracted. Organic layer was washed with brine $(2 * 20 \mathrm{~mL})$, dried with anhydrous $\mathrm{MgSO}_{4}$, gravity filtered, and concentrated to yield the p-toluenesulfinic acid. Sequentially, to flame-dried round bottom flask under nitrogen atmosphere was added 4-Tert-Butylphenol (0.528 g, 3.52 $\mathrm{mmol}), \mathrm{CH}_{2} \mathrm{Cl}_{2}(12 \mathrm{~mL})$, EDC (0.670 g, $\left.3.52 \mathrm{mmol}\right)$, DMAP (0.156 g, $\left.1.28 \mathrm{mmol}\right)$, and ptoluenesulfinic acid $(0.500 \mathrm{~g}, 3.20 \mathrm{mmol})$. The reaction mixture was allowed to stir at room for 12 hours. The resulting mixture was diluted with $\mathrm{CH}_{2} \mathrm{Cl}_{2}(60 \mathrm{~mL})$ and washed with $1 \mathrm{M} \mathrm{HCl}(20 \mathrm{~mL})$, the aqueous layer was extracted. The collected organic layer was washed with $1 \mathrm{M} \mathrm{NaOH}(3 * 20$ $\mathrm{mL})$, brine $(20 \mathrm{~mL})$, dried with $\mathrm{MgSO}_{4}$, filtered, and concentrated via reduced pressure. The crude product was purified by flash column chromatography (Hx: EtOAc, 80:20, $\mathrm{Rf}=0.63$ ) to yield 0.679 $\mathrm{g}(74 \%)$ of the title compound as a white solid.

Characterization: pg $302{ }^{1} \mathrm{H}$ NMR (500 MHz CDCl 3$): ~ \delta 8.5(\mathrm{~s}, 9 \mathrm{H}), 2.9(\mathrm{~s}, 3 \mathrm{H}), 7.04-7.06(\mathrm{~m}, 2 \mathrm{H})$, 7.3-7.4 (m, 4H), 7.6-7.7 (m, 2H) ppm.

${ }^{13} \mathrm{C}$ NMR (125 MHz $\left.\mathrm{CDCl}_{3}\right): \delta 21.5,31.4,34.4,120.8,125.0,126.2,126.5,129.7,142.4,143.3$, $148.6,150.5 \mathrm{ppm}$.

IR (neat): 702, 819, 1138,1502, $2959 v$.

HRMS ESI for $\mathrm{C}_{14} \mathrm{H}_{13} \mathrm{NO}_{4} \mathrm{SNa}$ : Calculated $\left(\mathrm{M}+\mathrm{Na}^{+}\right) 311.1076 \mathrm{~m} / \mathrm{z}$, found $31.1067 \mathrm{~m} / \mathrm{s}$ with mass error of $2.89 \mathrm{ppm}$ due to difference of $0.0009 \mathrm{~m} / \mathrm{z}$. 

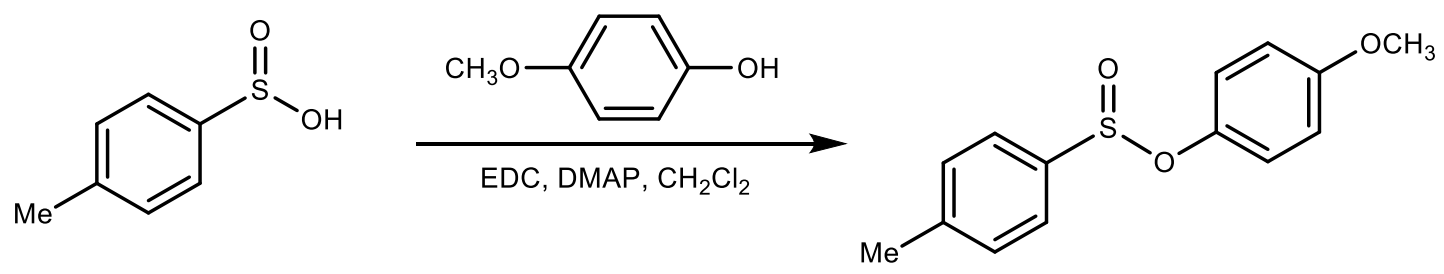

Methoxy phenoxysulfinate ester (35c): To a $500 \mathrm{~mL}$ Erlenmeyer flask was added ptoluenesulfinic acid sodium salt hydrate $(5.000 \mathrm{~g}, 28.06 \mathrm{mmol})$, ether $(60 \mathrm{~mL})$, and $1 \mathrm{M} \mathrm{HCl}(60$ $\mathrm{mL}$ ). The reaction mixture was stirred at room temperature for 45 minutes and the aqueous layer was extracted. Organic layer was washed with brine $(2 * 20 \mathrm{~mL})$, dried with anhydrous $\mathrm{MgSO}_{4}$, gravity filtered, and concentrated to yield the p-toluenesulfinic acid. Sequentially, to flame-dried round bottom flask under nitrogen atmosphere was added 4-methoxyphenol (4.371 g, 35.21 $\mathrm{mmol}), \mathrm{CH}_{2} \mathrm{Cl}_{2}(120 \mathrm{~mL}), \mathrm{EDC}(6.751 \mathrm{~g}, 35.21 \mathrm{mmol})$, DMAP (1.564 g, $\left.12.80 \mathrm{mmol}\right)$, and ptoluenesulfinic acid $(5.000 \mathrm{~g}, 32.00 \mathrm{mmol})$. The reaction mixture was allowed to stir at room for 12 hours. The resulting mixture was diluted with $\mathrm{CH}_{2} \mathrm{Cl}_{2}(100 \mathrm{~mL})$ and washed with $1 \mathrm{M} \mathrm{HCl}(50$ $\mathrm{mL}$ ), the aqueous layer was extracted. The collected organic layer was washed with $1 \mathrm{M} \mathrm{NaOH}$ (3*50 mL), brine $(50 \mathrm{~mL})$, dried with $\mathrm{MgSO}_{4}$, filtered, and concentrated via reduced pressure. The crude product was purified by flash column chromatography (Hx: EtOAc, 95:5, $\mathrm{Rf}=0.19$ ) to yield $2.313 \mathrm{~g}(28 \%)$ of the title compound collected.

Characterization: pg $364{ }^{1} \mathrm{H}$ NMR (500 MHz CDCl$\left.)_{3}\right): \delta 1.5(\mathrm{~s}, 1 \mathrm{H}), 2.4(\mathrm{~s}, 3 \mathrm{H}), 3.7(\mathrm{~s}, 3 \mathrm{H}), 6.7-$ $6.8(\mathrm{~m}, 2 \mathrm{H}), 6.9-7.0(\mathrm{~m}, 2 \mathrm{H}), 7.32-7.34(\mathrm{~m}, 2 \mathrm{H}), 7.6-7.7(\mathrm{~m}, 2 \mathrm{H}) \mathrm{ppm}$.

${ }^{13} \mathrm{C}$ NMR $\left(125 \mathrm{MHz} \mathrm{CDCl}_{3}\right): \delta 21.5,55.5,114.5,123.0,125.0,129.6,142.0,143.4,145.5,157.4$ ppm.

IR (neat): $668,755,833,1104,1136,3347 v$.

HRMS ESI for $\mathrm{C}_{14} \mathrm{H}_{13} \mathrm{NO}_{4} \mathrm{SNa}$ : Calculated $\left(\mathrm{M}+\mathrm{Na}^{+}\right) 285.0561 \mathrm{~m} / \mathrm{z}$, found $285.0560 \mathrm{~m} / \mathrm{z}$ with mass error of $0.00 \mathrm{ppm}$ due to difference of $0.0001 \mathrm{~m} / \mathrm{z}$ 


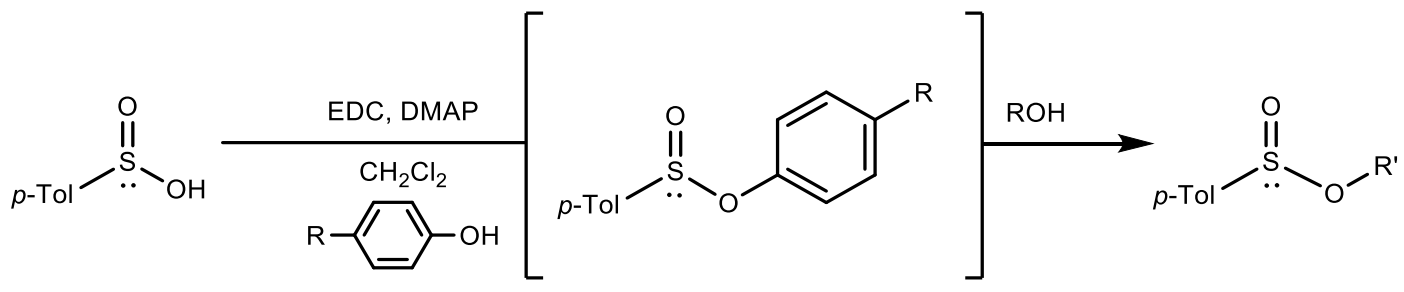

General Procedure A: Synthesis of sulfinate esters via the two-step process. To a $500 \mathrm{~mL}$ Erlenmeyer flask was added p-toluenesulfinic acid sodium salt hydrate (5.000 g, $28.06 \mathrm{mmol})$, ether $(60 \mathrm{~mL})$, and $1 \mathrm{M} \mathrm{HCl}(60 \mathrm{~mL})$. The reaction mixture was stirred at room temperature for 45 minutes and the aqueous layer was extracted. Organic layer was washed with brine $(2 * 20 \mathrm{~mL})$, dried with anhydrous $\mathrm{MgSO}_{4}$, gravity filtered, and concentrated to yield the p-toluenesulfinic acid. Sequentially, to flame-dried round bottom flask under nitrogen atmosphere was added 4-TertButylphenol (0.528 g, $3.52 \mathrm{mmol}), \mathrm{CH}_{2} \mathrm{Cl}_{2}(12 \mathrm{~mL})$, EDC (0.671 g, $\left.3.52 \mathrm{mmol}\right)$, DMAP (0.156 g, $1.28 \mathrm{mmol})$, and p-toluenesulfinic acid $(0.515 \mathrm{~g}, 3.20 \mathrm{mmol})$. The reaction mixture was allowed to stir at room temperature. After 12 hours to the reaction was added an alcohol (2.72 mmol) and $\mathrm{NEt}_{3}(0.54 \mathrm{~mL}, 3.84 \mathrm{mmol})$, and allowed to stir at room temperature for $12 \mathrm{hrs}$. The resulting mixture was diluted with $\mathrm{CH}_{2} \mathrm{Cl}_{2}(60 \mathrm{~mL})$ and washed with $1 \mathrm{M} \mathrm{HCl}(20 \mathrm{~mL})$, the aqueous layer was extracted. The collected organic layer was washed with $1 \mathrm{M} \mathrm{NaOH}(3 * 20 \mathrm{~mL})$, brine $(20 \mathrm{~mL})$, dried with $\mathrm{MgSO}_{4}$, filtered, and concentrated via reduced pressure. 


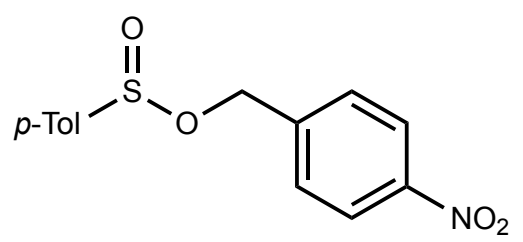

\section{Compound 37a}

The crude product was purified by flash column chromatography $(\mathrm{Hx}$ : EtOAc, $70: 30, \mathrm{Rf}=0.39)$ to yield $0.595 \mathrm{~g}(73 \%)$ of the title compound as a white solid.

Characterization: ${ }^{1} \mathrm{H}$ NMR (400 MHz $\left.\mathrm{CDCl}_{3}\right): \delta 2.4(\mathrm{~s}, 3 \mathrm{H}), 4.5(\mathrm{~d}, J=11.62 \mathrm{~Hz}, 2 \mathrm{H}), 4.9(\mathrm{~d}, J=$ 11.62 Hz, 2H), 7.1-7.2 (m, 2H), 7.2-7.3 (m, 2H), 7.3-7.4 (m, 2H), 7.60-7.63 (m, 2H) ppm.

${ }^{13} \mathrm{C}$ NMR (100 MHz CDCl 3 ): $\delta 21.5,63.4,123.7,125.3,128.6,128.9,141.1,143.1,143.4,147.7$ ppm.

IR (neat): $1134,817,746 \mathrm{v}$.

HRMS ESI for $\mathrm{C}_{14} \mathrm{H}_{13} \mathrm{NO}_{4} \mathrm{SNa}$ : Calculated $\left(\mathrm{M}+\mathrm{Na}^{+}\right) 314.0457 \mathrm{~m} / \mathrm{z}$, found $314.0453 \mathrm{~m} / \mathrm{z}$, mass error of $1.27 \mathrm{ppm}$ due to difference of $0.0004 \mathrm{~m} / \mathrm{z}$. 


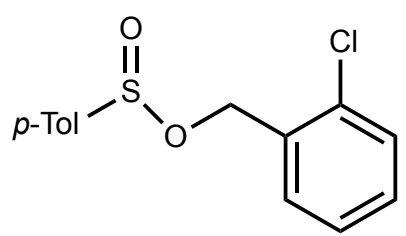

Compound 37b

The crude product was purified by flash column chromatography (Hx: EtOAc, 80:20, Rf=0.48). The resulting product was diluted with DCM $(60 \mathrm{~mL})$ washed with $1 \mathrm{M} \mathrm{NaOH}(2 * 20 \mathrm{~mL})$, Brine (20 mL), dried with $\mathrm{MgSO} 4$, filtered, and concentrated via reduced pressure to yield $0.548 \mathrm{~g}(72 \%)$ of the title compound as a clear and colorless liquid.

Characterization: ${ }^{1} \mathrm{H}$ NMR $\left(400 \mathrm{MHz} \mathrm{CDCl}_{3}\right): \delta 2.4(\mathrm{~s}, 3 \mathrm{H}), 4.7(\mathrm{~d}, J=12.09 \mathrm{~Hz}, 1 \mathrm{H}), 5.1(\mathrm{~d}, J=$ $12.09 \mathrm{~Hz}, 1 \mathrm{H})$, 7.23-7.27 (m, 2H), 7.3-7.4 (m, 4H), 7.6-7.7 (m, 2H) ppm.

${ }^{13} \mathrm{C}$ NMR (100 MHz $\left.\mathrm{CDCl}_{3}\right): \delta 21.4,63.0,125.2,126.8,129.4,129.6,129.7,130.3,133.4,133.6$, $141.4,142.9 \mathrm{ppm}$.

IR (neat): $1130,815,745 \mathrm{v}$.

HRMS ESI for $\mathrm{C}_{14} \mathrm{H}_{13} \mathrm{ClO}_{2} \mathrm{SNa}$ : Calculated $\left(\mathrm{M}+\mathrm{Na}^{+}\right) 303.0217 \mathrm{~m} / \mathrm{z}$, found $303.0210 \mathrm{~m} / \mathrm{z}$, mass error of $2.31 \mathrm{ppm}$ due to difference of $0.0007 \mathrm{~m} / \mathrm{z}$. 


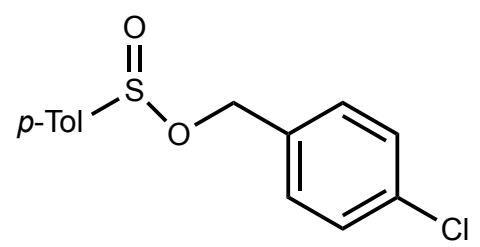

\section{Compound 37c}

Crude product was purified by flash column chromatography (Hx: EtOAc, 80:20, Rf=0.47). The resulting product was diluted with $\mathrm{DCM}(60 \mathrm{~mL})$ washed with $1 \mathrm{M} \mathrm{NaOH}(2 * 20 \mathrm{~mL})$, Brine $(20$ $\mathrm{mL})$, dried with MgSO4, filtered, and concentrated via reduced pressure to yield $0.632 \mathrm{~g}(83 \%)$ of the title compound as a clear and light-yellow liquid.

Characterization: ${ }^{1} \mathrm{H}$ NMR $\left(400 \mathrm{MHz} \mathrm{CDCl}_{3}\right): \delta 2.4(\mathrm{~s}, 3 \mathrm{H}), 4.9(\mathrm{~d}, J=11.62 \mathrm{~Hz}, 1 \mathrm{H}), 5.0(\mathrm{~d}, J=$ 11.62, 1H), 7.1-7.2 (m, 2H), 7.2-7.3 (m, 2H), 7.3-7.34 (m, 2H), 7.60-7.64 (m, 2H) ppm.

${ }^{13} \mathrm{C}$ NMR $\left(100 \mathrm{MHz} \mathrm{CDCl}_{3}\right): \delta 21.4,64.4,125.2,128.6,129.7,129.8,134.0,134.2,141.4$, and 142.9 ppm.

IR (neat): 1129, 915, $744 v$.

HRMS ESI for $\mathrm{C}_{14} \mathrm{H}_{13} \mathrm{ClO}_{2} \mathrm{SNa}$ : Calculated $\left(\mathrm{M}+\mathrm{Na}^{+}\right) 303.0217 \mathrm{~m} / \mathrm{z}$, found $303.0211 \mathrm{~m} / \mathrm{z}$, mass error of $1.98 \mathrm{ppm}$ due to difference of $0.0006 \mathrm{~m} / \mathrm{z}$. 


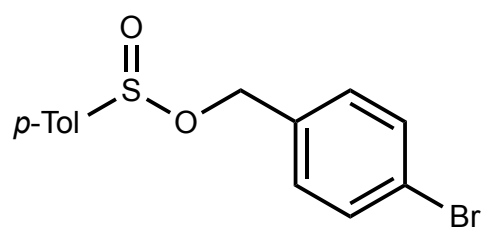

Compound 37d

Crude product was purified by flash column chromatography (Hx: EtOAc, 70:30 $\mathrm{Rf}=0.60$ ) The resulting product was diluted with $\mathrm{DCM}(60 \mathrm{~mL})$ washed with $1 \mathrm{M} \mathrm{NaOH}(2 * 20 \mathrm{~mL})$, Brine $(20$ $\mathrm{mL})$, dried with $\mathrm{MgSO} 4$, filtered, and concentrated via reduced pressure to yield $0.712 \mathrm{~g}(68 \%)$ of the title compound as a clear and light-yellow liquid.

Characterization: ${ }^{1} \mathrm{H}$ NMR $\left(400 \mathrm{MHz} \mathrm{CDCl}_{3}\right): \delta 2.4(\mathrm{~s}, 3 \mathrm{H}), 4.4(\mathrm{~d}, J=11.67 \mathrm{~Hz}, 1 \mathrm{H}), 4.9(\mathrm{~d}, J=$ 11.76 Hz, 1H), 7.12-7.14 (m, 2H), 7.3-7.4 (m, 2H), 7.4-7.5 (m, 2H), 7.60-7.63 (m, 2H) ppm.

${ }^{13} \mathrm{C}$ NMR (100 MHz CDCl 3 ): $\delta 21.4,64.4,122.4,125.2,129.7,130.0,131.6,134.6,141.3,142.9$ ppm.

IR (neat): $1129,738,688 \mathrm{v}$.

HRMS ESI for $\mathrm{C}_{14} \mathrm{H}_{13} \mathrm{BrO}_{2} \mathrm{SNa}$ : Calculated $\left(\mathrm{M}+\mathrm{Na}^{+}\right) 346.9712 \mathrm{~m} / \mathrm{z}$, found $346.9705 \mathrm{~m} / \mathrm{z}$, mass error of $2.02 \mathrm{ppm}$ due to difference of $0.0007 \mathrm{~m} / \mathrm{z}$. 


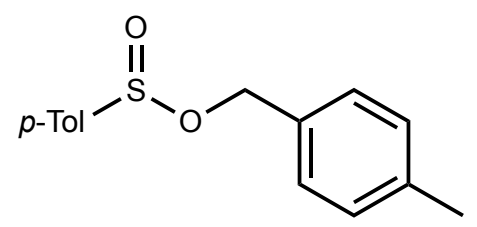

\section{Compound 37e}

Crude product was purified by flash column chromatography (Hx: EtOAc, 70:30 Rf=0.47) The resulting product was diluted with $\mathrm{DCM}(60 \mathrm{~mL})$ washed with $1 \mathrm{M} \mathrm{NaOH}(2 * 20 \mathrm{~mL})$, Brine $(20$ $\mathrm{mL})$, dried with $\mathrm{MgSO} 4$, filtered, and concentrated via reduced pressure to yield $0.531 \mathrm{~g}(75 \%)$ of the title compound as a clear and yellow liquid.

Characterization: ${ }^{1} \mathrm{H}$ NMR (400 $\left.\mathrm{MHz} \mathrm{CDCl}_{3}\right): \delta 2.3(\mathrm{~s}, 3 \mathrm{H}), 2.4(\mathrm{~s}, 3 \mathrm{H}), 4.5(\mathrm{~d}, J=11.24 \mathrm{~Hz}$, $1 \mathrm{H}), 5.0(\mathrm{~d}, J=11.24 \mathrm{~Hz}, 1 \mathrm{H}), 7.1-7.2(\mathrm{~m}, 4 \mathrm{H}), 7.3(\mathrm{~d}, J=8.24 \mathrm{~Hz}, 2 \mathrm{H}), 7.6(\mathrm{~d}, J=8.24 \mathrm{~Hz}, 2 \mathrm{H})$ ppm.

${ }^{13} \mathrm{C}$ NMR $\left(100{\left.\mathrm{MHz} \mathrm{CDCl}_{3}\right): \delta}^{2} 21.1,21.4,65.6,125.2,128.6,129.1,129.6,132.4,138.2,141.6\right.$, $142.6 \mathrm{ppm}$.

IR (neat): 724, 805, $1127 \mathrm{v}$.

ESI-MS for $\mathrm{C}_{15} \mathrm{H}_{16} \mathrm{O}_{2} \mathrm{SNa}$ : Calculated $\left(\mathrm{M}+\mathrm{Na}^{+}\right) 283.0763 \mathrm{~m} / \mathrm{z}$, found $283.0756 \mathrm{~m} / \mathrm{z}$, mass error of $2.47 \mathrm{ppm}$ due to difference of $0.0007 \mathrm{~m} / \mathrm{z}$. 


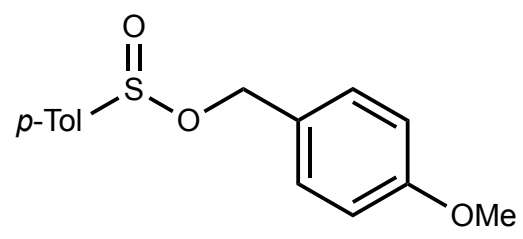

\section{Compound 37f}

Crude product was purified by flash column chromatography (Hx: EtOAc, 70:30 Rf=0.47). The resulting product was diluted with DCM $(60 \mathrm{~mL})$ washed with $1 \mathrm{M} \mathrm{NaOH}(2 * 20 \mathrm{~mL})$, Brine $(20$ $\mathrm{mL})$, dried with $\mathrm{MgSO} 4$, filtered, and concentrated via reduced pressure to yield $0.596 \mathrm{~g} \mathrm{(61 \% )} \mathrm{of}$ the title compound as a clear and yellow liquid.

Characterization: ${ }^{1} \mathrm{H}$ NMR (400 $\left.\mathrm{MHz} \mathrm{CDCl}_{3}\right): \delta 2.4(\mathrm{~s}, 3 \mathrm{H}), 3.8(\mathrm{~s}, 3 \mathrm{H}), 4.5(\mathrm{~d}, J=11.09 \mathrm{~Hz}, 1 \mathrm{H})$, $4.59(\mathrm{~d}, J=11.09 \mathrm{~Hz}, 1 \mathrm{H}), 6.8-6.9(\mathrm{~m}, 2 \mathrm{H}), 7.1-7.2(\mathrm{~m}, 2 \mathrm{H}), 7.3-7.4(\mathrm{~m}, 2 \mathrm{H}), 7.61-7.63(\mathrm{~m}, 2 \mathrm{H})$ ppm.

${ }^{13} \mathrm{C}$ NMR $\left(100 \mathrm{MHz} \mathrm{CDCl}_{3}\right): \delta 21.4,55.1,65.5,113.9,125.2,127.5,129.6,130.2,141.7,142.6$ ppm.

IR (neat): 699, 724, 809, $1127 \mathrm{v}$.

ESI-MS for $\mathrm{C}_{15} \mathrm{H}_{16} \mathrm{O}_{3} \mathrm{SNa}$ : Calculated $\left(\mathrm{M}+\mathrm{Na}^{+}\right) 299.0712 \mathrm{~m} / \mathrm{z}$, found $299.0706 \mathrm{~m} / \mathrm{z}$, mass error of $2.01 \mathrm{ppm}$ due to difference of $0.0006 \mathrm{~m} / \mathrm{z}$. 


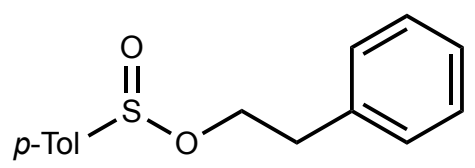

\section{Compound 37g}

Crude product was purified by flash column chromatography (Hx: EtOAc, 70:30 Rf=0.47). The resulting product was diluted with DCM $(60 \mathrm{~mL})$ washed with $1 \mathrm{M} \mathrm{NaOH}(2 * 20 \mathrm{~mL})$, Brine $(20$ $\mathrm{mL})$, dried with MgSO4, filtered, and concentrated via reduced pressure to yield $0.491 \mathrm{~g}(59 \%)$ of the title compound as a clear and colorless liquid.

Characterization: ${ }^{1} \mathrm{H}$ NMR (400 $\left.\mathrm{MHz} \mathrm{CDCl}_{3}\right)$ : $\delta 2.4(\mathrm{~s}, 3 \mathrm{H}), 2.8-2.9(\mathrm{~m}, 2 \mathrm{H}), 3.7-3.8(\mathrm{~m}, 1 \mathrm{H}), 4.1$ $4.2(\mathrm{~m}, 1 \mathrm{H}), 7.13-7.15(\mathrm{~m}, 2 \mathrm{H}), 7.2-7.3(\mathrm{~m}, 2 \mathrm{H}), 7.3(\mathrm{~d}, J=8.19 \mathrm{~Hz}, 2 \mathrm{H}), 7.5(\mathrm{~d}, J=8.19 \mathrm{~Hz}, 2 \mathrm{H})$ ppm.

${ }^{13} \mathrm{C} \mathrm{NMR}\left(100 \mathrm{MHz} \mathrm{CDCl}_{3}\right): \delta 21.5,36.3,64.7,125.2,126.6,128.5,128.9,129.6,137.3,141.6$, $142.6 \mathrm{ppm}$.

IR (neat): 724.82, 809, $1129 \mathrm{v}$.

HRMS ESI for $\mathrm{C}_{15} \mathrm{H}_{16} \mathrm{O}_{3} \mathrm{SNa}$ : Calculated $\left(\mathrm{M}+\mathrm{Na}^{+}\right) 283.0763 \mathrm{~m} / \mathrm{z}$, found $283.0758 \mathrm{~m} / \mathrm{z}$, mass error of $1.76 \mathrm{ppm}$ due to difference of 0.0005 . 


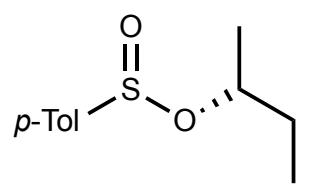

\section{Compound 37h}

Crude product was purified by flash column chromatography (Hx: EtOAc, 90:10 Rf=0.49. The resulting product was diluted with $\mathrm{DCM}(60 \mathrm{~mL})$ washed with $1 \mathrm{M} \mathrm{NaOH}(2 * 20 \mathrm{~mL})$, Brine $(20$ $\mathrm{mL})$, dried with $\mathrm{MgSO} 4$, filtered, and concentrated via reduced pressure to yield $0.367 \mathrm{~g}(54 \%)$ of the title compound as a clear and colorless liquid.

Characterization: ${ }^{1} \mathrm{H}$ NMR (400 MHz $\left.\mathrm{CDCl}_{3}\right): \delta 0.8(\mathrm{t}, J=7.44 \mathrm{~Hz}, 3 \mathrm{H}), 0.9(\mathrm{t}, J=7.44 \mathrm{~Hz}, 3 \mathrm{H})$, $1.2(\mathrm{~d}, J=6.32 \mathrm{~Hz}, 3 \mathrm{H}), 1.3(\mathrm{~d}, J=6.24 \mathrm{~Hz}, 3 \mathrm{H}), 1.5-1.7(\mathrm{~m}, 5 \mathrm{H}), 2.4(\mathrm{~s}, 6 \mathrm{H}), 4.3-4.4(\mathrm{~m}, 2 \mathrm{H})$, $7.3(\mathrm{~d}, J=8.11 \mathrm{~Hz}, 4 \mathrm{H}), 7.5-7.6(\mathrm{~m}, 4 \mathrm{H}) \mathrm{ppm}$.

${ }^{13} \mathrm{C}$ NMR (100 $\left.\mathrm{MHz} \mathrm{CDCl}_{3}\right): \delta$ 9.0, 9.2, 20.9, 21.0, 29.7, 30.1, 77.0, 77.2, 124.4, 124.5, 129.1, $141.9,141.9,142.5,142.6 \mathrm{ppm}$.

IR (neat): 730, 808, $1129 \mathrm{v}$.

HRMS ESI for $\mathrm{C}_{11} \mathrm{H}_{16} \mathrm{O}_{2} \mathrm{SNa}$ : Calculated $\left(\mathrm{M}+\mathrm{Na}^{+}\right) 235.0763 \mathrm{~m} / \mathrm{z}$ found $235.0769 \mathrm{~m} / \mathrm{z}$, mass error of $2.55 \mathrm{ppm}$ due to difference of $0.0006 \mathrm{~m} / \mathrm{z}$. 


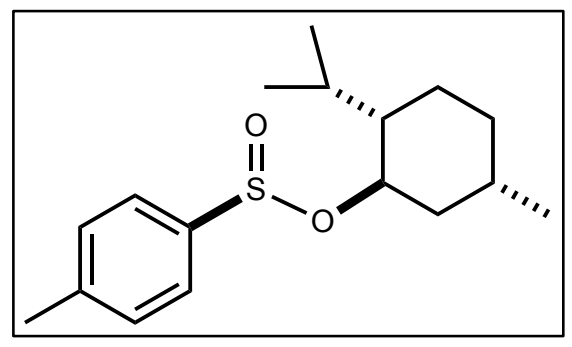

\section{Compound 37i}

Crude product was purified by flash column chromatography (Hx: EtOAc, 80:20 Rf=0.61). The resulting product was diluted with $\mathrm{DCM}(60 \mathrm{~mL})$ washed with $1 \mathrm{M} \mathrm{NaOH}(2 * 20 \mathrm{~mL})$, Brine $(20$ $\mathrm{mL})$, dried with $\mathrm{MgSO} 4$, filtered, and concentrated via reduced pressure to yield $0.626 \mathrm{~g}(66 \%)$ of the title compound as a white solid.

Characterization: ${ }^{1} \mathrm{H}$ NMR $\left(400 \mathrm{MHz} \mathrm{CDCl}_{3}\right): \delta$ 0.7-0.7 (m, 1H), 1.0-1.5 (m, 5H) 2.1-2.2 (m, 2H), 2.3-3.3 (m, 3H) 4.1-4.2 (m, 1H), $7.33(\mathrm{~d}, J=8.05 \mathrm{~Hz}, 2 \mathrm{H}) 7.61(\mathrm{~d}, J=8.05 \mathrm{~Hz}, 2 \mathrm{H}) \mathrm{ppm}$.

${ }^{13} \mathrm{C} \mathrm{NMR}\left(100 \mathrm{MHz} \mathrm{CDCl}_{3}\right): \delta 20.9,21.4,21.5,21.8,22.0,22.1,23.0,23.1,23.1,15.1,15.4,25.8$, 31.61, 31.7, 31.8, 33.9, 34.0, 34.5, 42.9, 43.5, 45.0, 47.8, 48.2, 50.1, 71.4, 80.0, 81.9, 124. 4, 124. $9,129.5,142.3,142.4,143.2,143.3 \mathrm{ppm}$.

IR (neat): 2947, 2919, $1130.83 v$. 
HRMS ESI for $\mathrm{C}_{17} \mathrm{H}_{2} \mathrm{O}_{2} \mathrm{SNa}$ : Calculated $\left(\mathrm{M}+\mathrm{Na}^{+}\right) 317.1546 \mathrm{~m} / \mathrm{z}$, found $317.1538 \mathrm{~m} / \mathrm{z}$, mass error of $2.52 \mathrm{ppm}$ due to a difference of $0.0008 \mathrm{~m} / \mathrm{z}$.

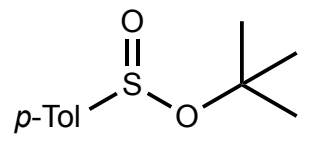

\section{Compound 37j}

Crude product was purified by flash column chromatography (Hx: EtOAc, 90:10 Rf=0.28). The resulting product was diluted with $\mathrm{DCM}(60 \mathrm{~mL})$ washed with $1 \mathrm{M} \mathrm{NaOH}(2 * 20 \mathrm{~mL})$, Brine $(20$ $\mathrm{mL}$ ), dried with $\mathrm{MgSO} 4$, filtered, and concentrated via reduced pressure to yield $14 \%$ of the title compound, as determined by ${ }^{1} \mathrm{H}$ NMR spectra analysis of the crude 50:50 diastereomeric mixture. Characterization: ${ }^{1} \mathrm{H}$ NMR (500 $\left.\mathrm{MHz} \mathrm{CDCl}_{3}\right): \delta 1.5(\mathrm{~s}, 9 \mathrm{H}), 2.4(\mathrm{~s}, 3 \mathrm{H}), 2.4(\mathrm{~s}, 3 \mathrm{H}) 3.7(\mathrm{~s}, 3 \mathrm{H})$, 6.7-6.8 (m, 2H), 6.9-7.0 (m, 2H), 7.2-7.3 (m, 4H), 7.5-7.6 (m, 2H), 7.6-7.7 (m, 2H) ppm. 
APPENDIX B: SELECTED NMR SPECTRA 


\section{${ }^{1} \mathrm{H}$ NMR (500 MHz) bromo-phenoxysulfinate ester (35a) in $\mathrm{CDCl}_{3}$}

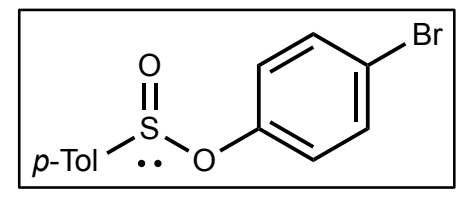

$35 \mathbf{a}$

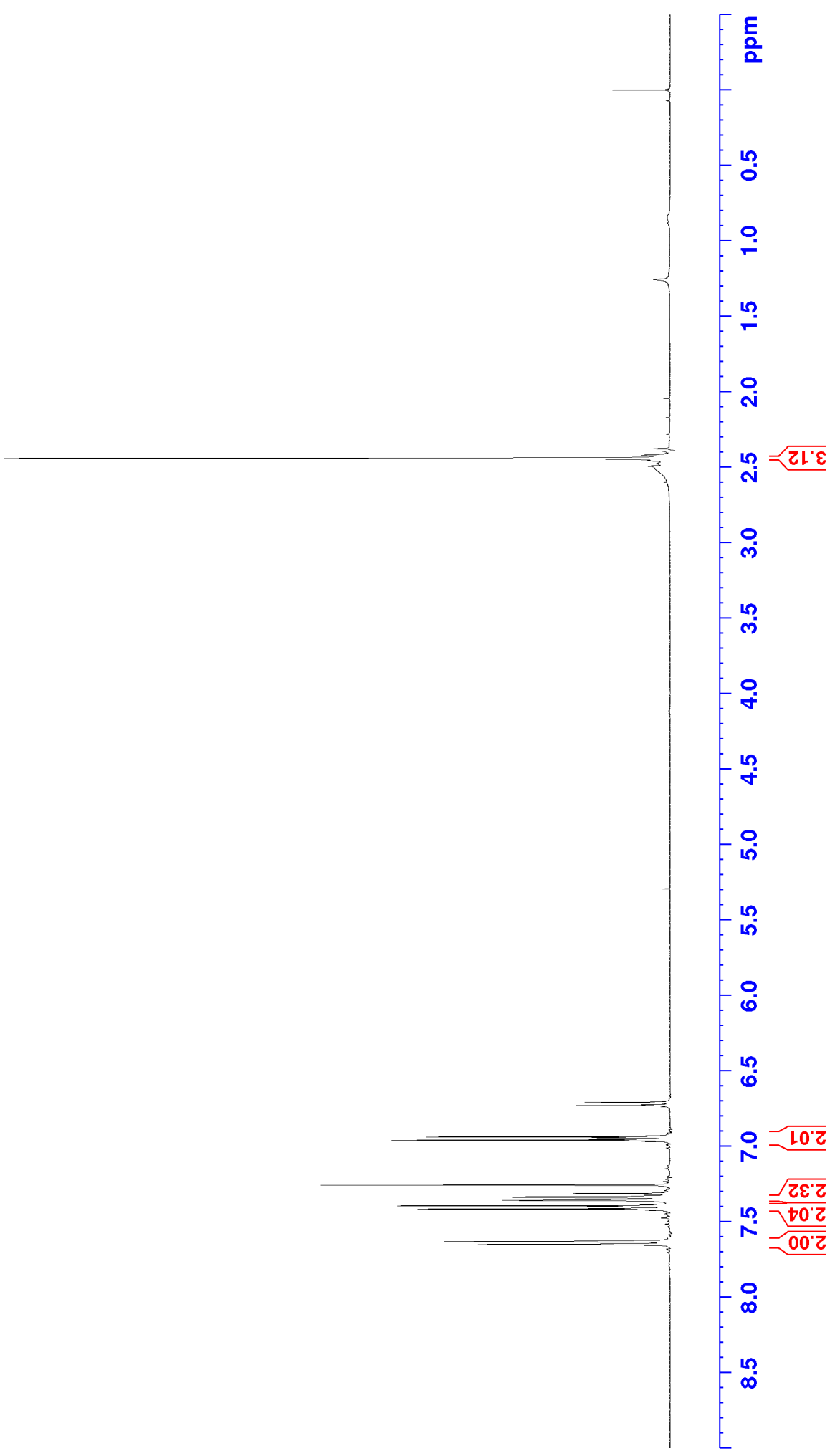




\section{${ }^{1} \mathrm{H}$ NMR (500 MHz) tert-butyl-phenoxysulfinate ester (35b) in $\mathrm{CDCl}_{3}$}

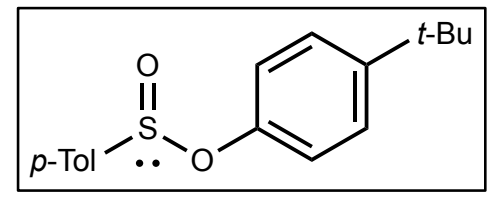

$35 b$
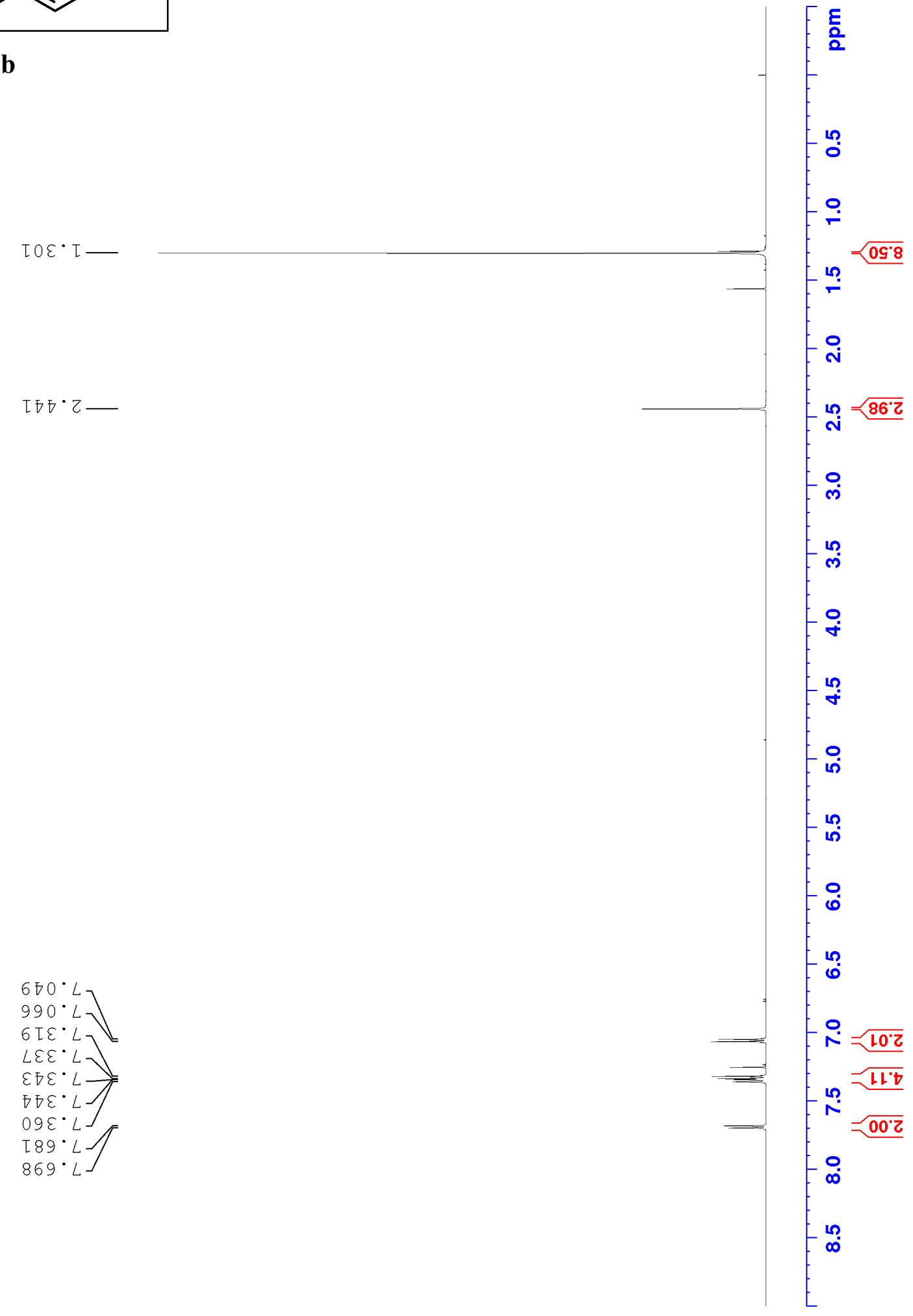
${ }^{13} \mathrm{C}$ NMR (125 MHz) tert-butyl-phenoxysulfinate ester (35b) in $\mathrm{CDCl}_{3}$

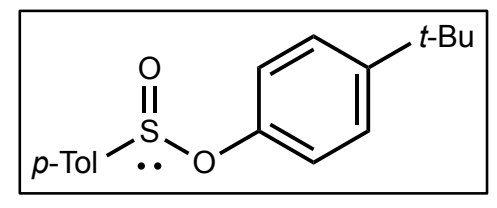

$35 \mathbf{b}$

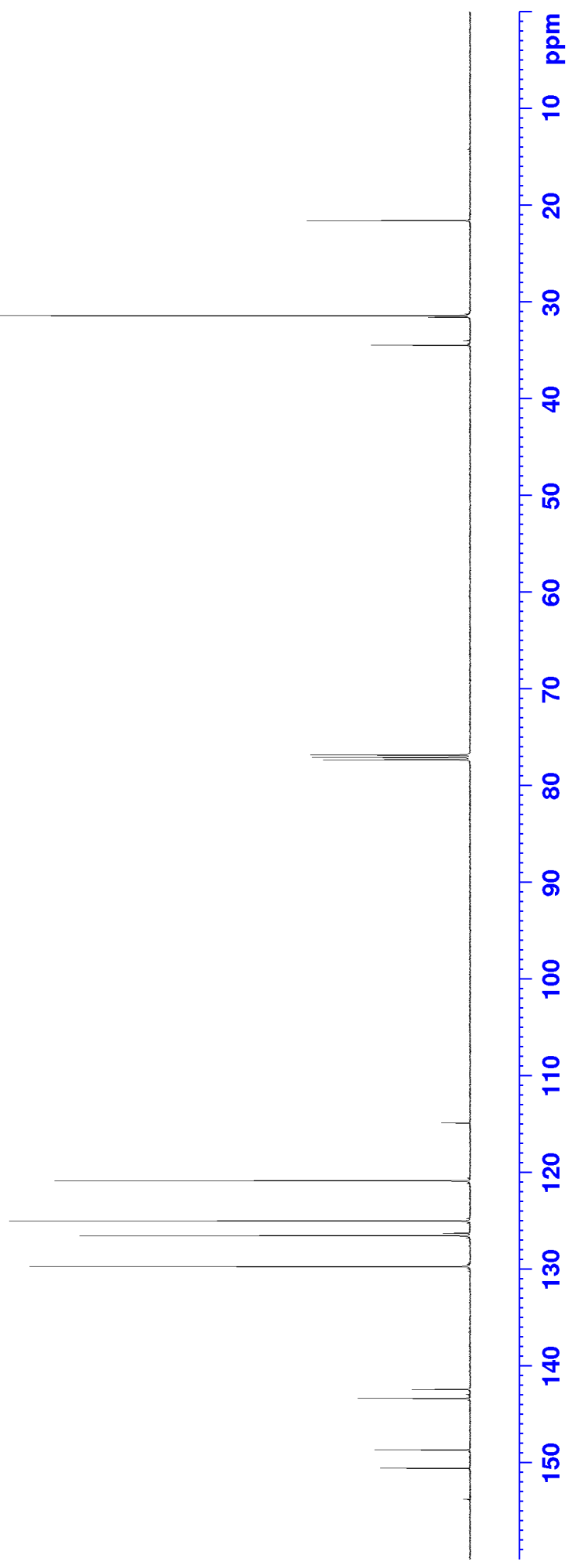


${ }^{1} \mathrm{H}$ NMR (500 MHz) methoxy-phenoxysulfinate ester (35c) in $\mathrm{CDCl}_{3}$

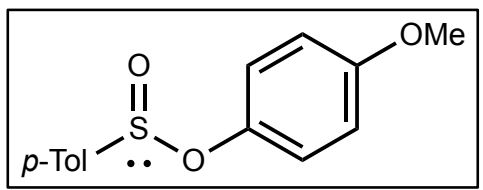

$35 c$
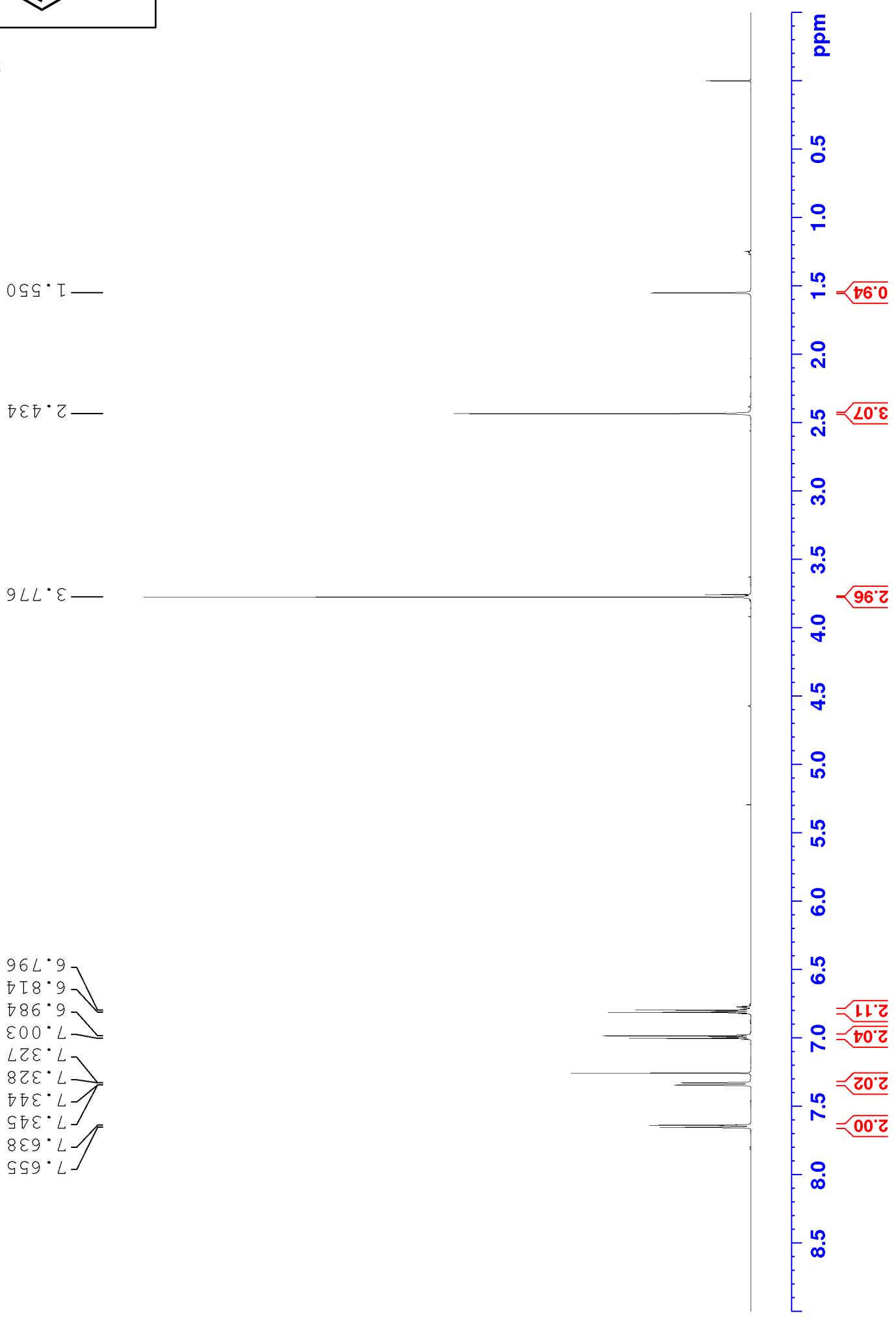
${ }^{13} \mathrm{C}$ NMR (125 MHz) methoxy-phenoxysulfinate ester (35c) in $\mathrm{CDCl}_{3}$

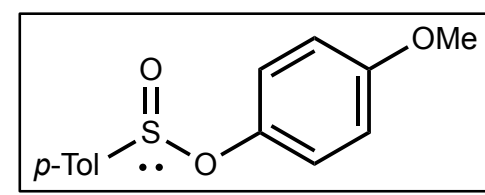

$35 c$

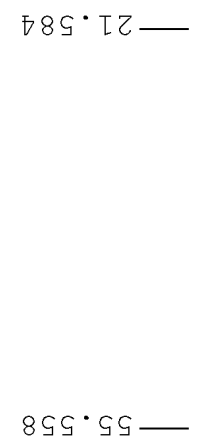

$S \nabla G^{\cdot} \nabla \tau$

$990^{\circ} \varepsilon Z \tau$

$0 \varepsilon 0^{\circ} \mathrm{SZT}-$

$\angle 89^{\circ} 62 \mathrm{I}$

$\varepsilon \angle O^{\circ} 2 \sigma \tau$

$\varepsilon O E \cdot \varepsilon E T=$
$L L G \cdot \operatorname{STI}=$

D9D. LSI

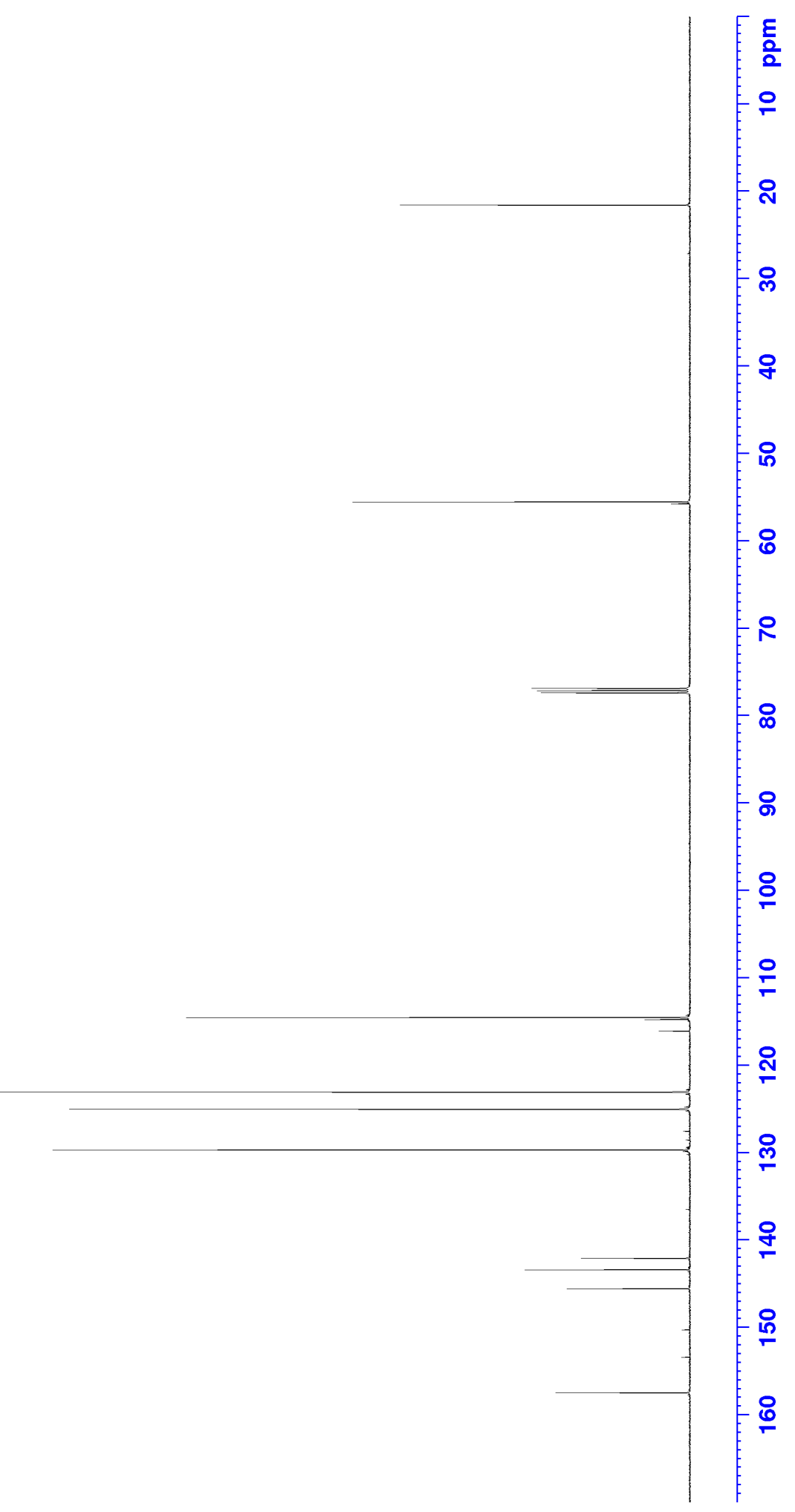


${ }^{1} \mathrm{H}$ NMR (400 MHz) 4-Nitrobenzyl-p-toluenesulfinate (37a) in $\mathrm{CDCl}_{3}$

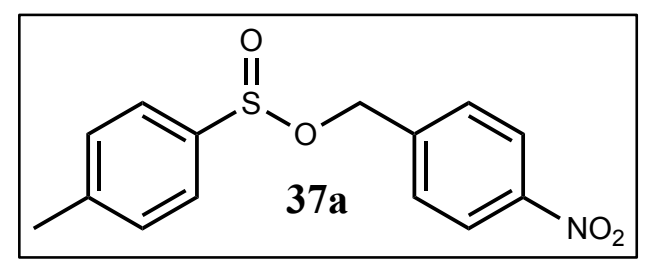

$\varepsilon 29 \cdot 0>$

$690 \cdot 9$

IOI.S

$S \mp S^{\cdot} \tau$

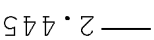

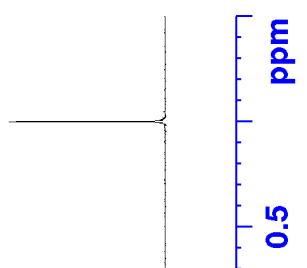

$\stackrel{9}{-}$

$\stackrel{n}{=0 t^{\prime \prime}}$
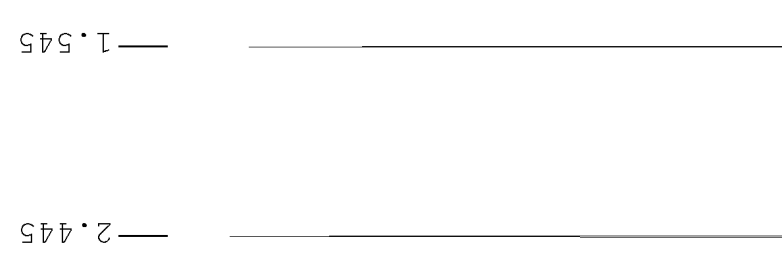

$\nabla \subseteq \varepsilon \cdot L$

$\overline{T L E} \cdot L$

$\varepsilon 乙 \nabla \cdot L$

与ाt・ $L$

ZE9 $299^{\circ}$

$\angle 9 I \cdot 8$

$68 \mathrm{I} \cdot \mathrm{=}$

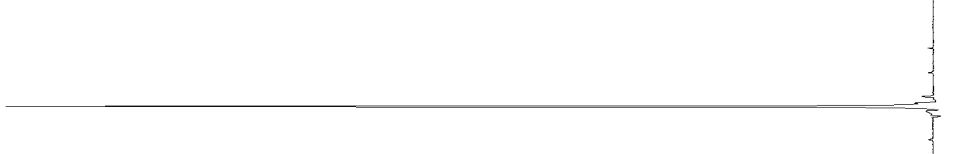

오

กา $\longdiv { 2 0 \% \varepsilon }$

웅

10

ल)

$\stackrel{\circ}{+}$

ㅇ?

$+\sqrt{66^{\circ} 0}$

○.

$=00.1$

10

in

0
-0

10
-6

웃

$\sqrt{86 " \mathrm{~L}}$

Lก $96^{\circ}$

NG6

$-\infty$

$\infty=\longdiv { 8 6 . t }$

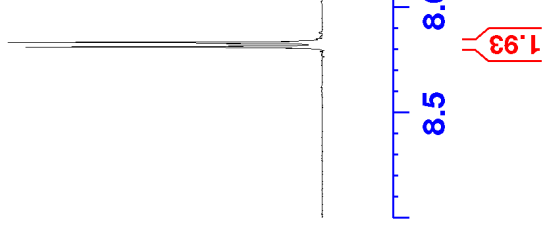


${ }^{13} \mathrm{C}$ NMR (100 MHz) 4-Nitrobenzyl-p-toluenesulfinate (37a) in $\mathrm{CDCl}_{3}$
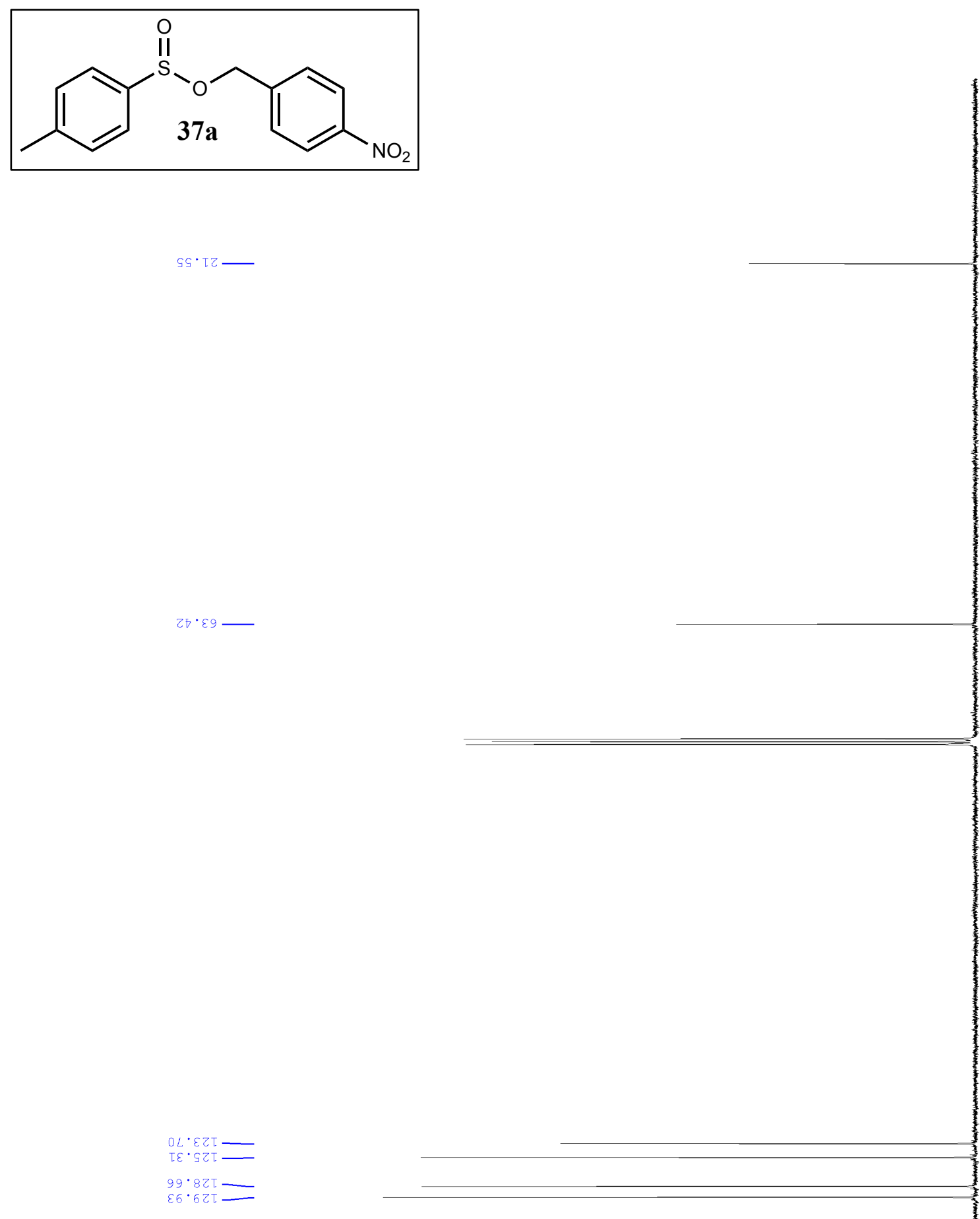

$99 \cdot 8 \mathrm{rT}=$
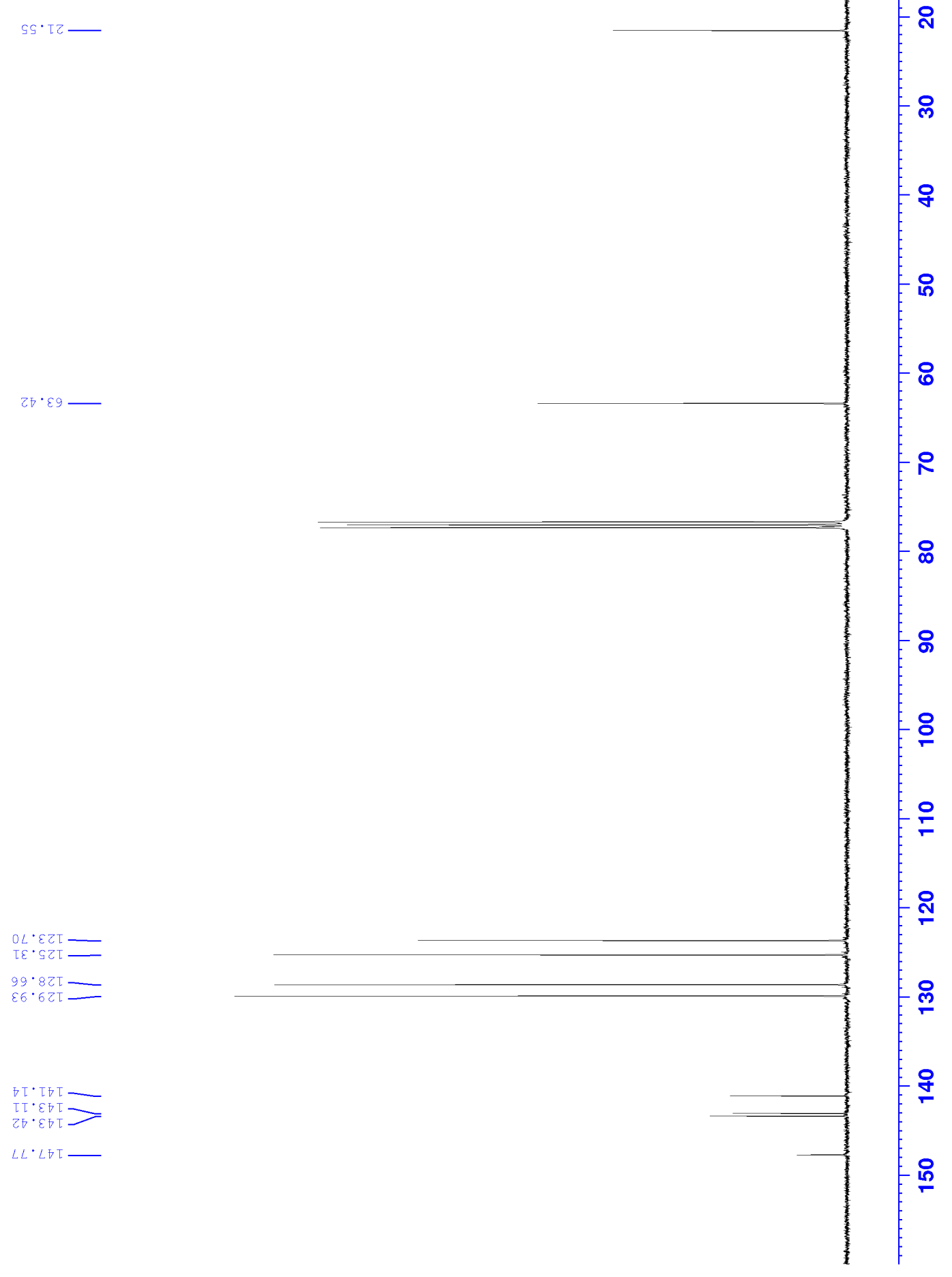
${ }^{1} \mathrm{H}$ NMR (400 MHz) 2-Chlorobenzyl-p-toluenesulfinate (37b) in $\mathrm{CDCl}_{3}$
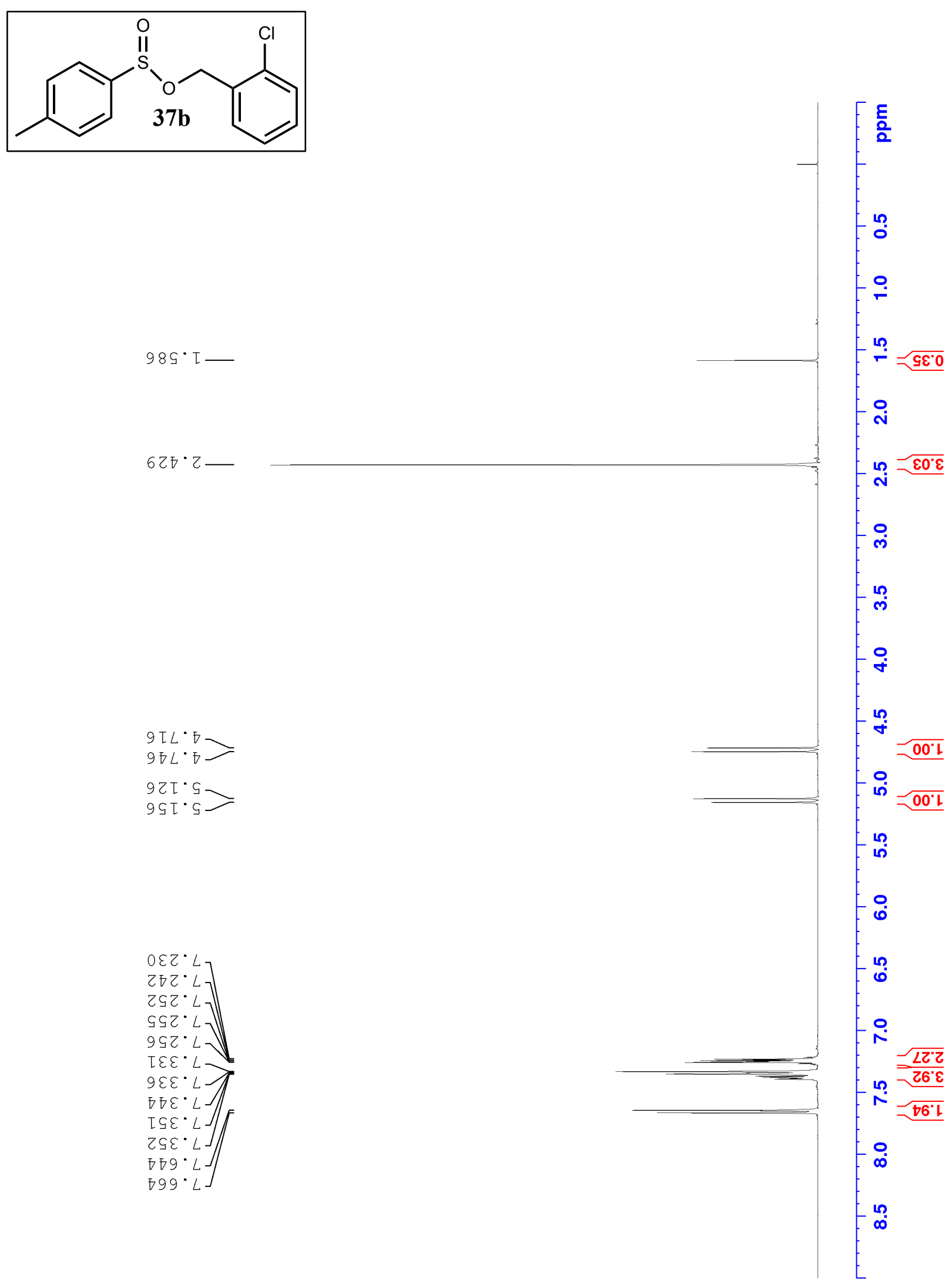
${ }^{13} \mathrm{C}$ NMR (100 MHz) 2-Chlorobenzyl-p-toluenesulfinate (37b) in $\mathrm{CDCl}_{3}$

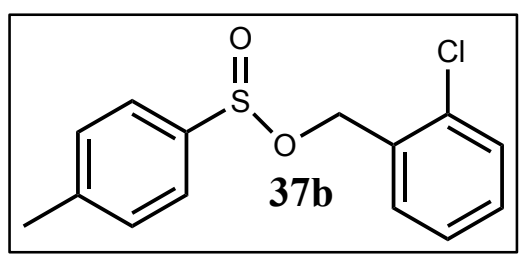

S97. [Z

$090 \cdot \varepsilon 9$

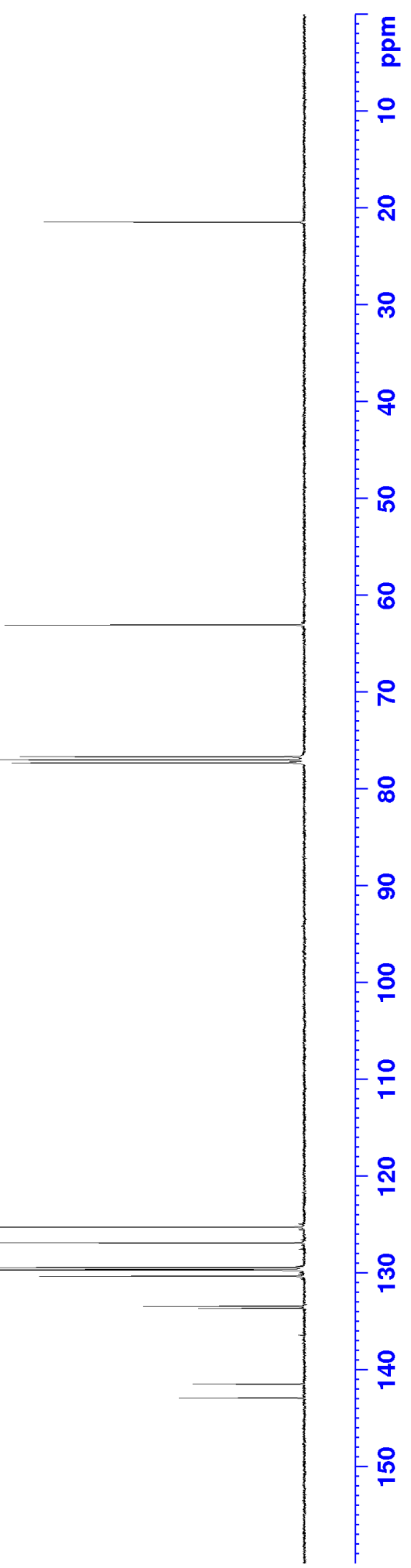


${ }^{1} \mathrm{H}$ NMR (400 MHz) 4-Chlorobenzyl-p-toluenesulfinate (37c) in $\mathrm{CDCl}_{3}$
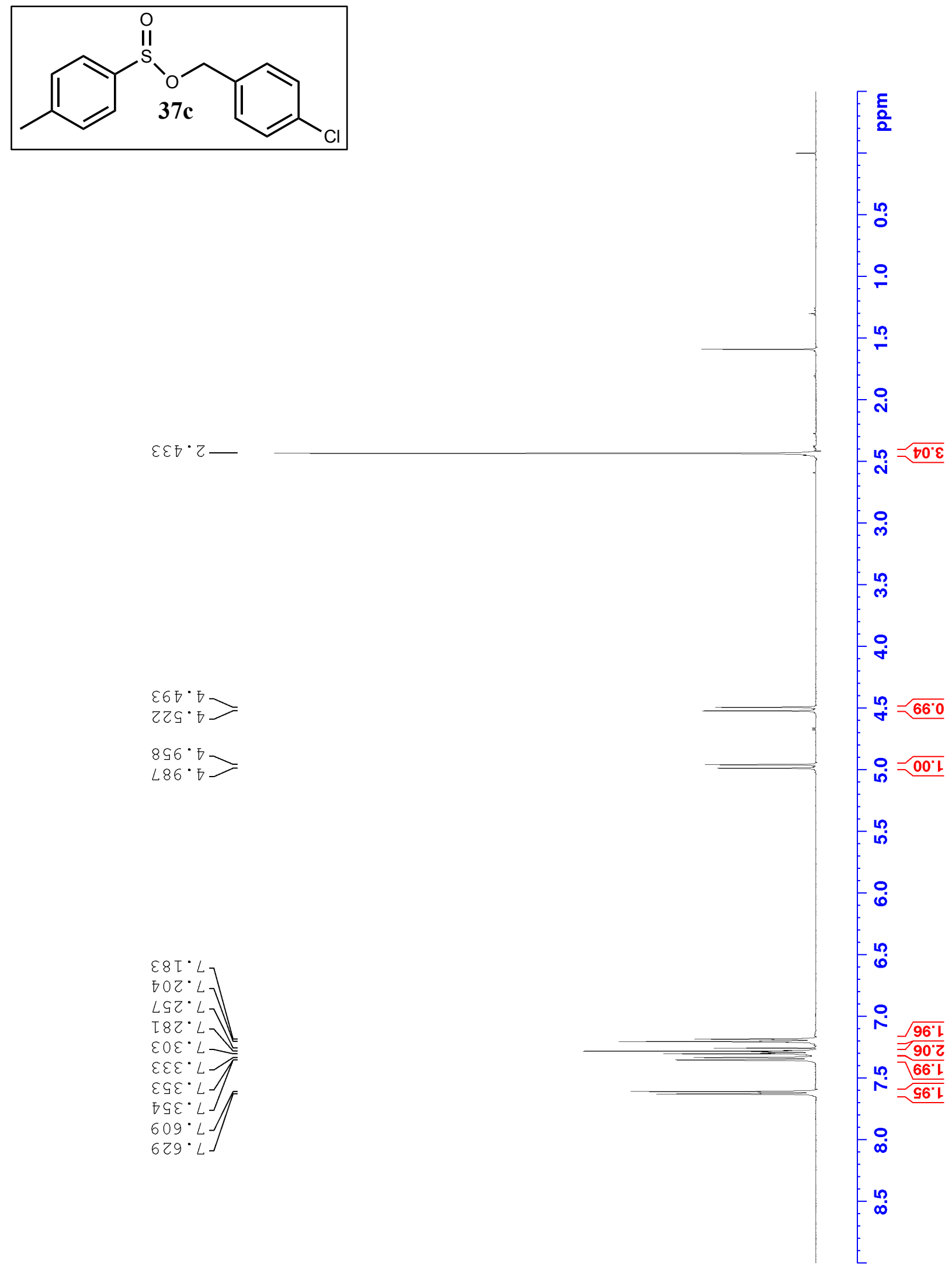
${ }^{13} \mathrm{C}$ NMR (100 MHz) 4-Chlorobenzyl-p-toluenesulfinate (37c) in $\mathrm{CDCl}_{3}$

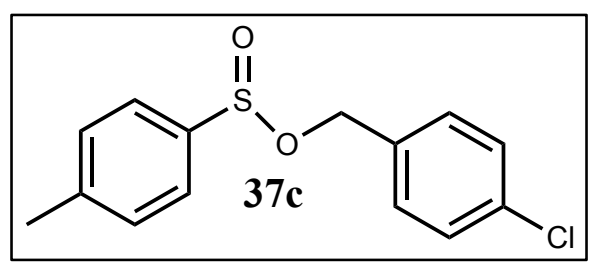

$9 \varepsilon \nabla \cdot[Z$

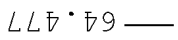

$\varsigma \varepsilon 乙 \cdot \varsigma 乙 \tau$

I $99 \cdot 8 Z \tau$

$\tau \varepsilon L \cdot 6 Z T>$

ZLL.6ZT

ง $0 \cdot 0 \varepsilon \tau \longrightarrow$

8๐乙・ธعโ

$66 \varepsilon \cdot \operatorname{tg}[$

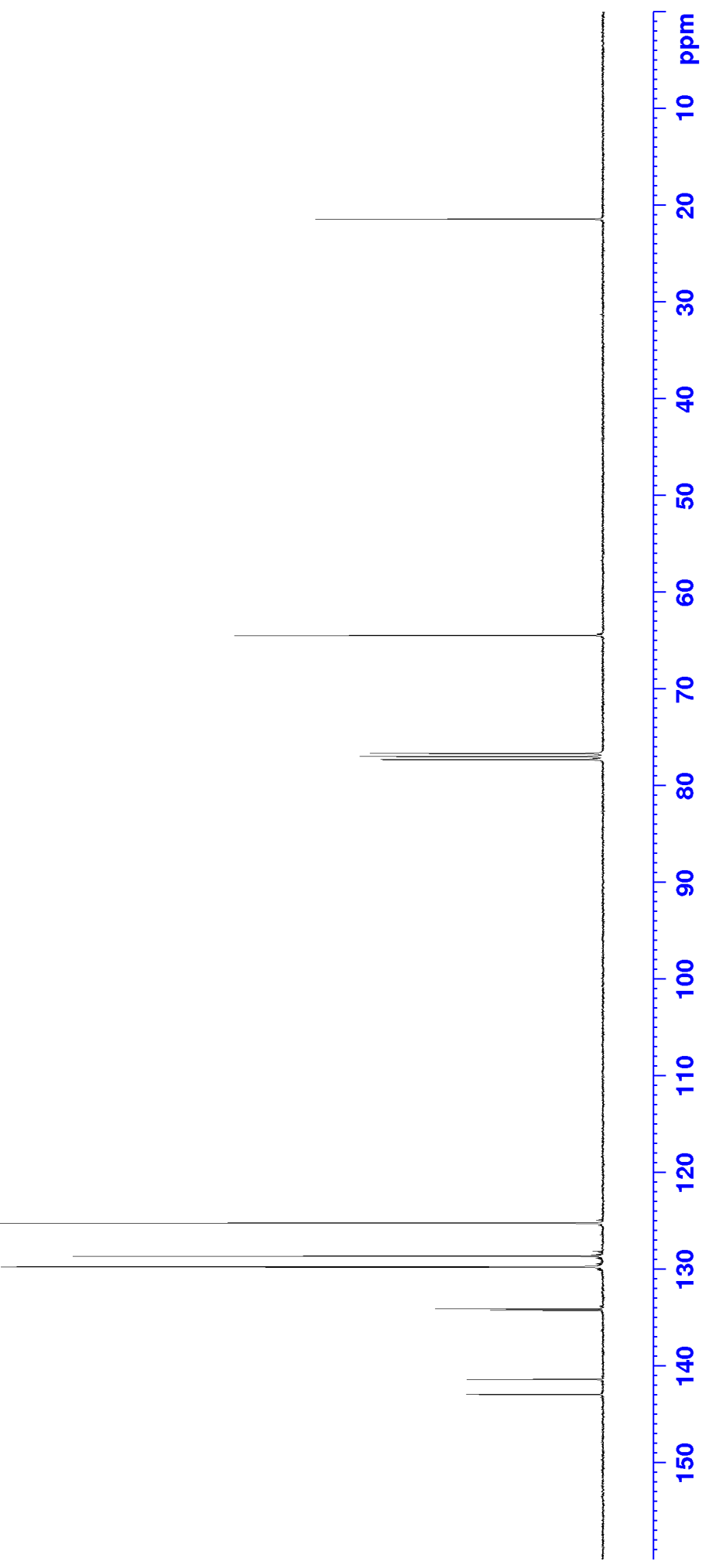


${ }^{1} \mathrm{H}$ NMR (400 MHz) 4-Bromobenzyl-p-toluenesulfinate (37d) in $\mathrm{CDCl}_{3}$
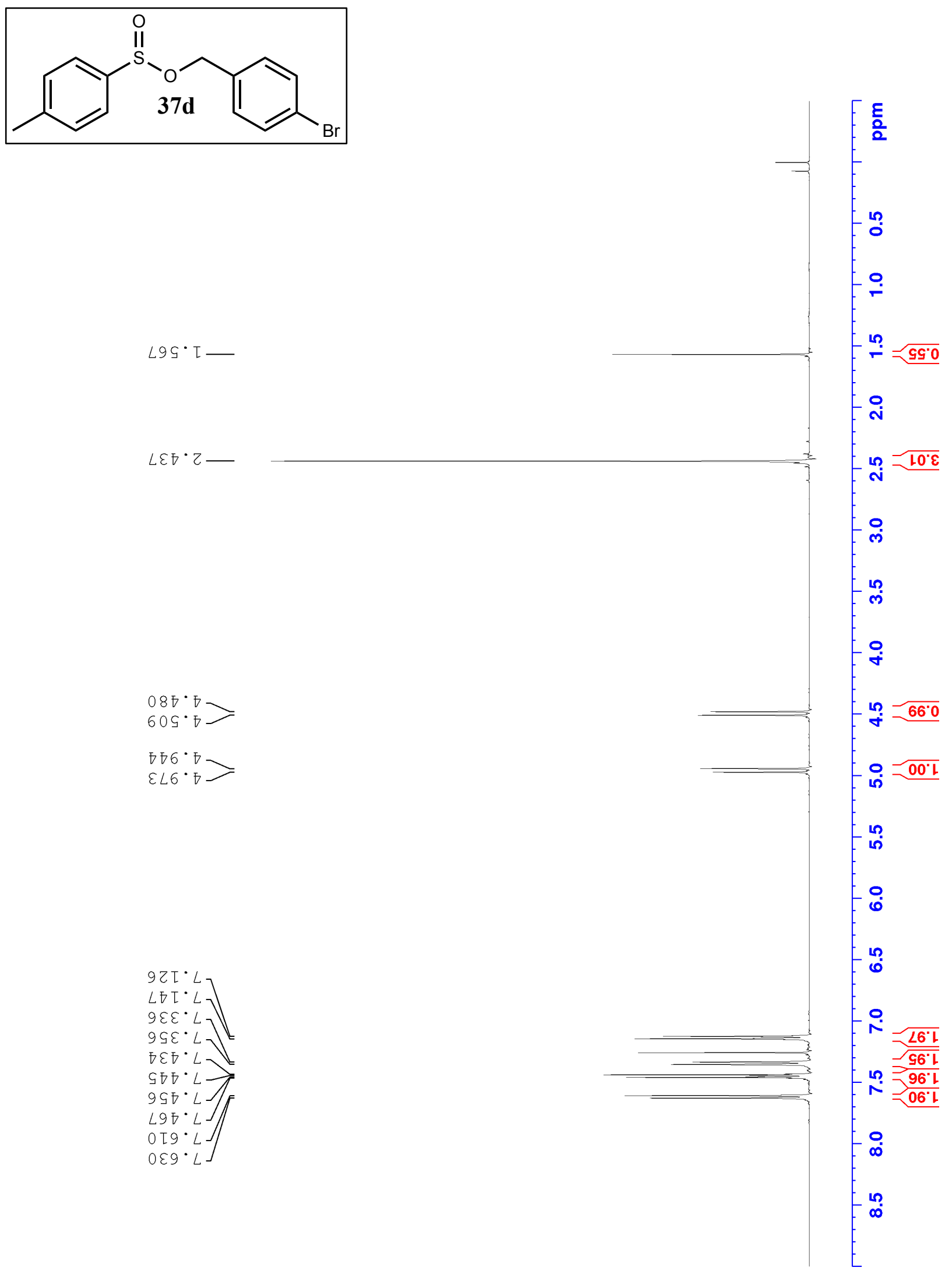
${ }^{13} \mathrm{C}$ NMR (100 MHz) 4-Bromobenzyl-p-toluenesulfinate (37d) in $\mathrm{CDCl}_{3}$

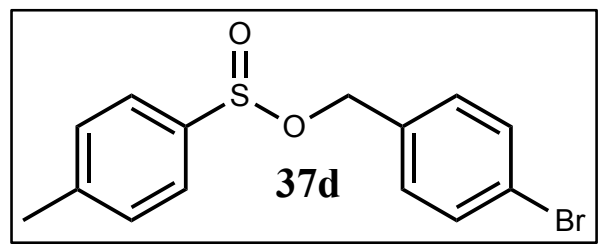

$\operatorname{IST} \cdot \operatorname{IZ}$

$987 \cdot 79$

$600 \cdot 2 Z T$

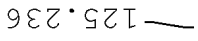

$S \varepsilon L \cdot 6 Z I$

$8 \nabla 0 \cdot 0 \varepsilon[$

$\bar{\tau}\left[9^{\cdot}[\varepsilon[\tau\right.$

$\varepsilon[9 \cdot \nabla \varepsilon[-$

$98 \varepsilon^{\circ}$ It

$096^{\circ} 27 \mathrm{~L}$

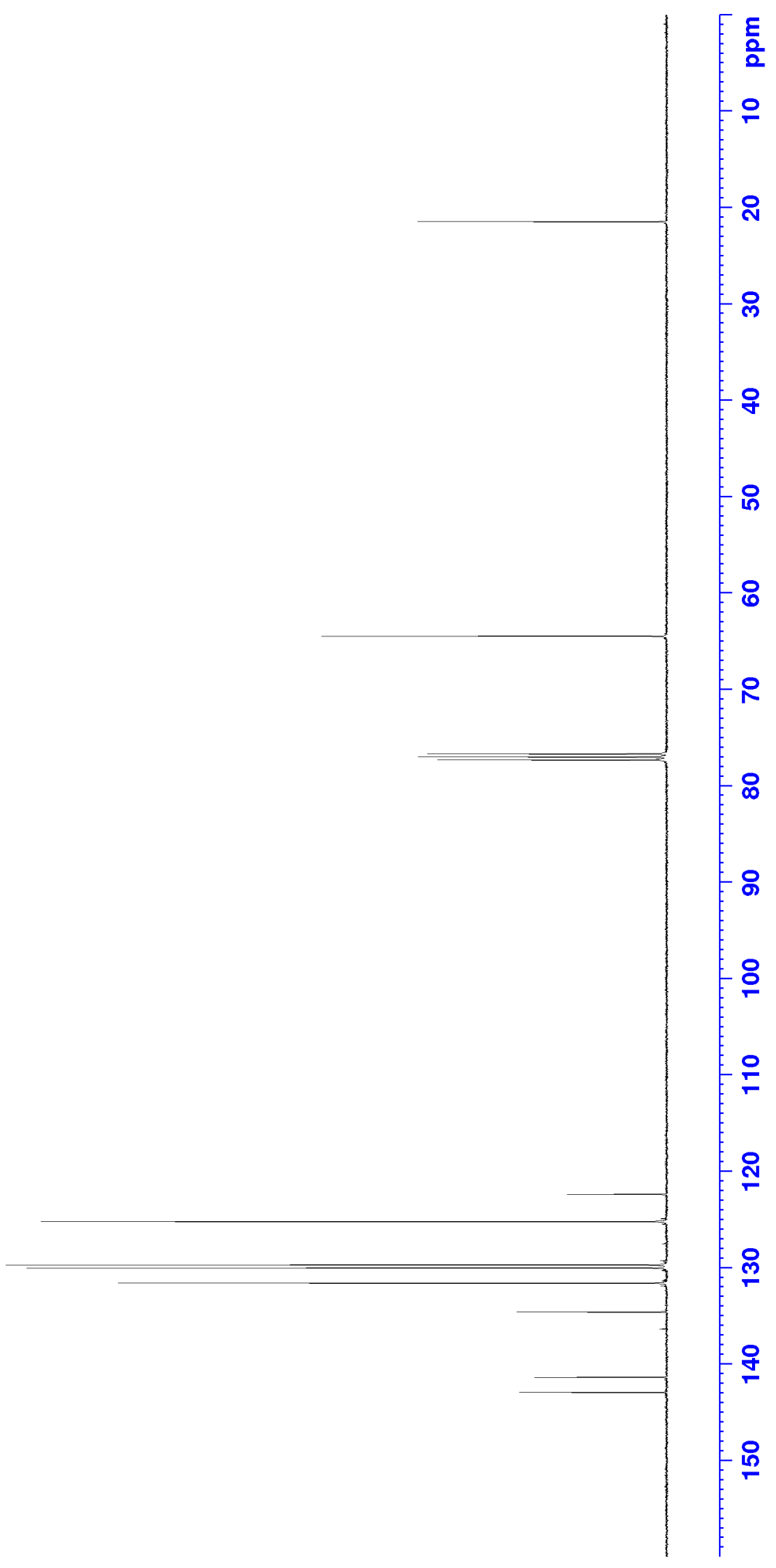


${ }^{1} \mathrm{H}$ NMR (400 MHz) 4-Methylbenzyl-p-toluenesulfinate (37e) in $\mathrm{CDCl}_{3}$
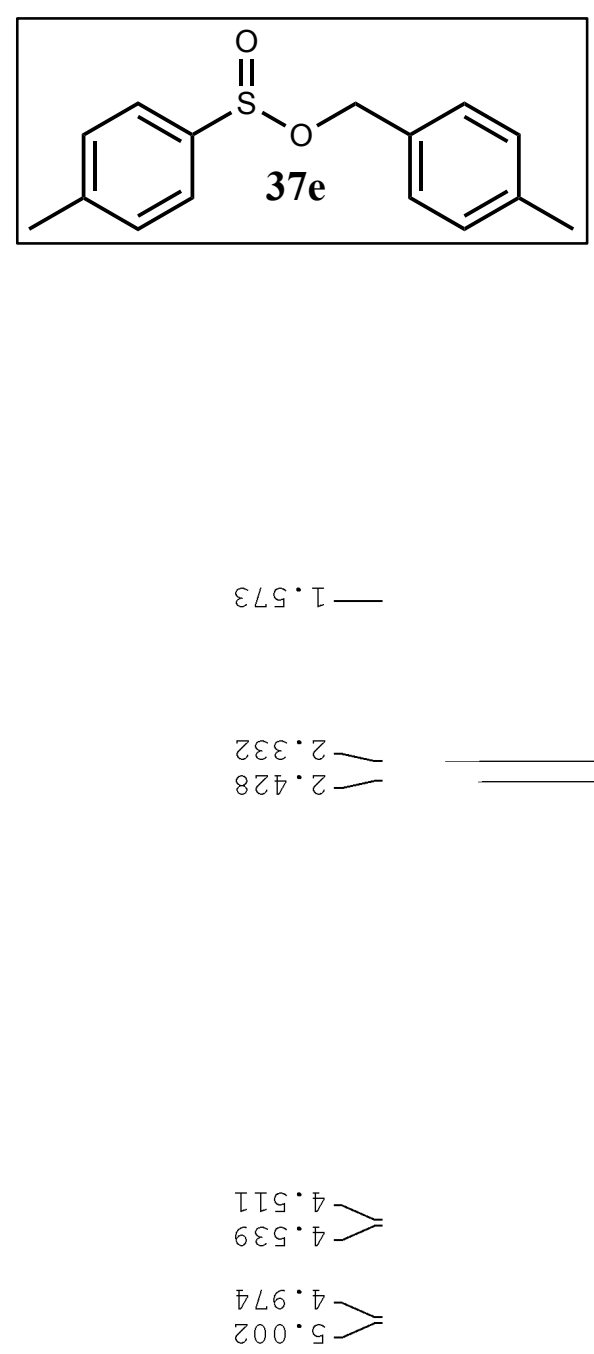

ZZT・L

$\left.\begin{array}{l}\operatorname{Z\nabla }[\cdot L] \\ \operatorname{\nabla G}[\cdot]\end{array}\right]$

$69 I \cdot L$

DLI $L$

$\subseteq Z \varepsilon \cdot L J$

$\triangle \mp \varepsilon^{\circ}\llcorner J$

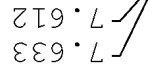
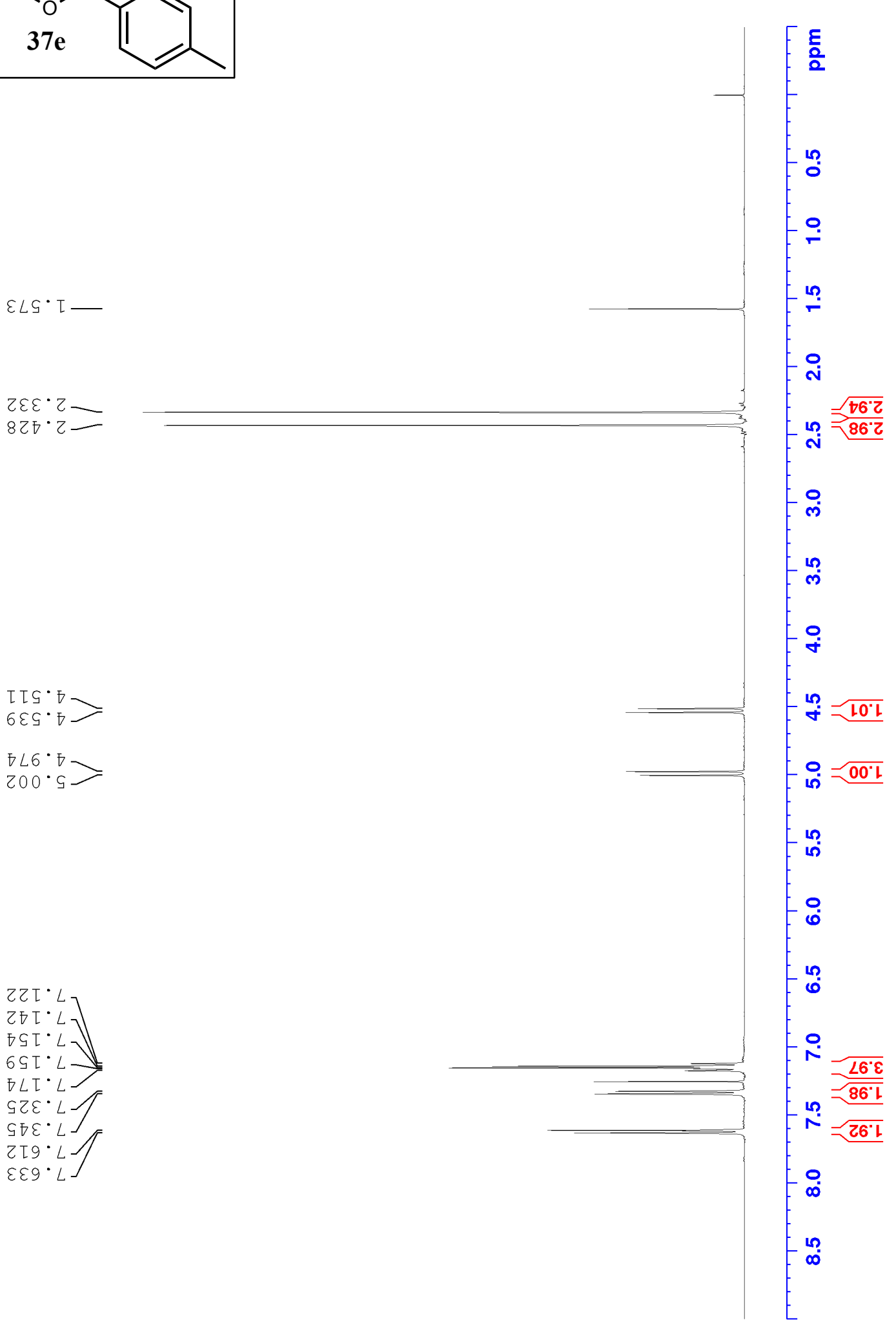


\section{${ }^{13} \mathrm{C}$ NMR (100 MHz) 4-Methylbenzyl-p-toluenesulfinate (37e) in $\mathrm{CDCl}_{3}$}
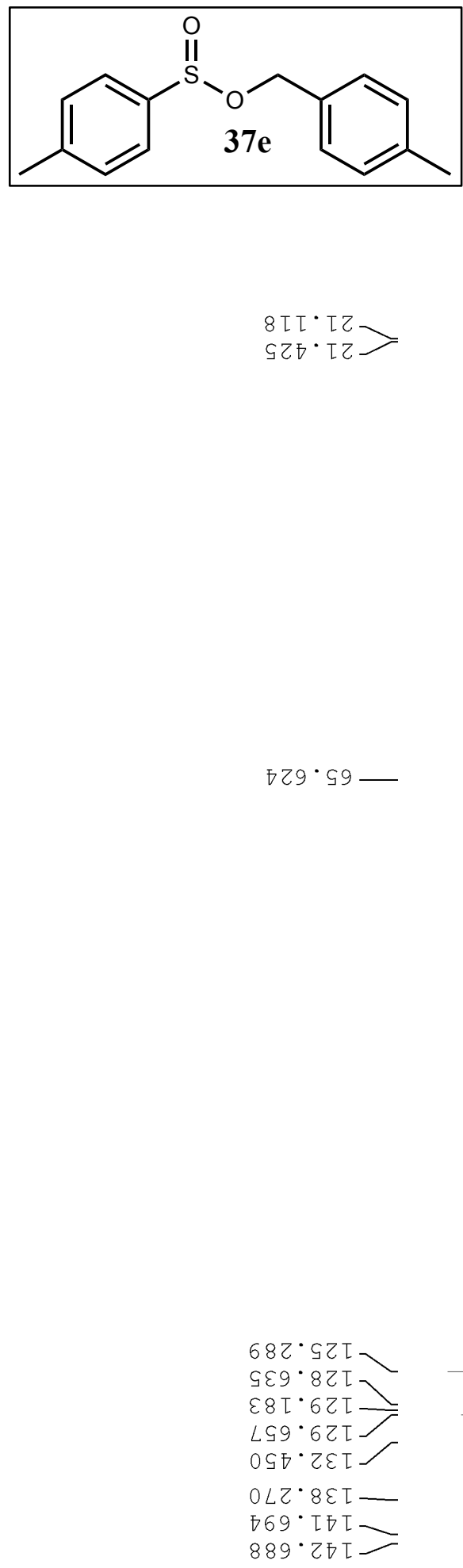

$729 \cdot 99$

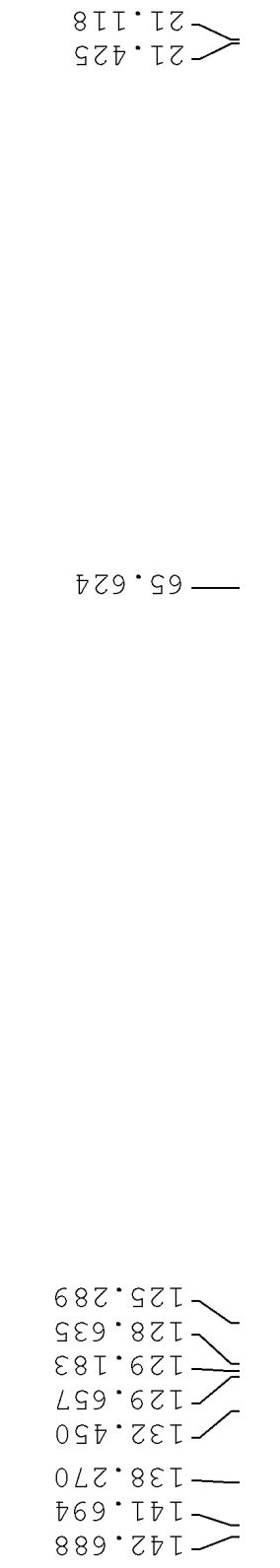

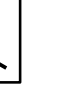
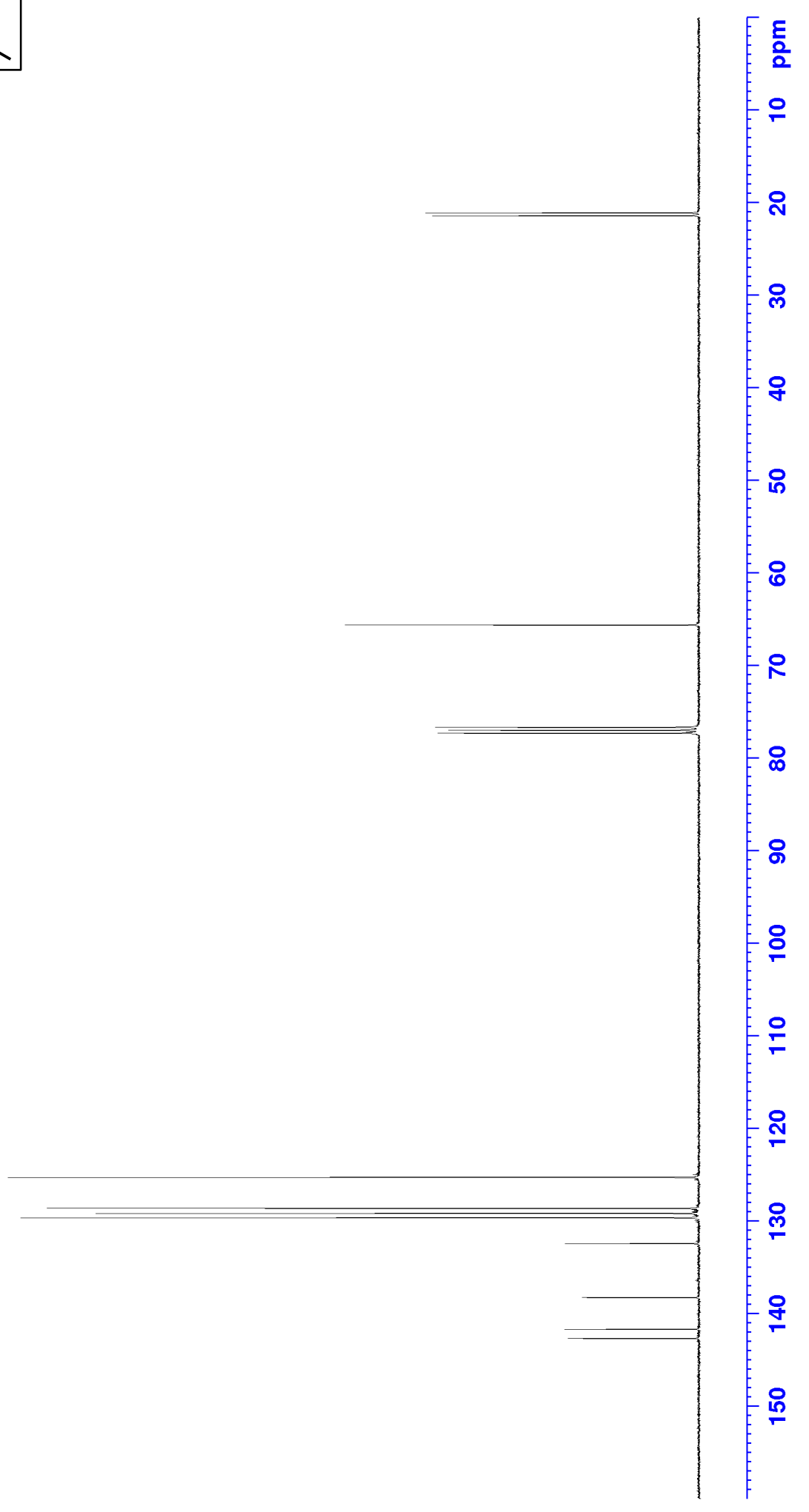
${ }^{1} \mathrm{H}$ NMR (400 MHz) 4-Methoxylbenzyl-p-toluenesulfinate (37f) in $\mathrm{CDCl}_{3}$

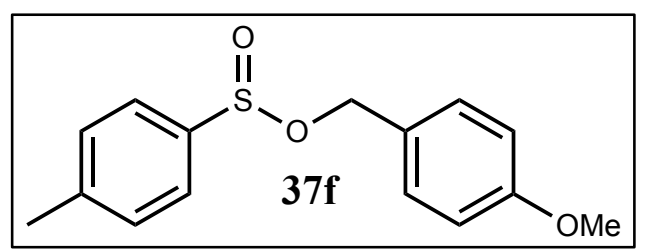

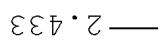

958.9

$898^{\circ}$.

I6 I' $L$

$2[2 \cdot L 】$

$6 Z \varepsilon \cdot L \bar{T}$

I $29 \cdot 1 \mathrm{~L} \cdot \mathrm{T}$

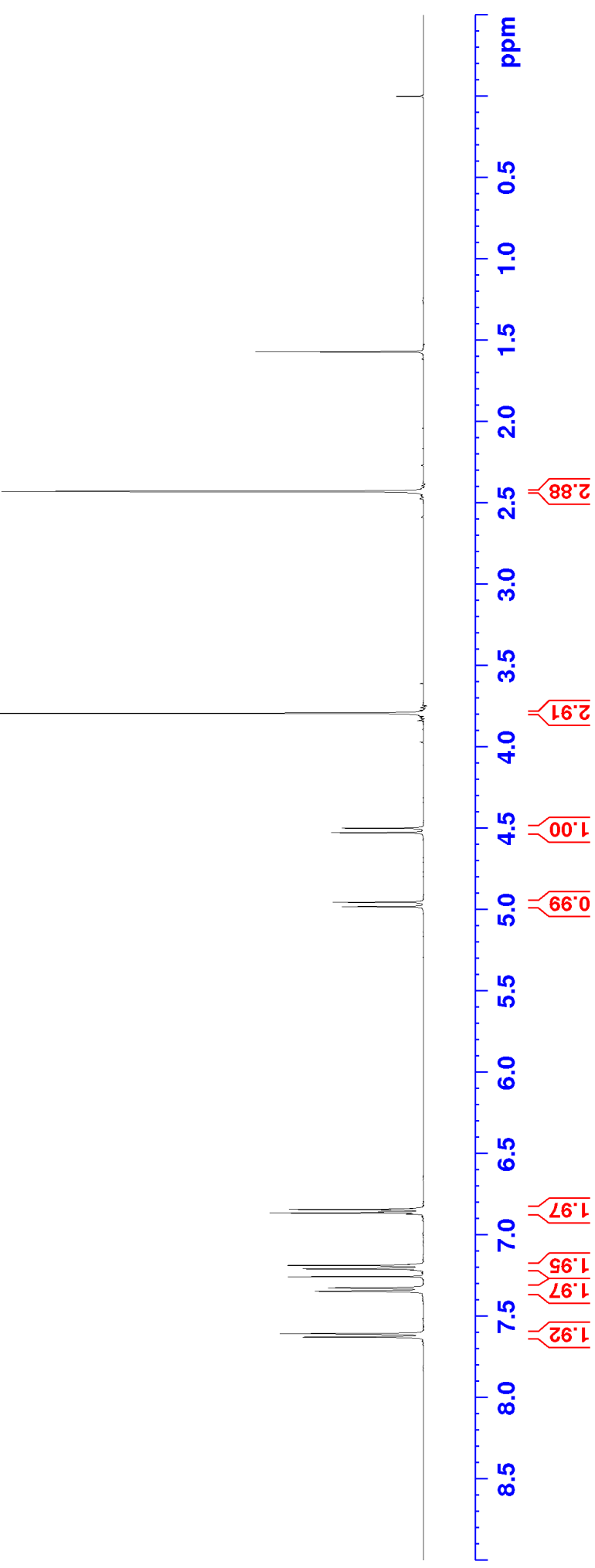


${ }^{13} \mathrm{C}$ NMR (100 MHz) 4-Methoxylbenzyl-p-toluenesulfinate (37f) in $\mathrm{CDCl}_{3}$

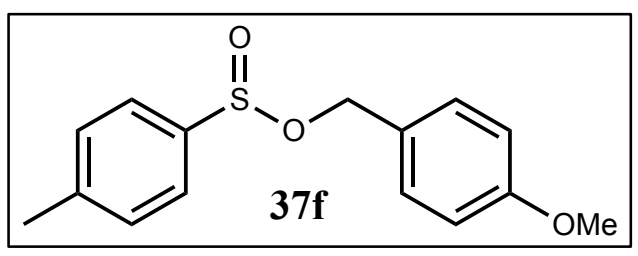

$90 \sigma^{\circ} \tau 2$

$69 I \cdot 99$

ISS. S9

$\varpi \tau \sigma^{*} \varepsilon \tau \tau$

$\angle S Z \cdot S Z T$

$96 \sigma^{\circ} \angle Z T=$

$079 \cdot 62 \mathrm{~T} \frac{-}{\gamma}$

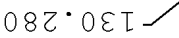

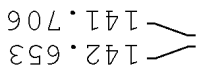

Me

틍

으

ำ

오

우

요

8

오

임

ㅇ

움

$=\frac{1}{5}$

오

요

움

옴

ESL·6SI -

8 
${ }^{1} \mathrm{H}$ NMR (400 MHz) 4-Ethylyphenylbenzyl-p-toluenesulfinate (37g) in $\mathrm{CDCl}_{3}$
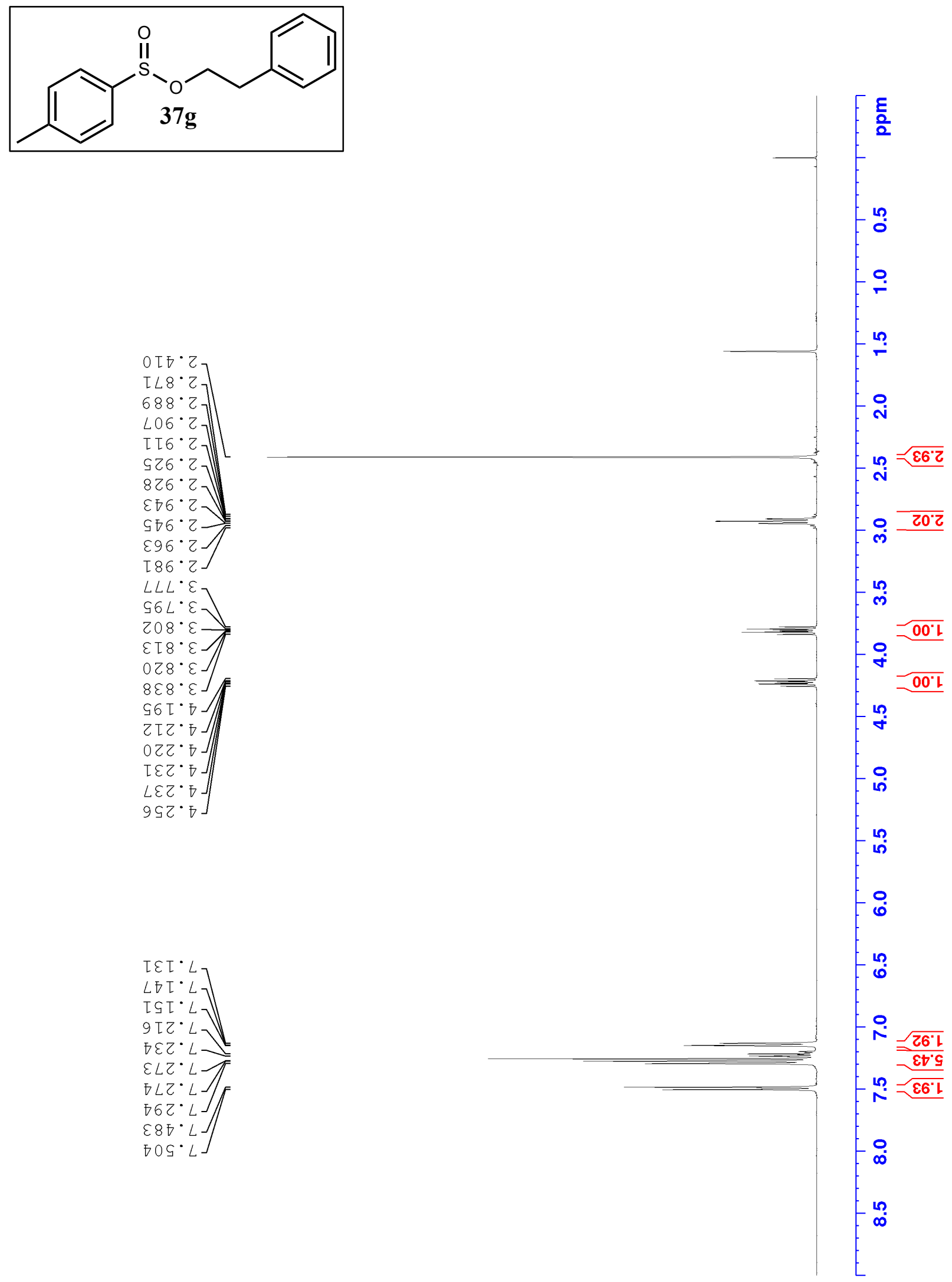
${ }^{13} \mathrm{C}$ NMR (100 MHz) 4-Ethylyphenylbenzyl-p-toluenesulfinate (37g) in $\mathrm{CDCl}_{3}$

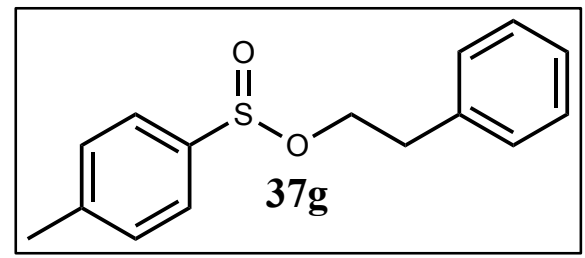

SOS $T Z$

$\varepsilon \tau \varepsilon \cdot 9 \varepsilon-$

ZLL・E9-

$[9 z \cdot 92 T$

$\angle 69 \cdot 9 z T$

$909 \cdot 8 Z T$

$586 \cdot 82 \tau$

$6 \angle 9 \cdot 62[$

Z๐E $L \varepsilon T-$

$\operatorname{sig} \cdot \operatorname{tg} T$

OL9.2DI

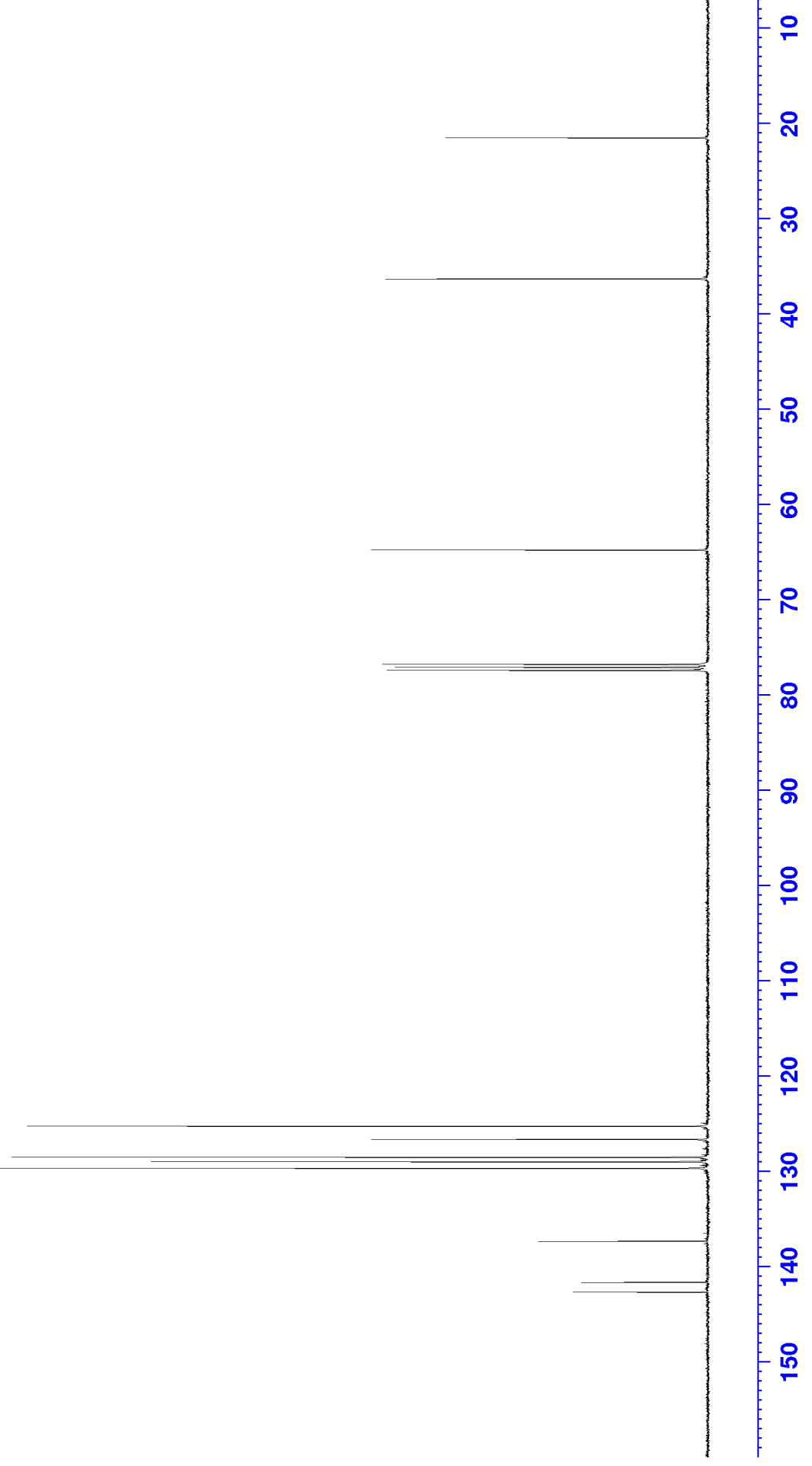


${ }^{1} \mathrm{H}$ NMR (400 MHz) Sec-butyl- $p$-toluenesulfinate (37h) in $\mathrm{CDCl}_{3}$

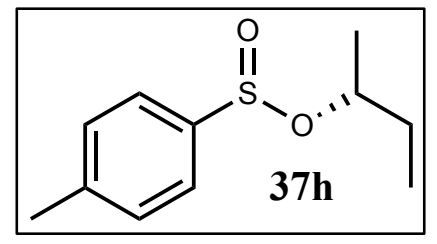

$568 \cdot 0$

$076^{\circ} 07$

$\left.896^{\circ} 0\right]$

$\angle L 6 \cdot 07$

$[Z 乙 \cdot[]$

$9 \varepsilon z \cdot[]$

$99 \varepsilon^{*}[\tau]$

$\left[8 \varepsilon^{\circ}[]\right.$

It $9^{\circ}[]$

$999^{\circ}[\sqrt{ }$

$699^{\circ} I \sqrt{ }$

$669^{\circ} \mathrm{L}-$

Zโg. [ I

$[\varepsilon 9 \cdot[]$

$\subseteq \varepsilon 9 \cdot[]$

$679^{\circ}[\mathrm{I}$

$\varepsilon 99^{\circ} \mathrm{I}$

$\left.899^{\circ} \mathrm{L}\right]$

$\left[89^{\circ} \mathrm{L}\right]$

$\left.869^{\circ} \mathrm{L}\right]$

$9\left[L^{\circ}[]\right.$

8โ哽

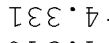

$9 \nabla \varepsilon \cdot \nabla$

29ع $\nabla$

$69 \varepsilon^{\circ} \sigma$

$\angle L \varepsilon^{\circ} T$

$\varsigma 8 \varepsilon \cdot \nabla-$

$\varepsilon \sigma \varepsilon^{\circ} \nabla$

$00 \sigma^{\circ}+$

$80 \sigma^{\circ} \sigma J$

9[万.

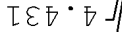

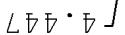
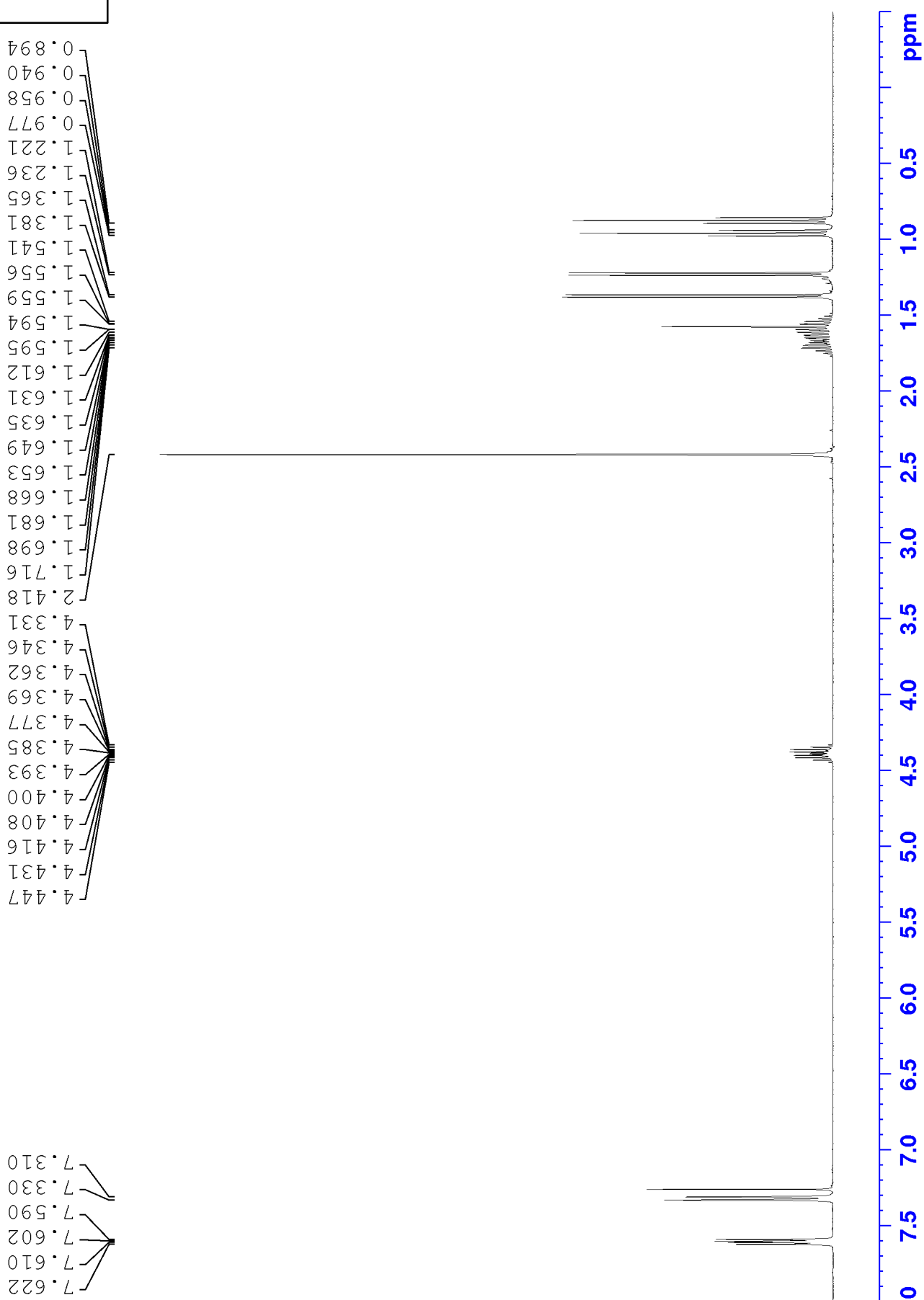

을

L?

$0 \longdiv { \mathrm { GZ } \varepsilon }$

$\stackrel{-}{\circ}$

$60^{\circ} \varepsilon$

เก

i

으 $=60^{\circ}$

N

웅

$\stackrel{10}{\infty}$

웅

$\dot{+}$

Ln $\overline{\varepsilon 0 " z}$

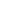

웅

in

in

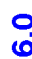

$\stackrel{4}{0}$

웃

r

농

$229^{\circ} \mathrm{L}$ 
${ }^{13} \mathrm{C}$ NMR (100 MHz) Sec-butyl-p-toluenesulfinate (37h) in $\mathrm{CDCl}_{3}$
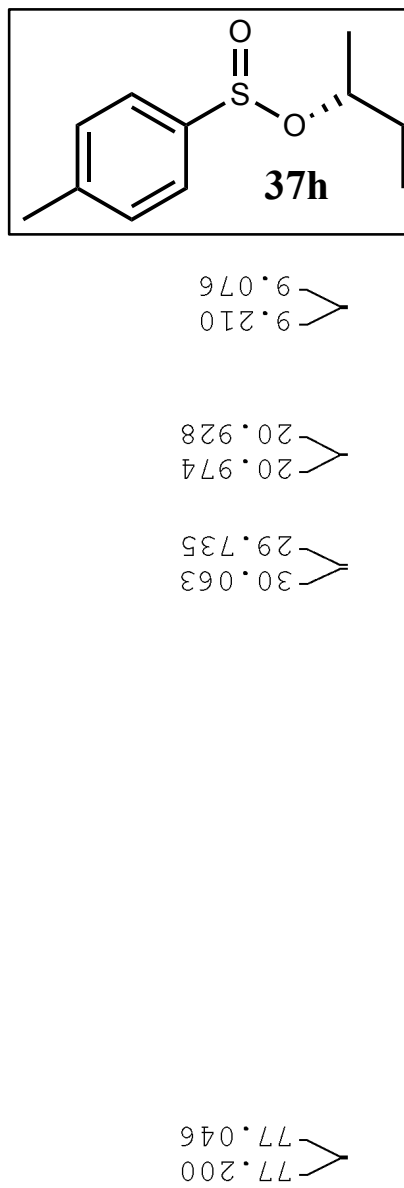

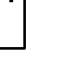

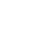$$
\text { . }
$$
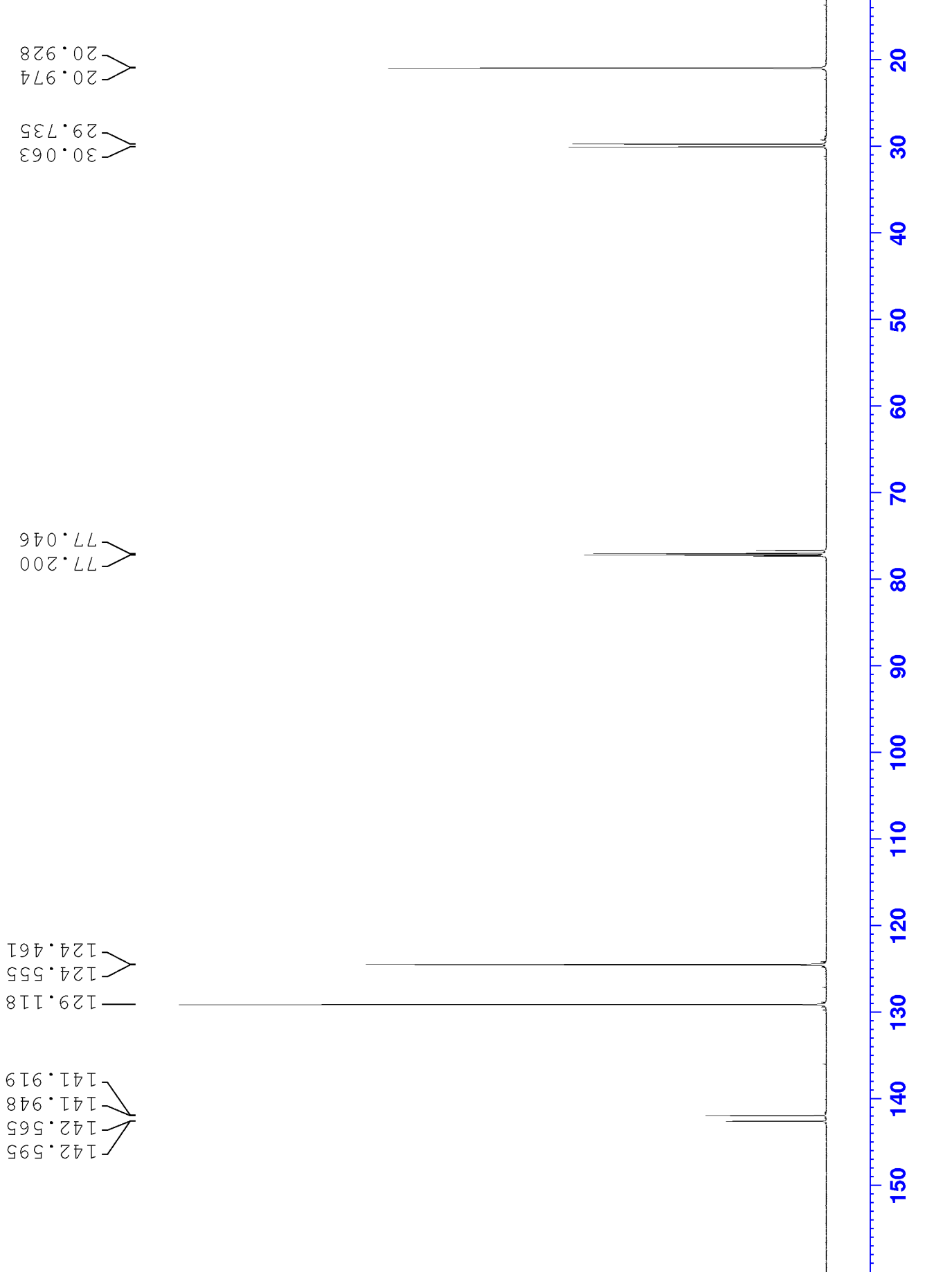


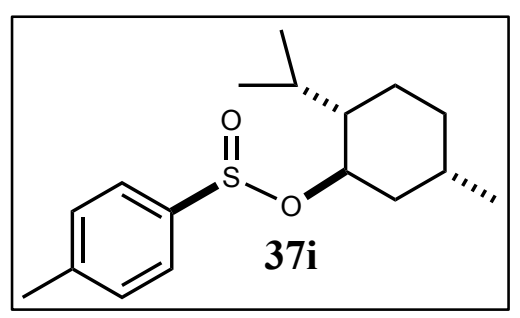

$80 L^{\circ} 0$ $S Z L^{\circ} 0$

[ซ 8.0$]$

$958^{\circ} 0$

$858^{\circ} 0$

$\varepsilon\left\llcorner 8^{\circ} 0\right.$ $\left[68^{\circ} 0\right.$ ㄴ

$168^{\circ} 0$

$2[6.0]$

256.0

$896^{\circ} 0 J$

GLI. [ ]

โ6 [ $\left.{ }^{\circ}\right]$

soz $[J$

$\mathrm{ZZ} \cdot[$

$\varepsilon \varepsilon \tau^{*}[]$

$0 \varsigma Z^{\circ}[]$

$292^{\circ}$ I

$G L Z^{\circ} \tau$

$\left.08 Z^{\circ} \tau\right]$

$699^{\circ} \mathrm{I}$

D $\angle 9^{\circ}$

IOL.

O乙T.

$8 \nabla \tau \cdot z$

万GI.

५ ${ }^{\circ} 乙$

$29 r^{\circ} \mathrm{z}$

$0 \angle z \cdot z-$

$98 z \cdot z-$

$\mathrm{Z} 6 \mathrm{Z}^{\circ} \mathrm{Z}$

$乙\left\llcorner\varepsilon^{\circ} \varepsilon\right.$

$8 \varepsilon \cdot \varepsilon-$

$\angle 6 \varepsilon \cdot \varepsilon$

$0 โ \overline{0} \cdot \varepsilon$

$\varepsilon 乙 \sigma^{\circ} \varepsilon$

बहि

$860^{\circ}$.

DIT.

SZI.

ODI.

ZST.

I9I.

$Z L I \cdot \sigma$

$88 I \cdot T-$

$66 I \cdot \sigma$

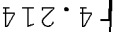

$9 Z 2 \cdot \tau]$

$80 \varepsilon^{\circ} L J$

$6 乙 \varepsilon^{\circ} L J$

$889^{\circ} L J$

$769^{\circ} \mathrm{L}$

$609^{\circ} L$

万[9 ${ }^{\circ} L$

\section{${ }^{1} \mathrm{H}$ NMR (400 MHz) Menthol-p-toluenesulfinate (37i) in $\mathrm{CDCl}_{3}$}

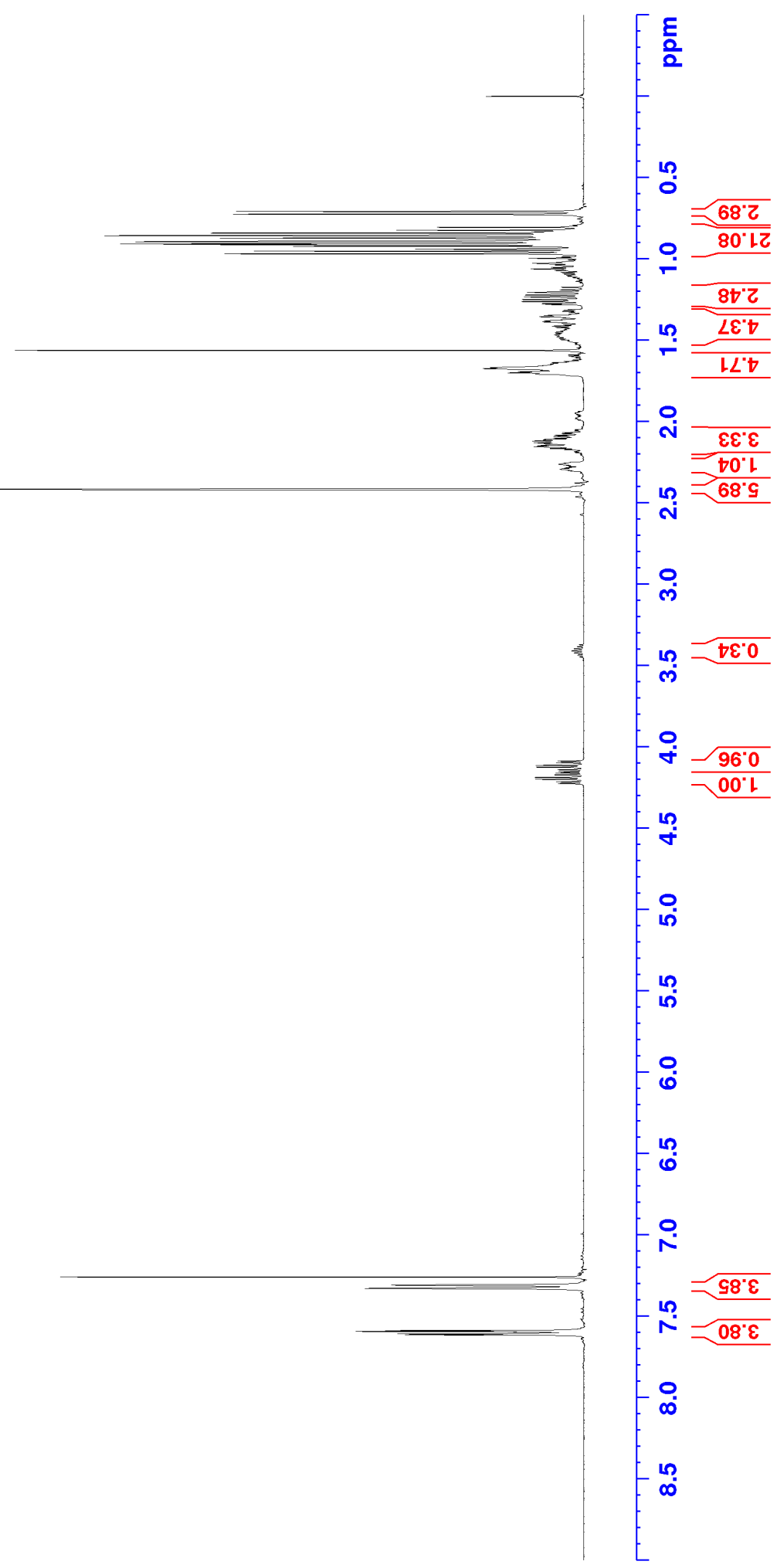




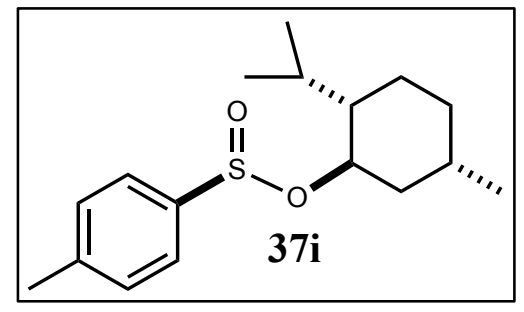

${ }^{13} \mathrm{C}$ NMR (100 MHz) Menthol-p-toluenesulfinate (37i) in $\mathrm{CDCl}_{3}$

$\varepsilon 96^{\circ} 02$

$\nabla \nabla \nabla \cdot[z]$

S95. [Z]

$888^{\circ}$ [Z]

$0 z 0^{\circ} z Z \sqrt{2}$

$\varepsilon L[\cdot Z Z]$

$\varepsilon \varepsilon 0 \cdot \varepsilon 乙$

$\varpi \tau[\varepsilon Z]$

$\varepsilon 9[\cdot \varepsilon$

$86 \tau \cdot \mathrm{GZ} /$

$\operatorname{LG} \cdot S Z-$

[च $\left.8^{\circ} \mathrm{sZ}\right] / /$

ธโg. $T \varepsilon-$

$\left.00 L^{\circ} \cdot \tau \varepsilon\right]$

$\angle \nabla 8 \cdot[\varepsilon]$

$\varepsilon[\sigma \cdot \varepsilon \varepsilon] / F$

$\left.866^{\circ} \varepsilon \varepsilon\right]$

$\left.8 \varepsilon G^{\circ} \nabla \varepsilon\right]$

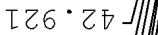

$989^{\circ} \varepsilon \bar{\varepsilon}$

$890^{\circ} 9 \overline{ } \mathrm{G}$

$978^{\circ} \angle \bar{D}$

$0[2 \cdot 87]$

9E[.0s]

$667^{\circ} \mathrm{TL}$

โย $0 \cdot 08$

$066^{\circ}$ [8 -

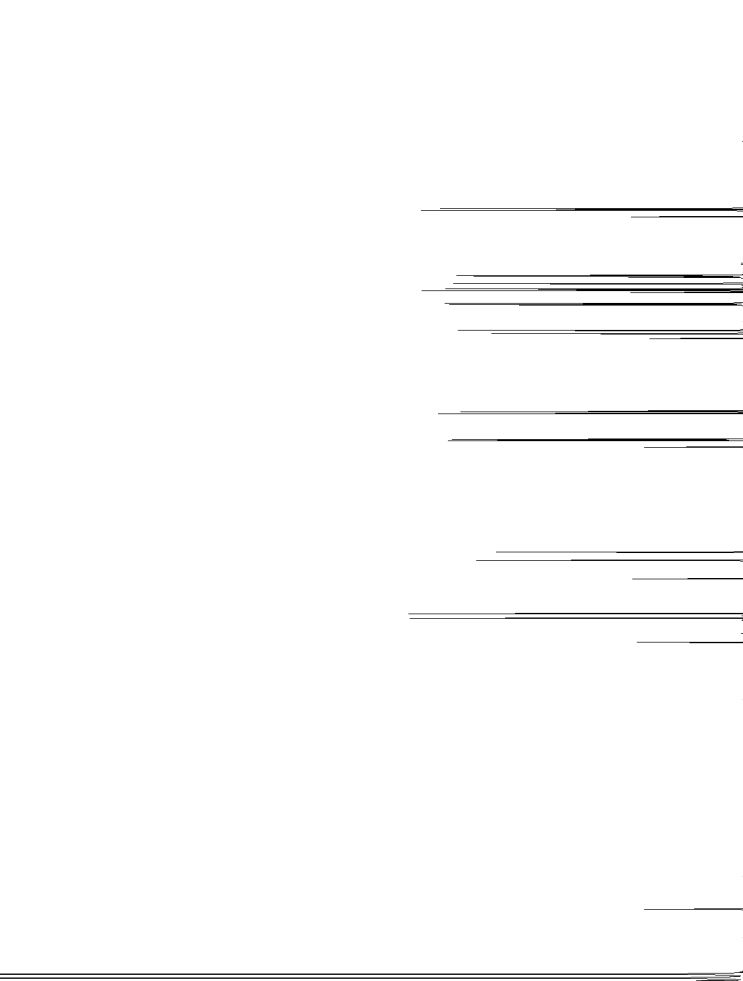

E응

은

요

= 오

o

요

- 웅

요

8

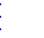

$=$ 웅

-

$660^{\circ} \cdot 72 T>$
$906 \cdot 72 T$

$906 \cdot 62 I=$

हLS.6ZI $>$

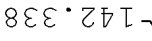

$\varpi 8 \sigma \cdot 2 \pi \tau$

$\angle I Z \cdot \varepsilon \nabla I J$

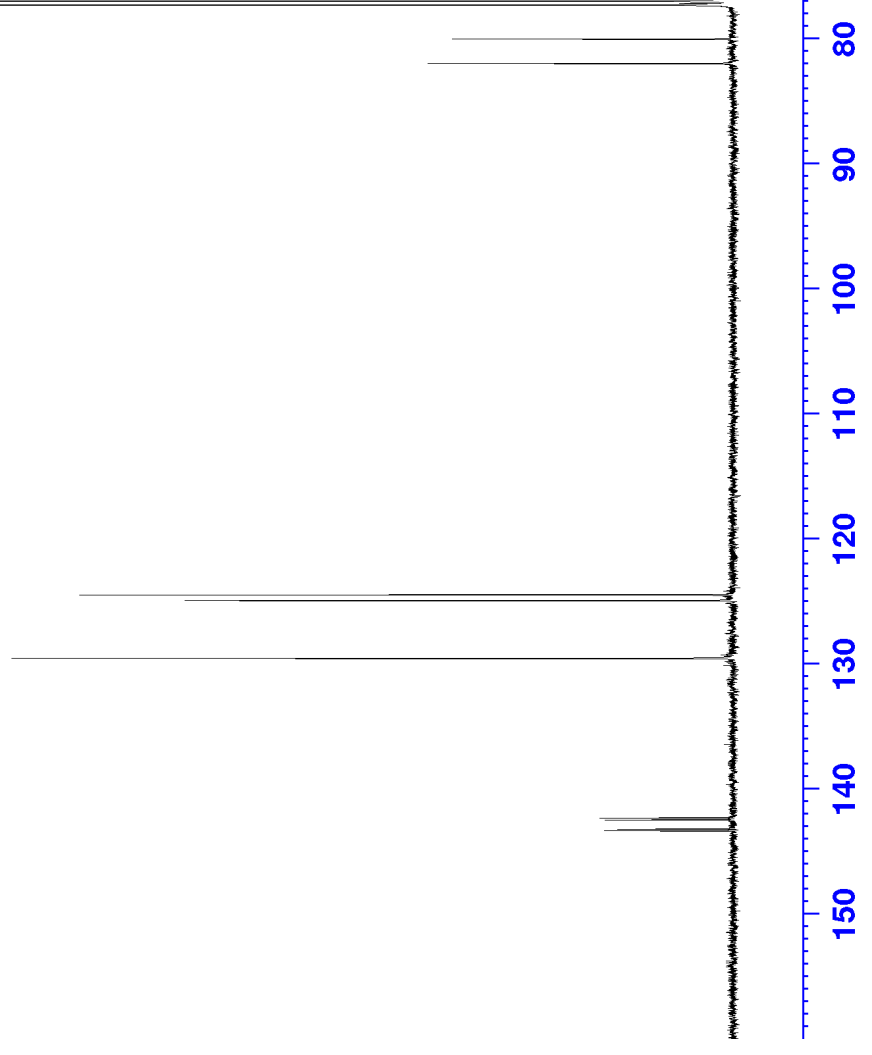


${ }^{1} \mathrm{H}$ NMR (400 MHz) tert-butyl-p-toluenesulfinate (37j) in $\mathrm{CDCl}_{3}$

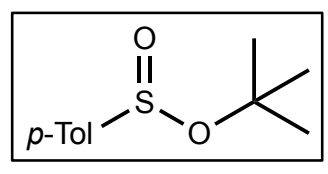

37j

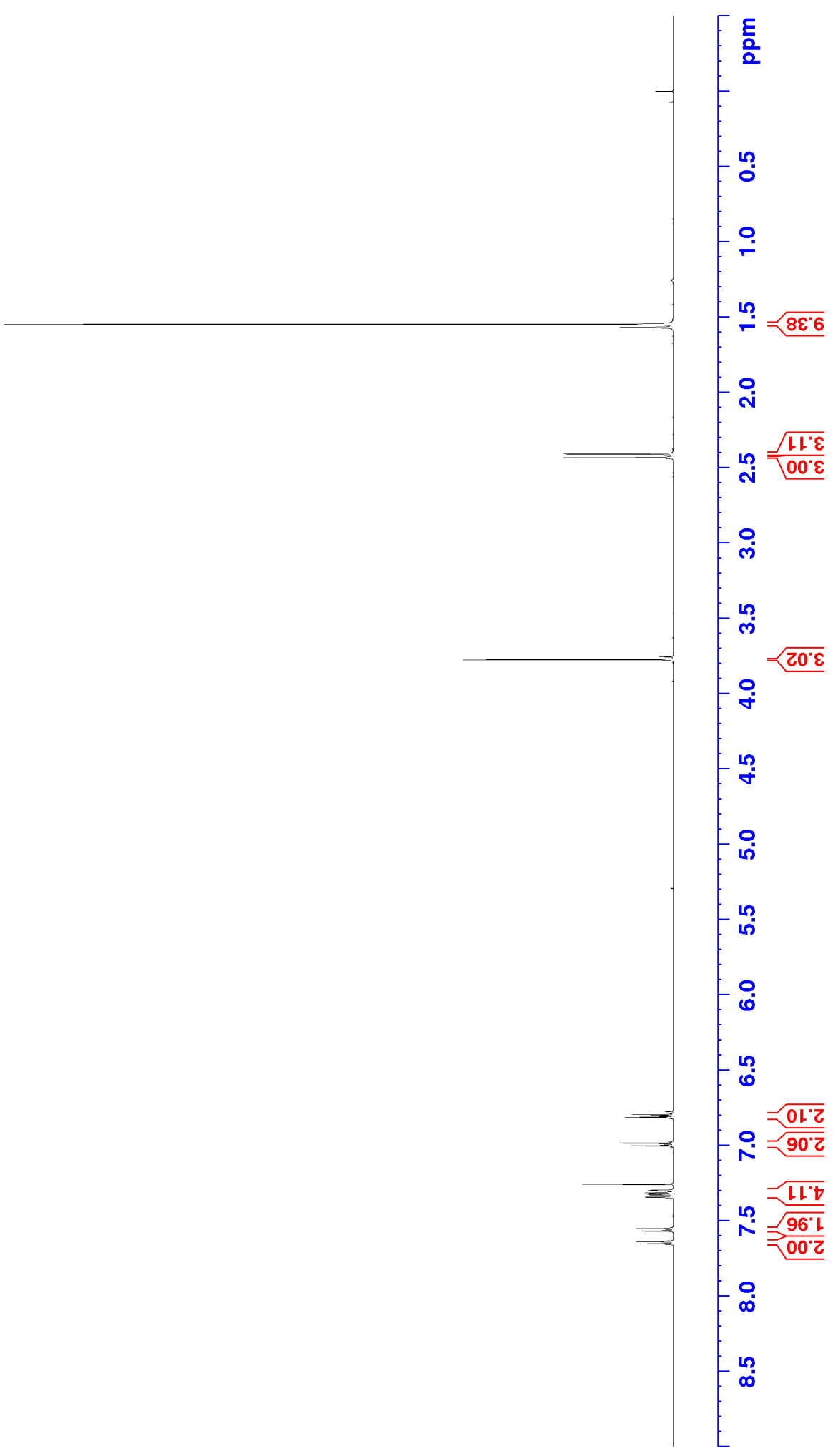


APPENDIX C: SELECTED HRMS ESI SPECTRA 
JS pg 270 MS \#1 RT: 0.01 AV: 1 NL: 1.75E+007

T: FTMS + p ESI Full ms [50.0000-400.0000]

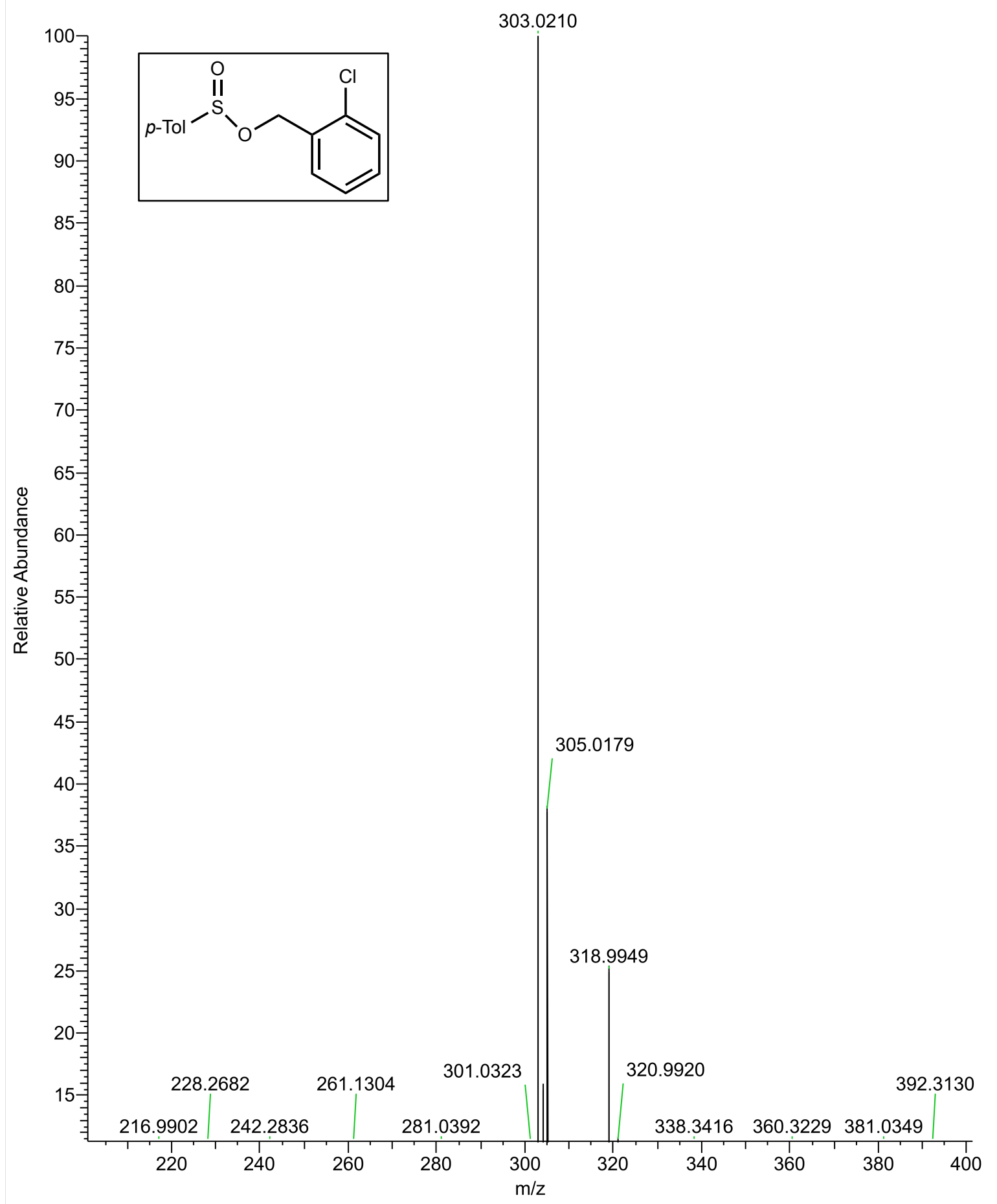


JS pg 274 MS \#1 RT: 0.01 AV: 1 NL: 9.85E+006

T: FTMS + p ESI Full ms [50.0000-400.0000]

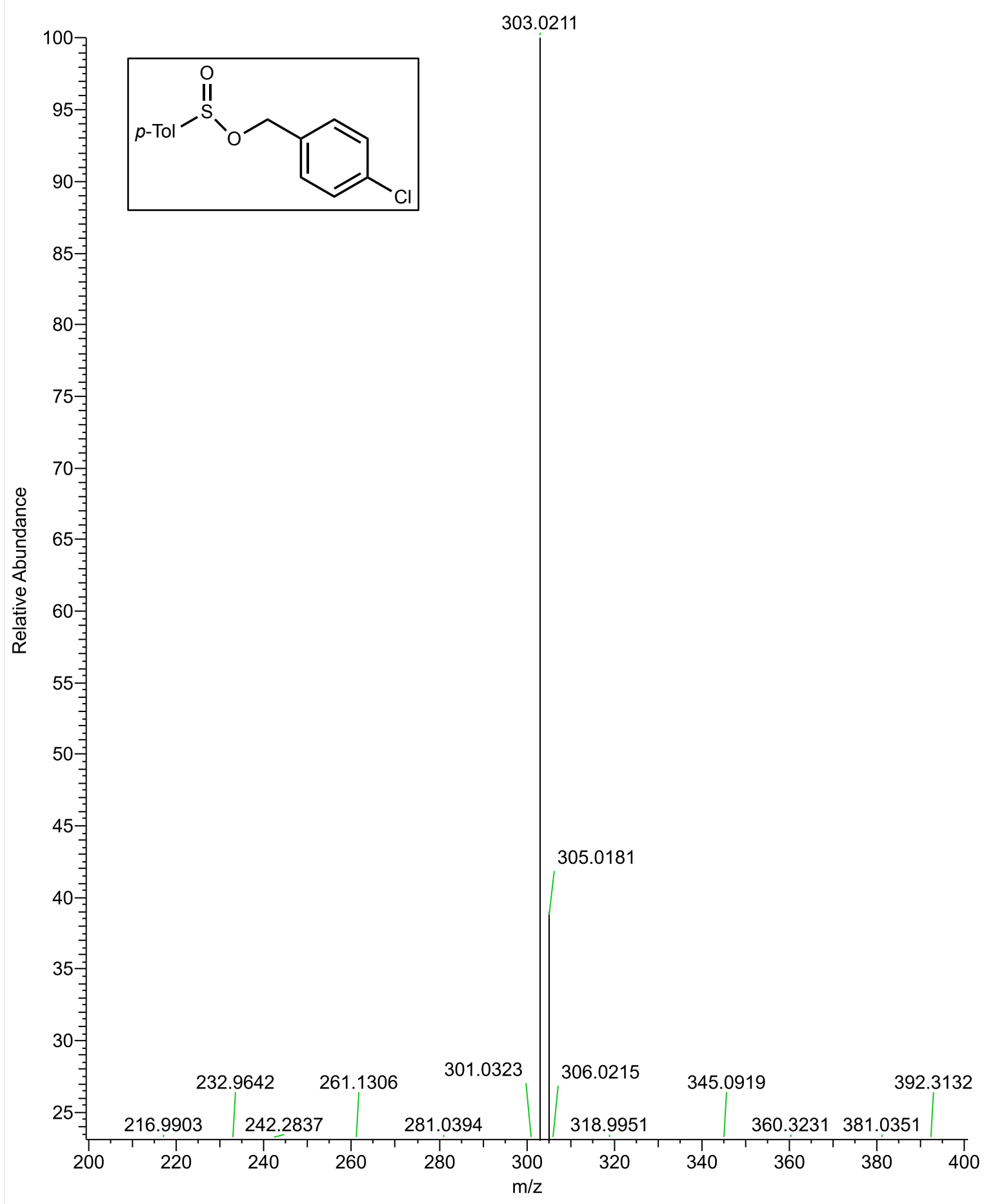


JS pg 286 MS \#1 RT: 0.01 AV: 1 NL: 1.70E+006

T: FTMS + p ESI Full ms [50.0000-400.0000]

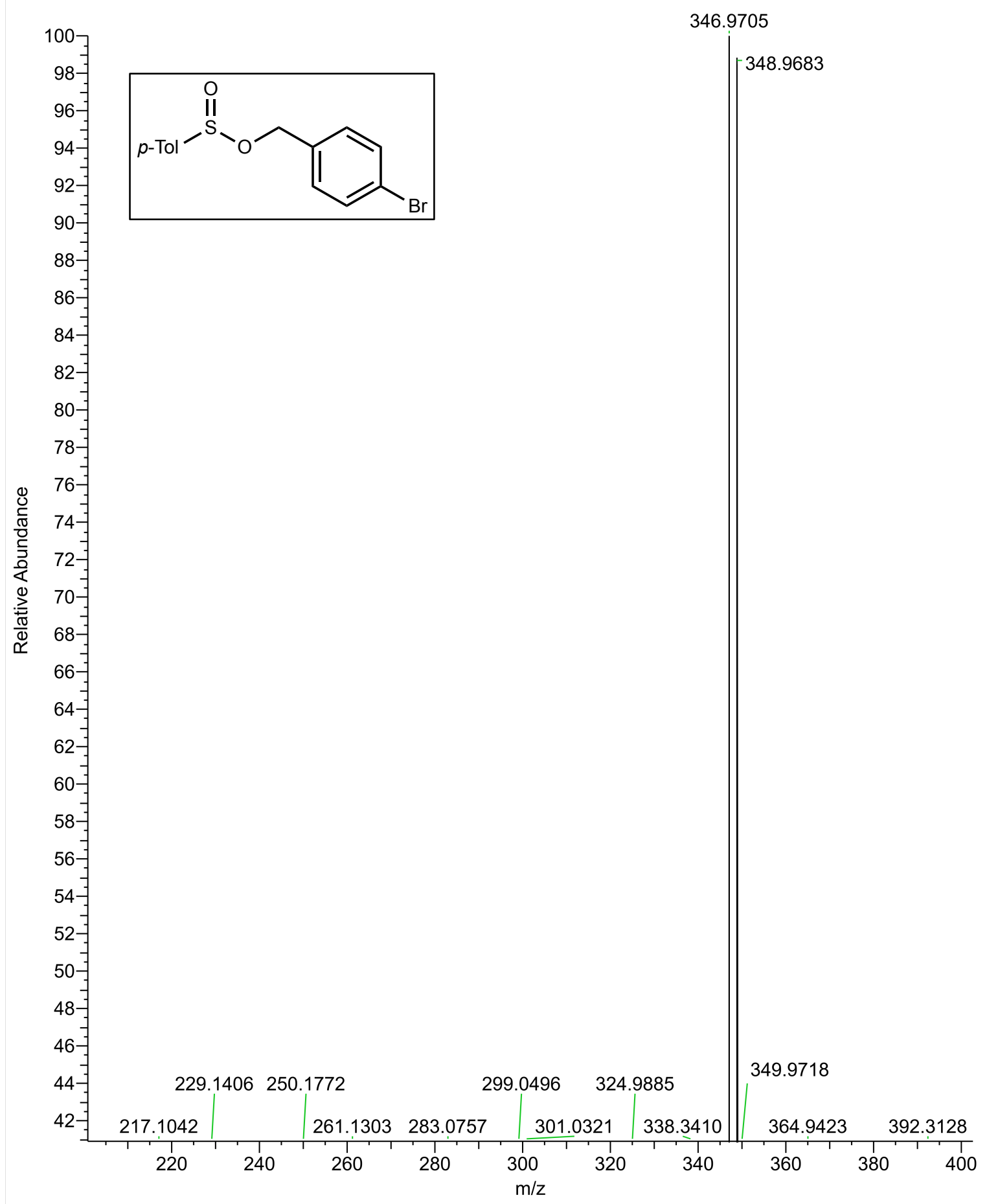


JS pg 278 MS \#1 RT: 0.01 AV: 1 NL: 9.56E+003

T: FTMS + p ESI Full ms [50.0000-400.0000]

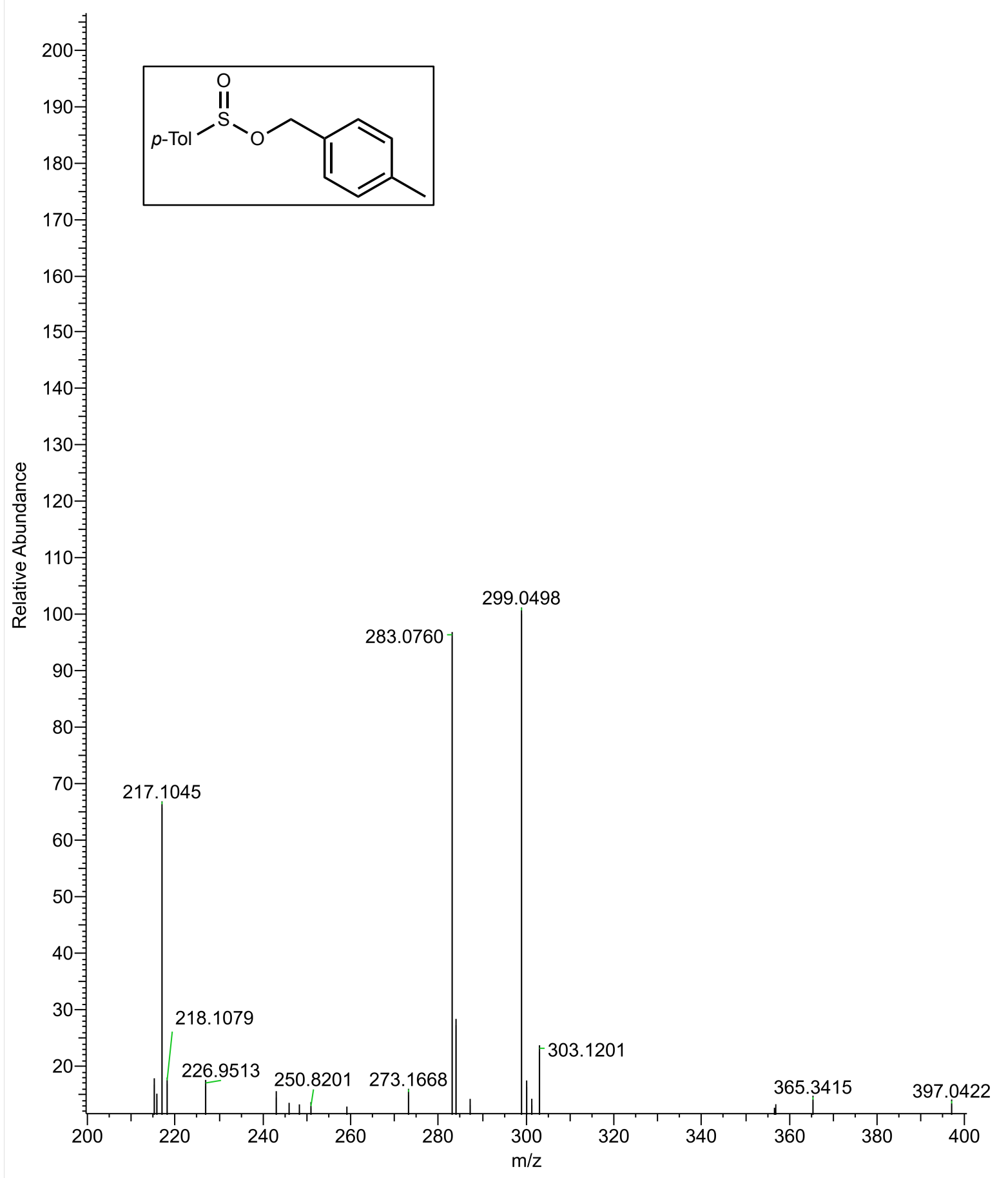


JS pg 282 MS \#1 RT: 0.01 AV: 1 NL: 1.54E+006

T: FTMS + p ESI Full ms [50.0000-400.0000]

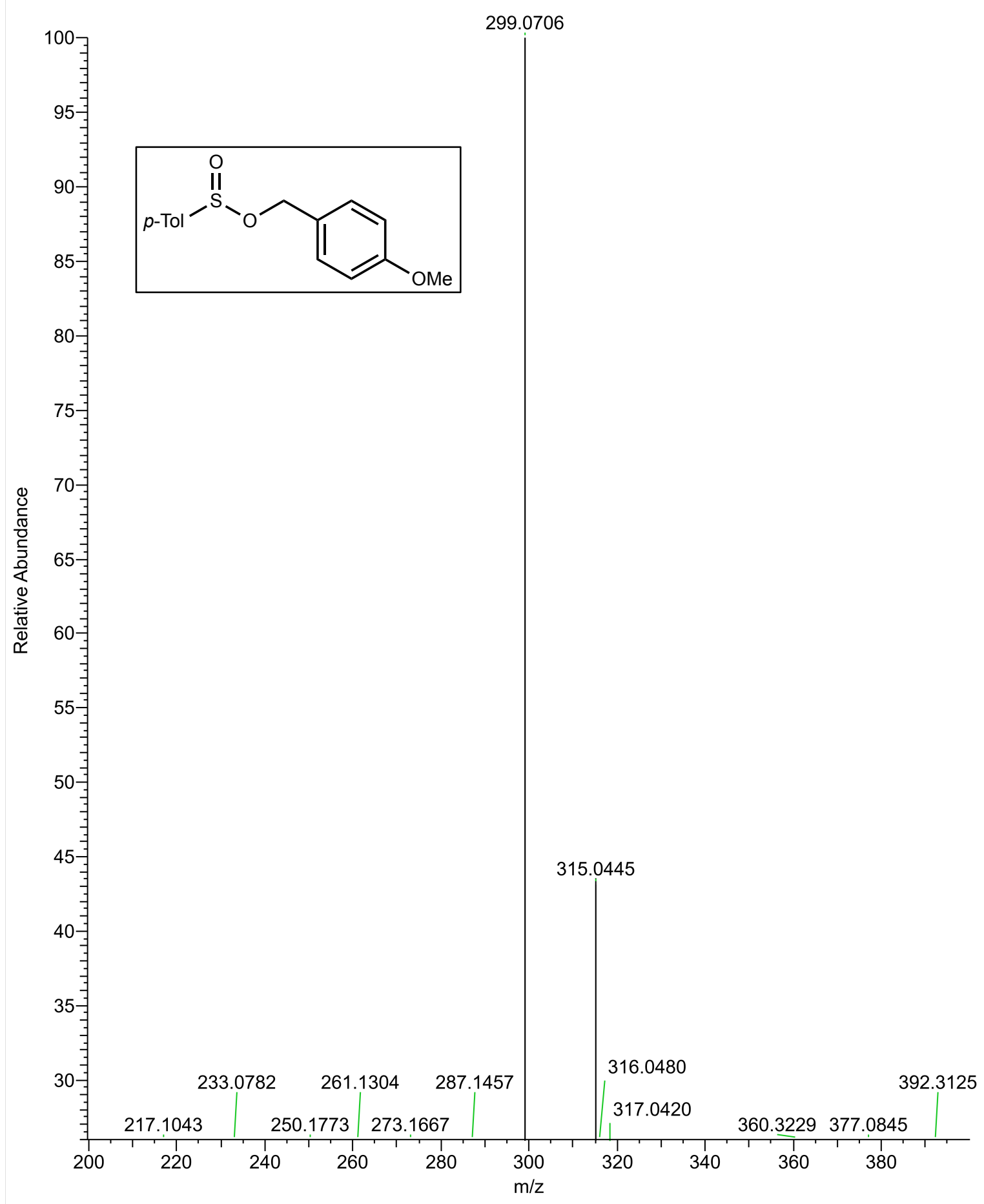


JS pg 290 MS \#1 RT: 0.01 AV: 1 NL: 5.20E+003

T: FTMS + p ESI Full ms [50.0000-600.0000]

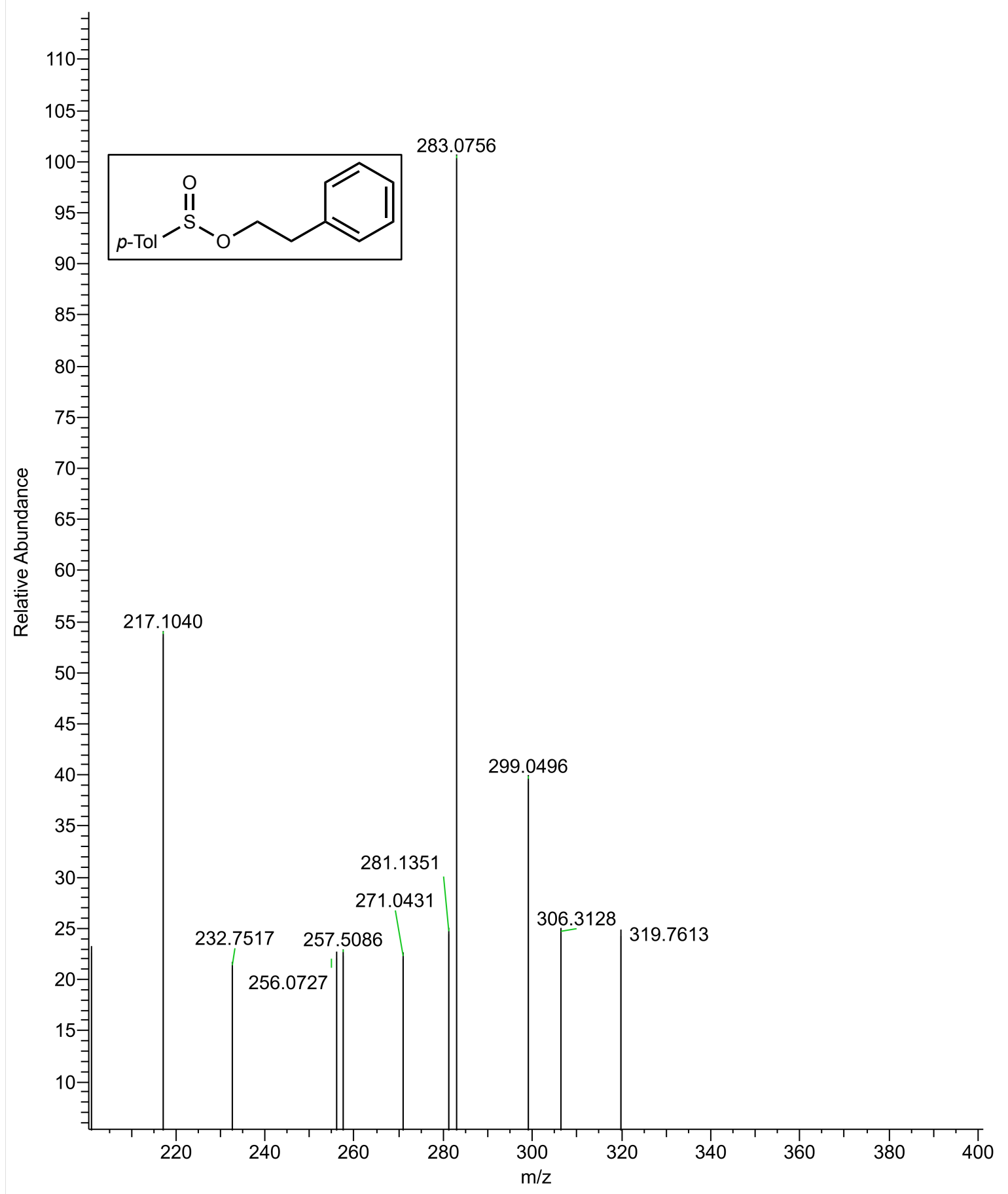


JS pg 298 MS \#1 RT: 0.01 AV: 1 NL: 1.12E+007

T: FTMS + p ESI Full ms [50.0000-400.0000]

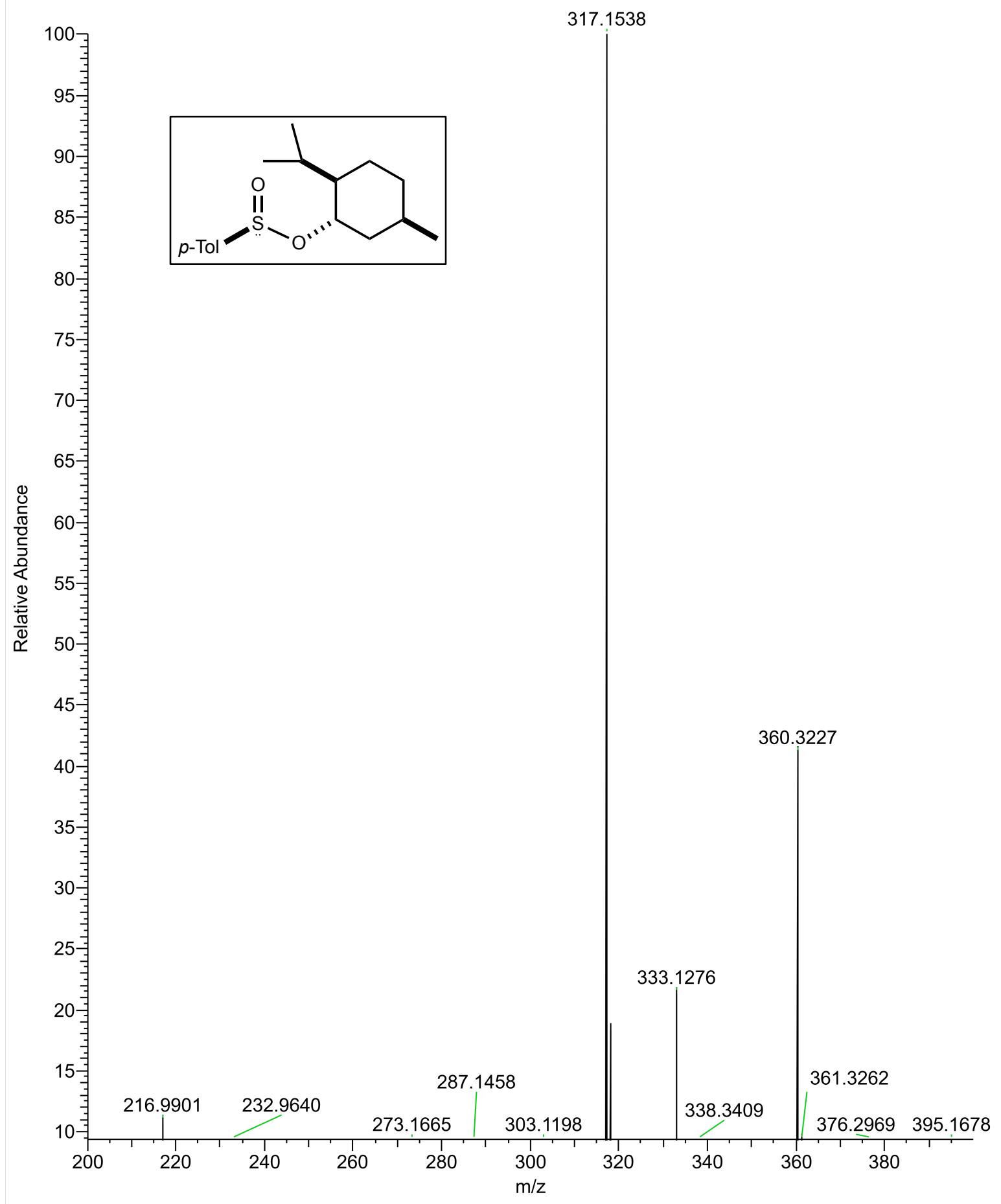

